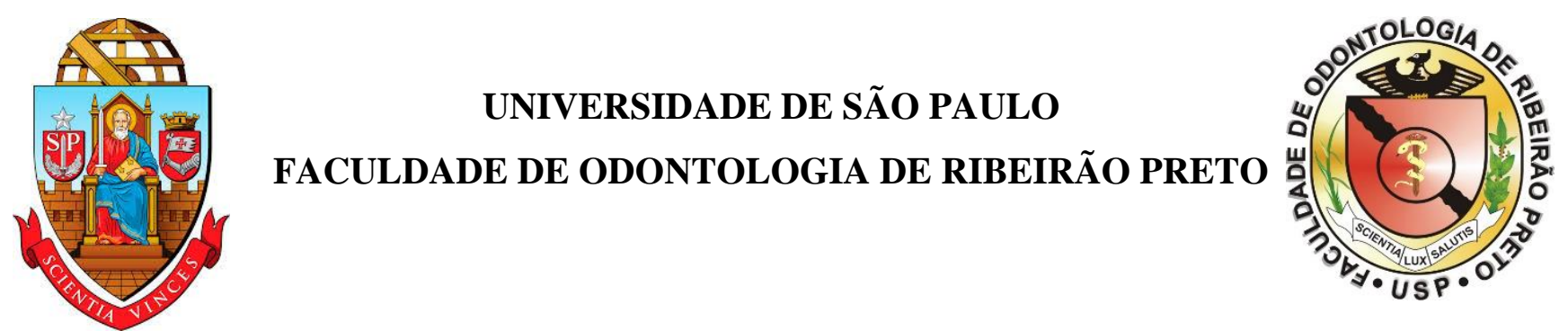

CRISTIAN SBARDELOTTO

ANÁLISE DA DISTRIBUIÇÃO DE TENSÃO EM PROTOCOLO MANDIBULAR CONFECCIONADO PELO SISTEMA CONVENCIONAL E CAD/CAM, VARIANDO TIPO, NÚMERO E INCLINAÇÃO DOS IMPLANTES 


\section{CRISTIAN SBARDELOTTO}

\section{ANÁLISE DA DISTRIBUIÇÃO DE TENSÃO EM PROTOCOLO MANDIBULAR CONFECCIONADO PELO SISTEMA CONVENCIONAL E CAD/CAM, VARIANDO TIPO, NÚMERO E INCLINAÇÃO DOS IMPLANTES}

Dissertação apresentada ao Programa de PósGraduação em Reabilitação Oral da Faculdade de Odontologia de Ribeirão Preto da Universidade de São Paulo para obtenção do título de Mestre em Odontologia.

Área de concentração: Reabilitação Oral

Orientador: Prof. ${ }^{\text {. }}$ Dr ${ }^{\mathrm{a}}$. Renata Cristina Silveira Rodrigues Ferracioli.

\section{VERSÃO CORRIGIDA}

\section{RIBEIRÃO PRETO}


AUTORIZO A REPRODUÇÃO E DIVULGAÇÃO DO TEOR TOTAL OU PARCIAL DESTE TRABALHO, POR QUALQUER MEIO CONVENCIONAL OU ELETRÔNICO, PARA FINS DE ESTUDO E PESQUISA, DESDE QUE CITADA A FONTE.

\section{Ficha catalográfica}

\section{Elaborada pela Biblioteca Central do Campus USP - Ribeirão Preto}

\section{Sbardelotto, Cristian}

Análise de distribuição de tensão em protocolo mandibular confeccionado pelo sistema convencional e Cad/Cam, variando tipo, número e inclinação dos implantes. Ribeirão Preto, 2015

93p.: il; $30 \mathrm{~cm}$

Dissertação apresentada a Faculdade de Odontologia de Ribeirão Preto/USP - para obtenção do grau de Mestre em Odontologia. Área de concentração: Reabilitação Oral

Orientador: Ferracioli, Renata Cristina Silveira Rodrigues

Versão corrigida da Dissertação. A versão original se encontra disponível na Unidade que aloja o Programa. 


\section{FOLHA DE APROVAÇÃO}

Cristian Sbardelotto. Análise da distribuição de tensão em protocolo mandibular confeccionado pelo sistema convencional e CAD/CAM, variando tipo, número e inclinação dos implantes

Dissertação apresentada à Faculdade de Odontologia de Ribeirão Preto, da Universidade de São Paulo, para obtenção do título de Mestre. Área de concentração: Reabilitação Oral.

Aprovado em

\section{Banca Examinadora}

Prof. (a). Dr. (a):

Instituição:

Julgamento: Assinatura:

Prof. (a). Dr. (a):

Instituição:

Julgamento: Assinatura:

Prof. (a). Dr. (a):

Instituição:

Julgamento: Assinatura: 
DEDICATÓRIA 
Dedico este trabalho,

Aos meus queridos Pais,

Moacir (in memoriam) e Nair, exemplos de vida a serem seguidos, minha eterna gratidão pelos ensinamentos, por todo o amor, carinho $\mathrm{e}$ compreensão, e principalmente por acreditarem nesse sonho. Obrigado por compartilhar comigo essa conquista. Pai e mãe, amo vocês!

À minha irmã Jaqueline,

Por suas palavras de sabedoria e pelo constante incentivo durante essa caminhada.

Obrigado pela força e pelo carinho.

\section{À Carolina}

Pelo amor, respeito e compreensão. Obrigado por caminhar ao meu lado.

Te amo muito 
AgRADECIMENTOS ESPECIAIS 
À minha orientadora:

Prof. ${ }^{a}$ Dr $^{a}$ Renata Cristina Silveira Rodrigues Ferracioli, pela orientação, amizade, dedicação e por contribuir para meu crescimento profissional e pessoal. Muito obrigado por tudo! 
AgradeCIMENTOS 
A toda minha família, pelo amor, carinho e dedicação.

À Faculdade de Odontologia de Ribeirão Preto, da Universidade de São Paulo, pela acolhida durante o período de pós-graduação.

Ao Departamento de Materiais Dentários e Prótese da FORP/USP, por disponibilizar os equipamentos necessários para a execução deste trabalho.

À coordenação do Curso de Pós-Graduação em Reabilitação Oral da Faculdade de Odontologia de Ribeirão Preto.

Ao Prof. Dr. Ricardo Faria Ribeiro pela amizade, incentivo, e por compartilhar sempre sua experiência e sabedoria, muito obrigado por despertar em mim o amor pela ciência.

A todos os professores que contribuíram para o meu crescimento e formação, serei grato eternamente.

À Adriana C. Lapria Faria Queiroz e Rafael Cândido, pela amizade e prestatividade durante a realização deste trabalho.

Aos amigos de mestrado e doutorado, pela convivência e por compartilharem momentos nessa trajetória.

Todos os funcionários do Departamento de Materiais Dentários e Prótese da FORP/USP pelo profissionalismo, atenção e amizade.

À FAPESP, pela bolsa de estudos para realizar esse trabalho (Processo FAPESP $\mathrm{n}^{\circ}$ 2014/12927-4)

À CAPES, pela bolsa de estudos concedida no início do mestrado.

A todos os que direta ou indiretamente contribuíram para a realização e conclusão desse trabalho. 
RESUMO 
SBARDELOTTO, C. Análise da distribuição de tensão em protocolo mandibular confeccionado pelo sistema convencional e cad/cam, variando tipo, número e inclinação dos implantes. 2015. 93f. Dissertação (Mestrado em Reabilitação Oral) - Faculdade de Odontologia de Ribeirão Preto, Universidade de São Paulo, Ribeirão Preto, 2015.

As próteses totais fixas implantossuportadas tem ganhado cada dia mais seu espaço no tratamento reabilitador de pacientes edêntulos, pois se trata de uma forma de tratamento que mais se aproxima dos quesitos funcionais e estéticos. Ainda não existe na literatura um consenso de qual a configuração que melhor distribui as tensões aos implantes e tecidos adjacentes. $\mathrm{O}$ objetivo deste estudo foi comparar as tensões geradas na interface osso-implante de próteses totais mandibulares implantossuportadas através do método de correlação de imagens digitais (CID). Foram analisadas duas configurações diferentes quanto à quantidade e posicionamento de implantes (4 ou 5 implantes), diferentes conexões [hexágono externo (HE) e cone morse $(\mathrm{CM})$ ] e barras para prótese fixa implantossuportada obtidas por fundição convencional e usinadas pelo sistema CAD-CAM. Foram confeccionados modelos em poliuretano, utilizando implantes de 3,75x11mm, divididos em 8 grupos: G1 (5 implantes/HE/CAD-CAM), G2 (5 Implantes/CM/CAD-CAM), G3 (5 Implantes/HE/Convencional), G4 (5 Implantes/CM/Convencional), G5 (4 Implantes/HE/CADCAM), G6 (4 Implantes/CM/CAD-CAM), G7 (4 Implantes/HE/Convencional) e G8 (4 Implantes/CM/Convencional). A análise por $\mathrm{CID}$ foi feita quantitativamente e qualitativamente, com aplicação de carga de $250 \mathrm{~N}$ na fossa central do primeiro molar inferior, onde foram estabelecidas diferentes regiões de interesse para a análise, sendo denominadas de C1 (cervical 1) e A1 (apical 1) para região distal ao último implante, C2 (cervical 2) e A2 (apical) para região mesial ao último implante. Foram encontradas diferenças significantes para o número de implantes em todas as regiões analisadas [C1 ( $\mathrm{p}=0,002), \mathrm{A} 1(\mathrm{p}=0,01), \mathrm{C} 2$ $(p=0,001), A 2(p=0,004)]$, para as conexões foram encontradas diferenças na região $C 2$ $(\mathrm{p}<0,05)$ e para as barras na região A2 $(\mathrm{p}=0,003)$. De acordo com os resultados pode-se concluir que as prótese com 4 implantes apresentaram maior quantidade de tensões por tração nas regiões apicais, não houve diferença significativa na concentração de tensões para as conexões HE e CM, exceto para a região $\mathrm{C} 2$, onde houve maior concentração de tensão para conexão CM e em comparação ao método de obtenção das barras, as barras convencionais apresentaram maior concentração de tensões de tração nas próteses com 5 implantes.

Palavras Chaves: Implantes Dentários, Prótese Dentária fixada por implante, CAD/CAM, análise de tensões, correlação de imagens digitais 
AbSTRACT 


\section{SBARDELOTTO, C. Stress distribution analysis of mandibular protocol confectioned by}

the conventional system and cad/cam, ranging type, number and inclination of the implants. 2015. 93f. Dissertação (Mestrado em Reabilitação Oral) - Faculdade de Odontologia de Ribeirão Preto, Universidade de São Paulo, Ribeirão Preto, 2015.

The implant-supported fixed dental prostheses have been used to rehabilitate edentulous patients as it fulfills not only functional aspects but also esthetic questions. Literature shows that there is no consensus about the best configuration to distribute stress to the implants and surrounding tissues. The objective of this study was to compare the stress generated at the boneimplant interface of implant-supported mandibular dentures by a digital image correlation method (DIC). Two different configurations were analyzed for the implants number and position (4 or 5 implants), different connections [external hexagon (EH) and Morse Taper (MT)] and bars for implant-supported fixed prosthesis obtained by conventional casting and machined by CAD-CAM system. Models were prepared from polyurethane and implants $(3.75 \times 11 \mathrm{~mm})$ were divided in 8 groups: G1 (5 implants/EH/CAD-CAM), G2 (5 Implants/MT/CAD-CAM), G3 (5 Implants/EH/Conventional) , G4 (5 Implants/MT/Conventional), G5 (4 Implants/EH/CAD-CAM), G6 (4 Implants/MT/CADCAM) G7 (4 Implants/EH/Conventional) and G8 (4 Implants/MT/Conventional). DIC analysis were quantitative and qualitatively made with a $250 \mathrm{~N}$ load at first molar central fossa, which were established in different regions of interest for analysis as $\mathrm{C} 1$ (cervical 1) and A1 (apical 1) to distal to the last implant, $\mathrm{C} 2$ (cervical 2) and $\mathrm{A} 2$ (apical) for mesial region to the last implant. Significant differences were found for number of implants in all regions examined $[\mathrm{C} 1$ $(\mathrm{p}=0.002), \mathrm{A} 1(\mathrm{p}=0.01), \mathrm{C} 2(\mathrm{p}=0.001)$ and $\mathrm{A} 2(\mathrm{p}=0.004)]$, for connections differences were found in the $\mathrm{C} 2$ region $(\mathrm{p}<0.05)$ and for the bar region at $\mathrm{A} 2(\mathrm{p}=0.003)$. According to the results it can be concluded that the prosthesis with four implants showed a higher stress at the apical regions, there was no significant difference in the concentration of stress for $\mathrm{EH}$ and $\mathrm{CM}$ connections, except for the $\mathrm{C} 2$ region, where there was a higher concentration of stress for $\mathrm{CM}$ connection, and comparing bars obtained methods, conventional bars showed a higher concentration of stresses in prosthesis with 5 implants.

Key words: Dental Implants; Implant-supported, fixed dental prosthesis; CAD/CAM;

Tensions analysis; Digital images correlation. 
SUMÁRIO 
RESUMO

\author{
ABSTRACT
}

1.INTRODUÇÃO E REVISÃO DE LITERATURA.

3. MATERIAL E MÉTODO........................................................................................... 29

3.1 Obtenção dos modelos de mandíbula edêntula ....................................... 31

3.2 Obtenção dos modelos de trabalho ........................................................... 33

3.3 Confecção do protótipo da prótese ...................................................... 35

3.4 Obtenção das barras em Co-Cr (CAD/CAM - Usinagem) …................. 37

3.5 Obtenção das barras em Co-Cr (Método Convencional) ......................... 40

3.6 Enceramento, montagem de dentes e acrilização das próteses ................ 44

3.7 Análise por correlação de imagens digitais (CID) …................................. 48

4. RESULTADOS.................................................................................................... 51

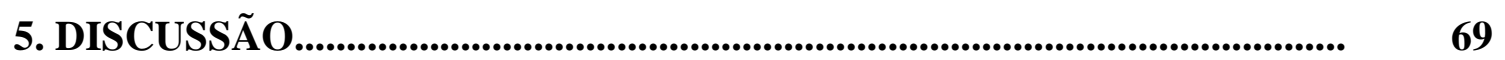

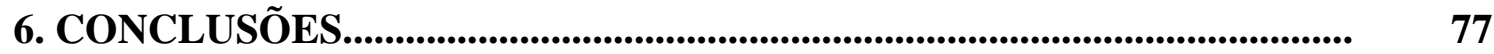

REFERÊECIAS.............................................................................................. 81 
INTRODUÇ̃̃O E REVISÃO DE LITERATURA 

Os implantes osseointegráveis assumiram credibilidade incontestável na ciência odontológica graças a previsibilidade demostrada nos estudos pioneiros de Branemark, que introduziu o conceito de osseointegração como a união de um corpo ao tecido vivo sem a presença de qualquer tecido mole intermediário, de modo que haja transmissão direta das cargas para o osso de suporte (Branemark, 1983). Após uma análise detalhada da interface ossoimplante, pode-se observar duas regiões peri-implantares, a primeira formada por uma camada de fibroblastos $(40 \mu \mathrm{m})$ e uma segunda camada, continua com a primeira, composta de formada por fibras colágenas e estruturas vasculares $(160 \mu \mathrm{m})$ (Moon et al. 1999). Em 1991, Zarb \& Albrektsson, redefiniram o conceito de osseointegração pode como um processo de fixação rígida e assintomática clinicamente de materiais alopláticos mantida após a conexão da prótese e incidência de cargas oclusais.

A prótese fixa mandibular totalmente suportada por implantes osseointegrados foi primeiramente descrita por Branemark e coautores, e os primeiros resultados clínicos em longo prazo foram publicados no início de 1980 (Branemark et al., 1969; Branemark et al., 1977, Adell et al., 1981). O tratamento da mandíbula desdentada por meio de implantes osseointegrados consistiu na inserção de cinco ou seis implantes no osso mandibular na região entre forames e, após um período de cicatrização de 3 meses, a entrega de uma prótese fixa parafusada com cantiléveres distais de comprimentos variáveis. Mais tarde, Branemark estabeleceu que um mínimo de quatro implantes era adequado para suportar uma prótese fixa total, mas recomendou aumentar o número de implantes até seis para garantir apoio adequado, caso ocorra qualquer perda de implante (Branemark, 1985; Naini, 2011). A utilização de um número menor implantes e sua colocação em locais estratégicos pode melhorar a distribuição das forças de forma favorável (Mericske - Stern, 2000; Attard, 2005; Ogawa et al., 2010). Os dados clínicos de longo prazo sobre implante e prótese confirmaram que prótese fixa sobre quatro implantes na mandíbula edêntula mostrou resultados que foram semelhantes para a mesma modalidade de tratamento com mais implantes (Branemark, 1999; Maló, 2005), tornando o tratamento de pacientes edêntulos totais com próteses totais fixas, uma alternativa viável e de sucesso em longo prazo (Naert et al., 1992; Ekelund et al., 2003; Attard, 2004; Friberg et al., 2015).

Desde a introdução do sistema Branemark para a comunidade científica em 1960 e 1970, uma longa série de sistemas de implantes têm sido desenvolvidos e tornaram-se disponíveis para o cirurgião dentista (Kirsh, 1983; Albrektsson et al., 1986; Babbush, 1986). Uma das características que tem sido objeto de pesquisa entre os sistemas é o tipo de conexão que permite à estrutura superior protética ser adaptada ao implante. Desde o início, o sistema 
Branemark foi caracterizado por um hexágono exterior, que foi desenvolvido para facilitar a inserção do implante, em vez de agir clinicamente como um dispositivo anti-rotacional (Branemark et al., 1985). Esta configuração hexágono externo tem servido bem ao longo dos anos e foi incorporada em uma série de sistemas. O sistema de hexágono externo tem algumas vantagens, porque é um sistema adequado para qualquer procedimento cirúrgico, tem um mecanismo de anti rotação e a reversibilidade e compatibilidade com sistemas diferentes. No entanto, tem alguns inconvenientes, devido à sua limitada eficácia quando submetidos a cargas fora do longo eixo (Weinberg, 1993) este sistema apresenta micro movimentos, devido à reduzida dimensão do hexágono, além disso, o seu centro de rotação mais elevado promove menor resistência à rotação com os movimentos laterais e cria uma possível diferença na interface implante-pilar, que pode levar à reabsorção óssea. Portanto, este sistema é contraindicado em situação de sobrecarga (Merz et al., 2000; Maeda et al., 2006). Assim, temse especulado que, sob altas cargas oclusais, o hexágono externo pode permitir micro movimentos do pilar, causando instabilidade da articulação que pode resultar em afrouxamento do parafuso do pilar ou fratura por fadiga (Worthington et al., 1987; Zarb \& Schmitt, 1990; Adell et al., 1990; Jemt et al., 1991; Hermmings et al., 1994; Jemt \& Lekholm, 1995; Becker \& Becker 1995). Segundo Asvanund (2014), o sistema de conexão hexágono externo, em comparação aos outros sistemas de conexão, tem apresentado maior concentração de tensões em casos de reabilitação de mandíbulas edêntulas, por meio de próteses totais sobre implantes, suportada por quatro implantes.

Diferente de outras conexões, na concepção de cone Morse, o pilar é unido ao implante por meio de uma conexão de cone interno. Esta ligação bloqueia o sistema por causa da fricção mecânica entre a parede exterior do pilar e da parede interna do implante, e a não rotação do pilar é observada (Salvi, 2001). Além disso, o sistema de cone Morse é caracterizado para eliminar a junção entre pilar-implante da região infra-óssea para a região intra óssea (Inove et al., 2006), promovendo elevada fiabilidade em relação a afrouxamento e fratura de componentes protéticos (Merz et al., 2000), e uma elevada estabilidade no uso em longo prazo (Joly, 2001; Chun et al., 2006). A interface cônica cone morse, apresenta um design preciso, de tal forma que durante a instalação do pilar intermediário junto ao implante ocorra a íntima adaptação entre as superfícies sobrepostas (Pierrisnard et al., 2002). Como nenhum microgap existe entre os dois componentes, o pilar intermediário apresenta maior resistência a movimentos rotacionais, uma concentração de pontos de tensão ocorre sobre as superfícies sobrepostas do cone morse, deixando o parafuso de retenção com um papel secundário (Goiato et al., 2013). Por outro lado, o ajuste passivo em casos de múltiplas restaurações se torna mais 
difícil de conseguir. Além disso, a compatibilidade com outros sistemas protéticos é limitada. A inserção cirúrgica é crítica, e o implante deve ser colocado intraósseo sem ou com pouca inclinação. Assim, a posição correta dos implantes é imprescindível para que os pilares possam ser colocados axialmente aos implantes (Norton, 1997). O custo deste sistema também é uma desvantagem relativa.

A reabilitação da mandíbula severamente atrófica usando próteses implantossuportadas é frequentemente um desafio, devido a pobre qualidade e quantidade de rebordo residual, o uso combinado de implantes colocados no sentido axial e inclinados representa uma alternativa para o tratamento da mandíbula edêntula (Patzelt et al., 2014). A inclinação do implante pode ser cuidadosamente planejada pelo cirurgião para evitar danos às estruturas anatômicas importantes (Lin et al., 2008).

Cinco a seis implantes e cantiléver distal foram tradicionalmente indicados para reabilitar a mandíbula e maxila edêntulas por meio de próteses implantossuportadas. Relatos clínicos têm mostrado sucesso em curto e médio prazos utilizando menos implantes combinados ou não com a inclinação distal (Krekmanov et al., 2000), necessários para suportar uma prótese implantossuportada com maior previsibilidade.

A técnica do implante inclinado foi introduzida para casos selecionados de múltiplos implantes na maxila e mandíbula edêntulas (Maló et al., 2003). Na mandíbula, o procedimento pode ser usado quando o forame mentual está em uma posição baixa em relação ao rebordo alveolar para reduzir a extensão do cantiléver e aumentar a área poligonal de suporte da prótese. Sem o uso de implantes inclinados, estas regiões receberiam implantes mais curtos ou necessitariam de cirurgia de enxerto ósseo, aumentando a complexidade do tratamento, tempo e custos. Segundo Bonnet et al. (2009), em de seu estudo de análise de tensões utilizando o método de elementos finitos, na técnica “All-on-four", principalmente na região de molares, houve grande incidência de tensão durante o ato mastigatório (Duyck et al, 2000). Entretanto, Malhotra et al. (2012), utilizando o método de análise por elementos finitos, verificaram que a instalação de implantes com inclinação maior de $30^{\circ}$ (All-on-Four) não aumenta a tensão local de forma significativa, e leva em consideração que a arquitetura mandibular é um fator importante no planejamento e tratamento de pacientes edêntulos (Naconecy, 2006; Fazi et al., 2011). Os níveis de tensões para implantes inclinados e osso adjacente e a deformação dos componentes protéticos ainda não estão totalmente entendidos. Forças axiais e não-axiais geradas durante a função oral, podem resultar dos efeitos somatórios, sinérgicos e antagônicos da inclinação, número e distribuição dos implantes no arco. Estudos de fotoelasticidade têm sido usados para explicar o comportamento biomecânico de próteses implantossuportadas 
simulando a variação do número e inclinação dos implantes. (Fernandes et al., 2003; Ueda et al., 2004; Cehreli et al., 2004; Turcio et al., 2009).

Segundo Watanabe et. al. (2000), os dentes podem se mover até $100 \mu \mathrm{m}$ pela presença do ligamento periodontal, enquanto os implantes têm mobilidade de até $10 \mu \mathrm{m}$, limitados pela elasticidade óssea, de modo que desajustes protéticos mínimos podem provocar altos níveis de tensões. Como os implantes encontram-se rigidamente integrados ao tecido ósseo, estas tensões podem resultar em reabsorções ósseas (Waskewicz, 1994; Duyck et al., 2001). A reabsorção do osso em torno da plataforma está relacionada não só com a presença de espaços na interface implante-pilar, mas também com a redução de diâmetro, em relação ao implante, o que promove a formação de tecido mole nesta área e aumenta as defesas naturais do organismo (Riedy, 1997).

Um estudo mostrou que tensões entre 4000 a $25000 \mu \mathrm{s}$, proporcionam defeitos microscópicos na estrutura óssea (Frost 1992) posteriormente outros estudos mostraram que tensões acima de $4000 \mu$ s podem desenvolver um processo patológico no tecido ósseo (Melsen \& Land, 2001; Frost, 2003). Essa resposta biológica do tecido ósseo pode ser influenciada por fatores como: passividade, desajuste cervical, tipo do material restaurador empregado, número, distribuição e posição dos implantes no arco e oclusão (Carr et al.,1996; Kan et al., 1999; Sones, 1989) e pode levar à perda total da osseointegração (Sanz et al., 1991; Naert et al., 1992; Brunski et al., 1992; Isidor, 1996; Stegaroiu et al., 1998). A sobrecarga mecânica pode resultar, também, em falhas como perda ou fratura dos parafusos, parafusos do intermediário e até do próprio implante e prótese (Lang, 2000; Schwarz, 2000). Dessa forma, alternativas para minimizar as forças transmitidas pelos implantes vêm sendo estudadas, entre elas, variações na disposição dos implantes, sua forma e tamanho, na forma das próteses, nos requisitos oclusais, nos componentes protéticos e nos materiais das próteses sobre implantes (Skalak, 1983; Papavasiliou et al., 1996; Brunski, 1999).

O sucesso em longo prazo dos implantes é determinado também pela escolha da estrutura metálica; por causa do alto custo das ligas áureas e algumas de suas propriedades físicas e mecânicas, as ligas de cobalto-cromo (Co-Cr), tornaram-se a liga padrão para estruturas metálicas. As ligas de Co-Cr são mais duras e apresentam peso especifico menor (densidade), boa resistência à corrosão, baixo custo, alto módulo de elasticidade e alta temperatura de fusão. Entretanto, alguns autores afirmavam que suas maiores desvantagens estariam menor reprodução de detalhes, maior dificuldade de acabamento e polimento. (Hulterström \& Nilsson, 1994; Goodacre, 1999), o que não corresponde a real situação atual, onde com o avanço da pesquisa e da tecnologia, as ligas de $\mathrm{Co}-\mathrm{Cr}$ apresentam maior riqueza de detalhes e facilidade no acabamento e polimento. O padrão de distribuição de tensões entre 
pilares depende do tipo de liga usada para a infraestrutura metálica (White, 1994; Akça et al., 2002). Um material com menor módulo de elasticidade oferece menor resistência flexional; estruturas feitas com ligas básicas rígidas sofrem menos deformação, sendo menos propensas à fadiga, e consequentemente, aumentam a tensão local ao osso. A taxa de sobrevivência é significativamente melhor para próteses com comprimentos de cantiléver de $15 \mathrm{~mm}$ ou menos, comparados com cantiléveres mais longos que $15 \mathrm{~mm}$, porém dependendo da qualidade óssea nos quais os implantes estão ancorados um comprimento de 10 a 20mm é aceitável (Rangert et al., 1989; Jemt, 1991, Taylor, 1991; Naert et al., 1992; Van Zyl et al., 1995; Sertgoz \& Guvener, 1996; Jacques et al., 2009).

Infraestruturas de próteses múltiplas implanto-retidas devem exibir adaptação passiva aos pilares (Hecker \& Eckert, 2003). No entanto, há relatos de que níveis de desajuste entre 10 e $150 \mu \mathrm{m}$ poderiam ser clinicamente aceitáveis (Branemark, 1983; Jemt, 1991). Atualmente os padrões de níveis de desadaptação, são diferentes devido ao auxílio de novas técnicas de confecção das preças protéticas, não sendo mais aceitável valores que pode chegar a $150 \mu \mathrm{m}$. O que se deve ter em mente é que os procedimentos clínicos e laboratoriais, mesmo quando realizados com rigor de técnica, invariavelmente acabarão por gerar algum nível de distorção na prótese finalizada, em decorrência de técnicas e materiais de moldagem utilizados, modelos de gesso, obtenção do padrão em cera, procedimentos de fundição, acabamento e polimento, aplicação de porcelana ou resina acrílica sobre a infraestrutura (Wee et al., 1999), e que todos podem, de alguma forma e em algum grau, comprometer o assentamento passivo da prótese.

A confecção de próteses extensas favorece a ocorrência de maior distorção que as próteses unitárias. Ao fazer a fundição de vários pilares unidos, a contração do metal poderá induzir desajustes sobre cada componente, produzindo uma peça em monobloco com grande desajuste entre os pilares e as plataformas dos implantes. A desadaptação de uma infraestrutura implantossuportada pode ser corrigida através da secção e união dos segmentos entre os pilares por soldagem. Após este procedimento, a barra ainda poderá apresentar pequenos desajustes marginais e a região da soldagem será um ponto de fragilidade da estrutura protética (Ford, 2003).

Atualmente, a busca por tratamentos envolvendo maior rapidez, aliada à máxima precisão, tem se tornado constante na Odontologia (Carr et al, 1996; Kapos et al, 2009; Ichi, 2010). Com o advento da computação gráfica, ocorreu evolução significativa na Odontologia, e os sistemas dentários de tecnologia CAD/CAM podem combinar qualidade das restaurações com a automatização do processo e simplificar o esforço requerido para sua produção (Beuer, 2008; Harder, 2009). 
Todos os sistemas CAD/CAM são compostos por três fases: a primeira se baseia na conversão de uma imagem do caso ou da sua réplica em gesso por meio de um digitalizador ou scanner em dados digitais que podem ser processados por um computador, criando uma imagem virtual em três dimensões (3D). Uma vez obtida esta imagem digital 3D, a próxima fase será desenhar a estrutura protética com o uso de um software (CAD) de acordo com requisitos odontológicos preconizados. A terceira fase é a transformação dos dados digitais do desenho elaborado no produto desejado por meio do sistema CAM (Strub, 2006).

Apesar dos problemas amplamente relatados na literatura, a fundição convencional é, ainda hoje, a técnica mais utilizada para a confecção de barras e infraestruturas protéticas em geral (Jemt et al., 1995; Cariello, 2009). A tecnologia CAD/CAM tem mostrado bons resultados protéticos em curto prazo, mas ainda pouco se sabe sobre a longevidade das reabilitações orais principalmente no que diz respeito a transmissão de tensões, principalmente quando comparadas com método de confecção convencional (Harder, 2009). Outro fator importante para ser levado em consideração é o custo para a confecção das peças produzidas a partir dessa tecnologia $\mathrm{CAD} / \mathrm{CAM}$, que são significantemente maiores comparadas às de confecção convencional, exigindo aplicação de recurso financeiro maior por parte dos laboratórios (Beuer, 2008). Observando a realidade atual, há necessidade evidente do desenvolvimento de novas técnicas, que proporcionem bons resultados com custos mais acessíveis.

Vários métodos têm sido utilizados nos estudos científicos para verificação das tensões geradas em torno dos implantes dentários, dentre eles a fotoelasticidade, a extensiometria, a análise de modelos por elementos finitos e a correlação digital de imagens. A análise por correlação digital de imagens é um método que tem sido utilizado para medir a distribuição das tensões de deformação superficial em testes de materiais odontológicos (Li et al., 2009).

Durante a aplicação de carga, uma série de imagens da superfície do modelo é capturada com câmera digital e os movimentos de pontos individuais na superfície do espécime são localizados e analisados com o uso de programas específicos para determinar o deslocamento desses pontos. Em comparação a outros métodos quantitativos de análise de tensões, a vantagem da correlação digital é a possibilidade de determinar as tensões em toda superfície analisada, enquanto que outros métodos, como a extensiometria, são capazes de determinar apenas as tensões médias geradas na área do sensor (Li et al., 2009). O método de correlação de imagens digitais também é capaz de analisar e determinar tensões de cisalhamento, o que é importante para o estudo da causa da perda de implantes, uma vez que a resistência ao cisalhamento da interface osso/implante é consideravelmente inferior à resistência ao cisalhamento do osso homogêneo (Hasson, 2000).

A previsibilidade e a longevidade de próteses implantosuportadas são excelentes embora uma taxa de falhas significativas exista. Elas têm sido atribuídas às fases cirúrgicas e 
protéticas. Atualmente, o desenho da prótese está baseado na experiência clínica e no empirismo, ao invés de pautar-se em princípios determinados cientificamente. Pouco é conhecido a respeito da biomecânica da transferência de tensões ao osso por meio das próteses protocolo com diferentes configurações.

Sendo assim, o objetivo deste estudo foi analisar as tensões geradas por barras para prótese tipo protocolo com diferentes configurações quanto a quantidade, posicionamento do implante, tipo de conexão protética e modo de obtenção das barras. Para análise das tensões será utilizada a correlação digital de imagens. 

Proposição 

Este estudo propôs avaliar as tensões geradas na superfície do modelo com diferentes configurações de próteses totais fixas implantossuportadas mandibulares. As tensões foram analisadas e comparadas qualitativamente e quantitativamente com o auxílio do método de correlação de imagens digitais (CID).

Foram analisadas:

1. Duas configurações diferentes quanto à quantidade e inclinação dos implantes (4 ou 5 implantes);

2. Diferentes conexões protéticas: hexágono externo e cone morse;

3. Barras para prótese fixa implantossuportada obtidas por fundição convencional e usinadas pelo sistema CAD/CAM. 

MATerial e Métodos 

Para este estudo, foram confeccionadas próteses totais fixas mandibulares implantossuportadas que foram divididas nos seguintes grupos:

$\square$ Grupo 1 (G1): Próteses com 5 implantes, conexão hexágono externo e barras obtidas por CAD/CAM;

$\square$ Grupo 2 (G2): Próteses com 5 implantes, conexão cone morse e barras obtidas por $\mathrm{CAD} / \mathrm{CAM}$;

( Grupo 3 (G3): Próteses com 5 implantes, conexão hexágono externo e barras obtidas por fundição convencional;

$\square$ Grupo 4 (G4): Próteses com 5 implantes, conexão cone morse e barras obtidas por fundição convencional;

$\square$ Grupo 5 (G5): Próteses com 4 implantes, conexão hexágono externo e barras obtidas por CAD/CAM;

$\square$ Grupo 6 (G6): Próteses com 4 implantes, conexão cone morse e barras obtidas por $\mathrm{CAD} / \mathrm{CAM}$;

G Grupo 7 (G7): Próteses com 4 implantes, conexão hexágono externo e barras obtidas por fundição convencional;

- Grupo 8 (G8): Próteses com 4 implantes, conexão cone morse e barras obtidas por fundição convencional;

Para a obtenção dos modelos e próteses foi utilizada a metodologia descrita a seguir.

\subsection{Obtenção dos modelos de mandíbula edêntula}

Para realização deste estudo foram utilizados como matrizes iniciais quatro modelos de mandíbula edêntula em poliuretano rígido (Nacional Ossos, Jaú, SP, Brasil) (Figura 1).

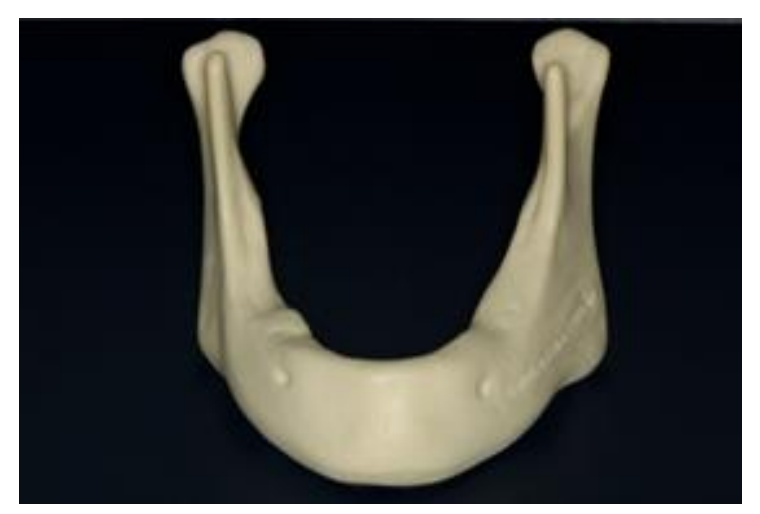

Figura 1. Matriz Inicial - Mandíbula edêntula 
Para o grupo com 5 implantes, na região interforames mentuais, foram feitas as fresagens dos leitos e instalação de 5 implantes de hexágono externo ou cone morse de 3,75 x 11,0 mm (Neodent, Curitiba, PR, Brasil), a distância entre os implantes foi de 10mm, paralelos entre si, Sobre os implantes posicionados foram instalados Mini Pilares cônicos e Mini Pilares cônicos CM (Neodent, Curitiba, PR, Brasil), sem angulação, para peças múltiplas padrão Brånemark (Neodent, Curitiba, PR, Brasil) (Figura 2).
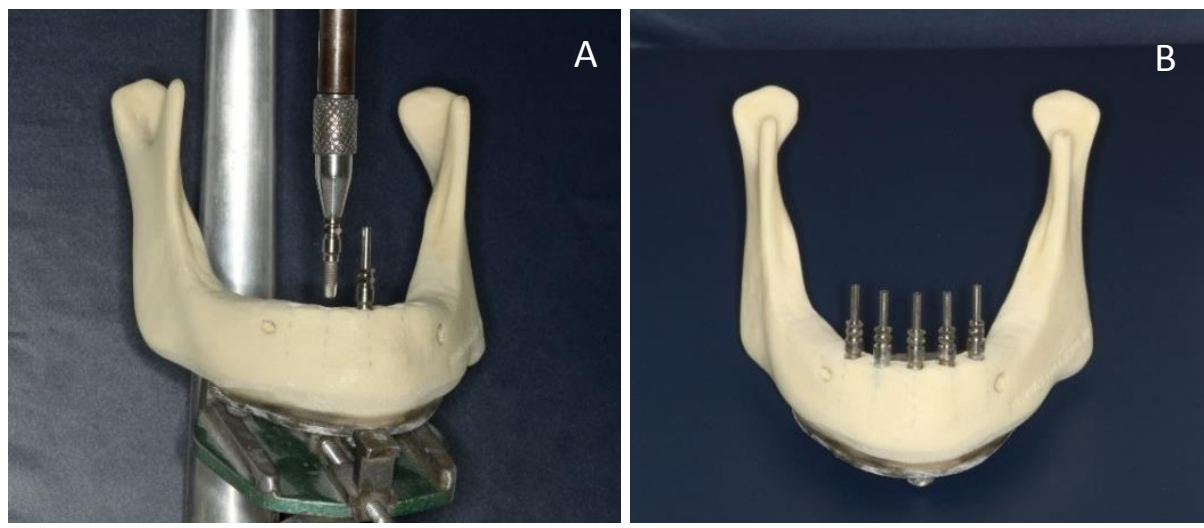

Figura 2. A) e B) - Colocação dos 5 Implantes

No grupo com 4 implantes, os dois implantes mais anteriores foram instalados paralelamente entre si e os dois implantes mais distais foram instalados de acordo com a preconização da técnica “All-on-four”, ou seja, com inclinação de $30^{\circ}$ para distal (Maló, Rangert e de Araújo Nobre, 2003), proporcionando distância entre os implantes de 15mm, nas perfurações foram instalados implantes hexágono externo em um grupo e cone morse em outro. Os quatro implantes foram instalados equidistantes entre si e os dois anteriores receberam pilares protéticos sem angulação e os dois posteriores, Mini Pilares Cônicos Angulados $30^{\circ} \mathrm{e}$ Mini Pilares cônicos angulados CM 30 (Neodent, Curitiba, PR, Brasil) componentes para peças múltiplas padrão Brånemark (Neodent, Curitiba, PR, Brasil). Todos os pilares foram apertados com torque de $20 \mathrm{Ncm}$, de acordo com a recomendação do fabricante (Figura 3). 


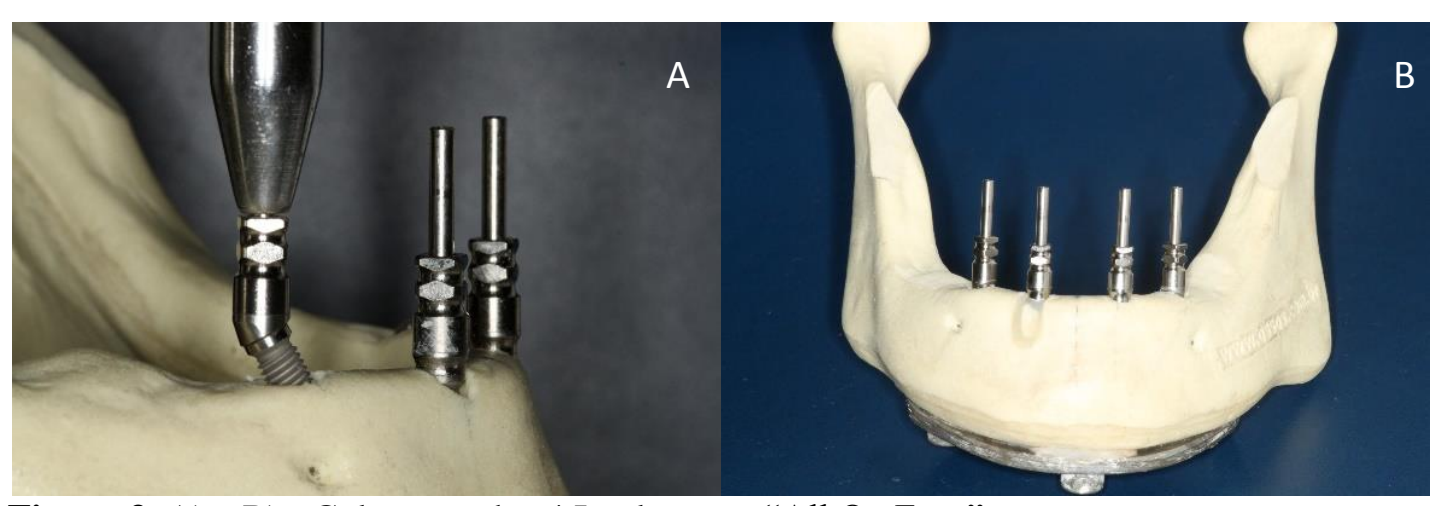

Figura 3. A) e B) - Colocação dos 4 Implantes - "All On Four"

\subsection{Obtenção dos modelos de trabalho}

Foram feitas a duplicação das matrizes iniciais para a confecção dos 4 modelos de trabalho a serem utilizados neste estudo. Com o objetivo de replicar o posicionamento dos implantes, foram utilizados transferentes dos pilares (Neodent, Curitiba, PR, Brasil) que foram parafusados sobre os pilares da matriz inicial e unidos entre si com fio dental e resina acrílica vermelha (Duralay, Reliance Dental Mfg. Co, Worth, IL, EUA). Aguardado o tempo de polimerização da resina, as uniões obtidas foram separadas com disco de carborundum e nova porção de resina foi manipulada para o preenchimento destes espaços, com a finalidade de compensar a contração de polimerização da resina Duralay, (Figura 4). 

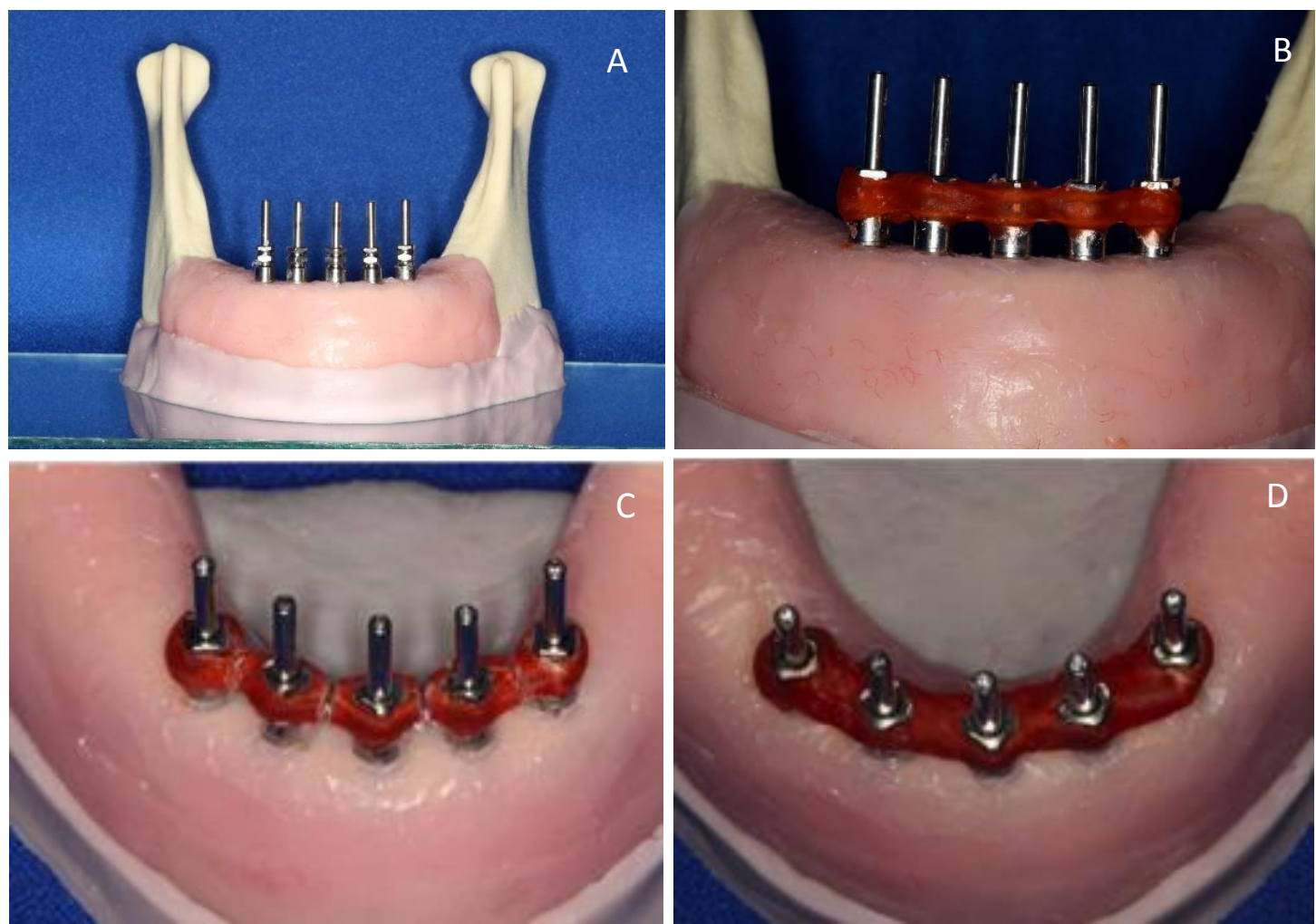

Figura 4. A) Posicionamento dos transferentes; B) União dos transferentes com fio dental e resina Duralay; C) Seccionamento da resina; e D) Nova união com resina acrílica Duralay.

Posteriormente foram duplicadas utilizando silicone para duplicação (Silicone Master, Talmax, Curitiba, PR, Brasil). Para cada matriz, foram manipulados $440 \mathrm{ml}$ do silicone para 20 $\mathrm{ml}$ de catalisador durante 50 segundos. As matrizes foram circundadas com lâminas de cera 7 (Polidental Ind. e Com., Cotia, SP, Brasil), dando forma ao molde e impedindo o extravasamento do silicone para duplicação. Em seguida, foi realizado o preenchimento do recipiente deixando apenas os parafusos dos transferentes expostos. Depois de decorridos 60 minutos para a polimerização do silicone, conforme instruções do fabricante, os parafusos dos transferentes foram soltos para permitir a remoção da matriz (Figura 5).
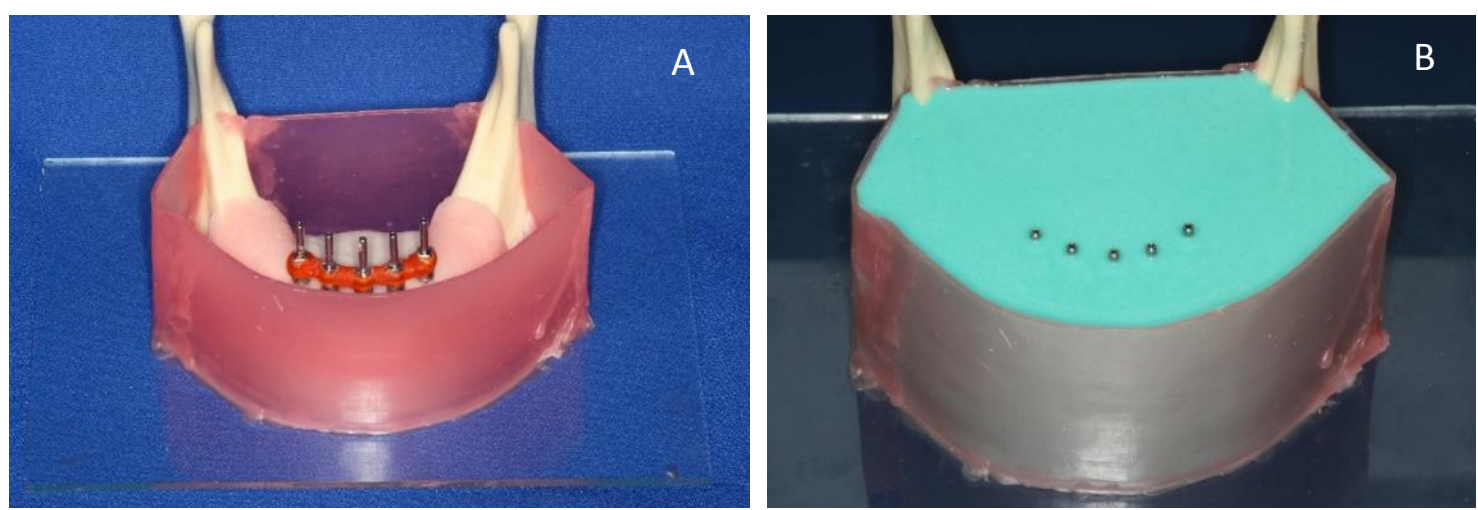

Figura 5. A) Matriz confeccionada com cera para conter o silicone para duplicação; B) após vertido o silicone de duplicação mostrando a exposição dos transferentes. 
Os análogos dos pilares foram posicionados no molde e em seguida foram vazados os modelos em poliuretano (Poliuretano para vazamento F16, Axson, Cergy, França), o qual foi manipulado de acordo com as instruções do fabricante, sendo $15 \mathrm{~g}$ da parte A (Poliol) para $15 \mathrm{~g}$ da parte B (Isocianato) pelo período de 1 minuto. Foram aguardados 60 minutos para a polimerização do material. Os parafusos dos transferentes foram desrosqueados obtendo-se a réplica das matrizes, denominados de modelos de trabalho (Figura 6).
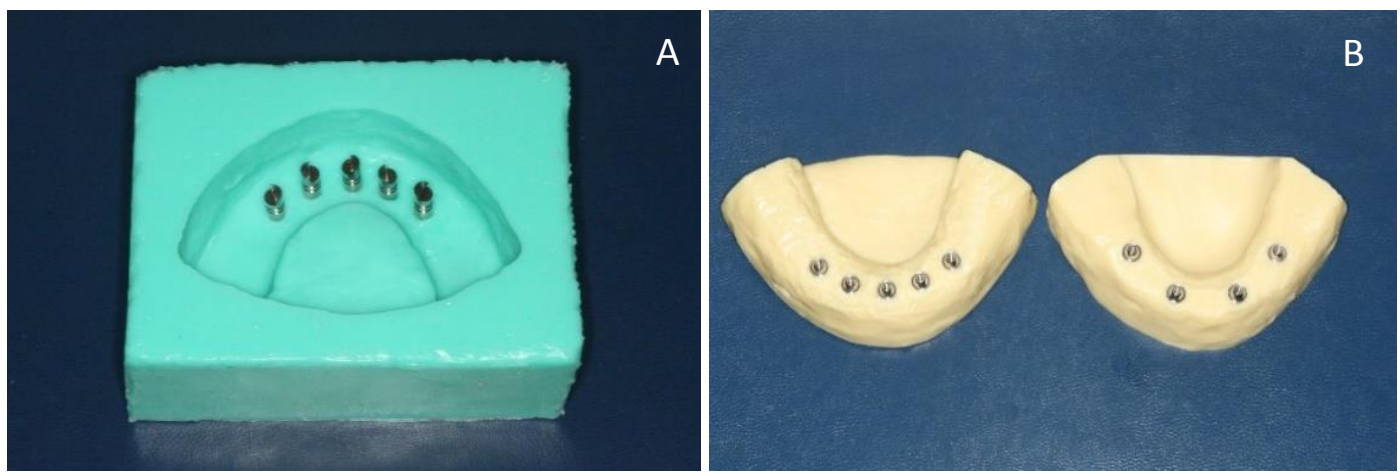

Figura 6. A) Análogos dos pilares em posição; B) Modelos em poliuretano

\subsection{Confecção do protótipo da prótese}

Previamente à confecção das barras, foi confeccionado um protótipo da prótese protocolo. Esta etapa foi planejada para padronizar os limites finais das próteses neste estudo, ou seja, tanto as próteses do grupo com 5 implantes, quanto as próteses do grupo com 4 implantes que deveriam ter tamanhos idênticos.

Para a confecção deste protótipo um modelo de trabalho foi escolhido aleatoriamente e montado em articulador semi-ajustável onde foi realizada a montagem dos dentes e enceramento da prótese (Figura 7). 

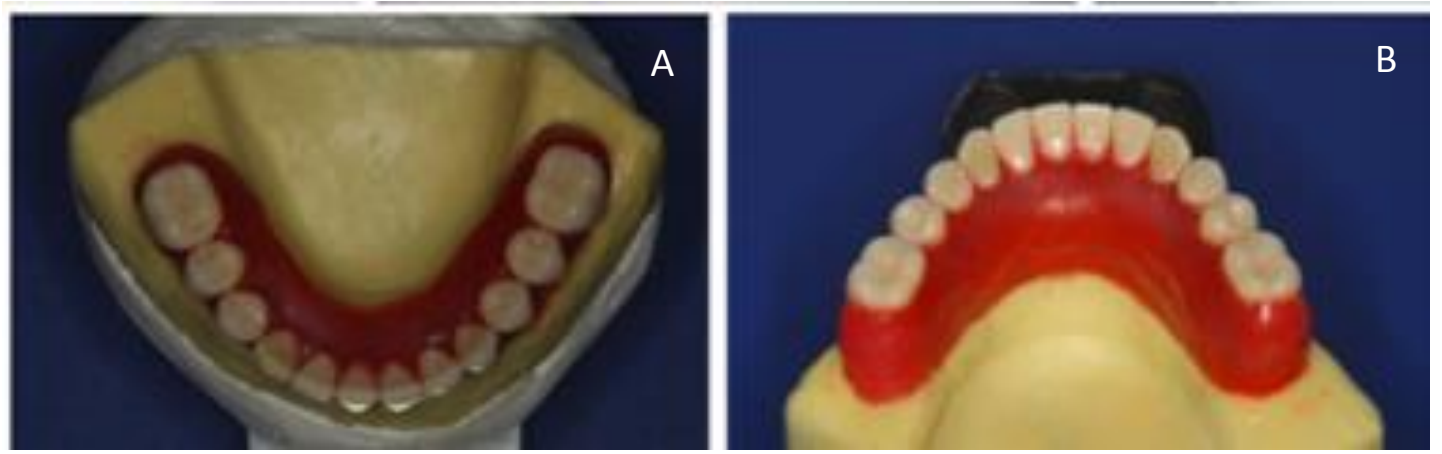

Figura 7. A) e B) - Protótipo da prótese

Após a realização do enceramento, a prótese foi duplicada em silicone de consistência pesada (Zetalabor). Após esta etapa, na região dos dentes foi vazada resina acrílica autopolimerizável na cor 62 (Dencôr, Artigos Odontológicos Clássico LTDA, São Paulo, São Paulo, Brasil) e na região gengival, resina acrílica autopolimerizável na cor rosa (Jet, Artigos Odontológicos Clássico LTDA). Para este processo foram utilizados cilindros de titânio (Neodent) sobre dois modelos de trabalho (Figura 8).
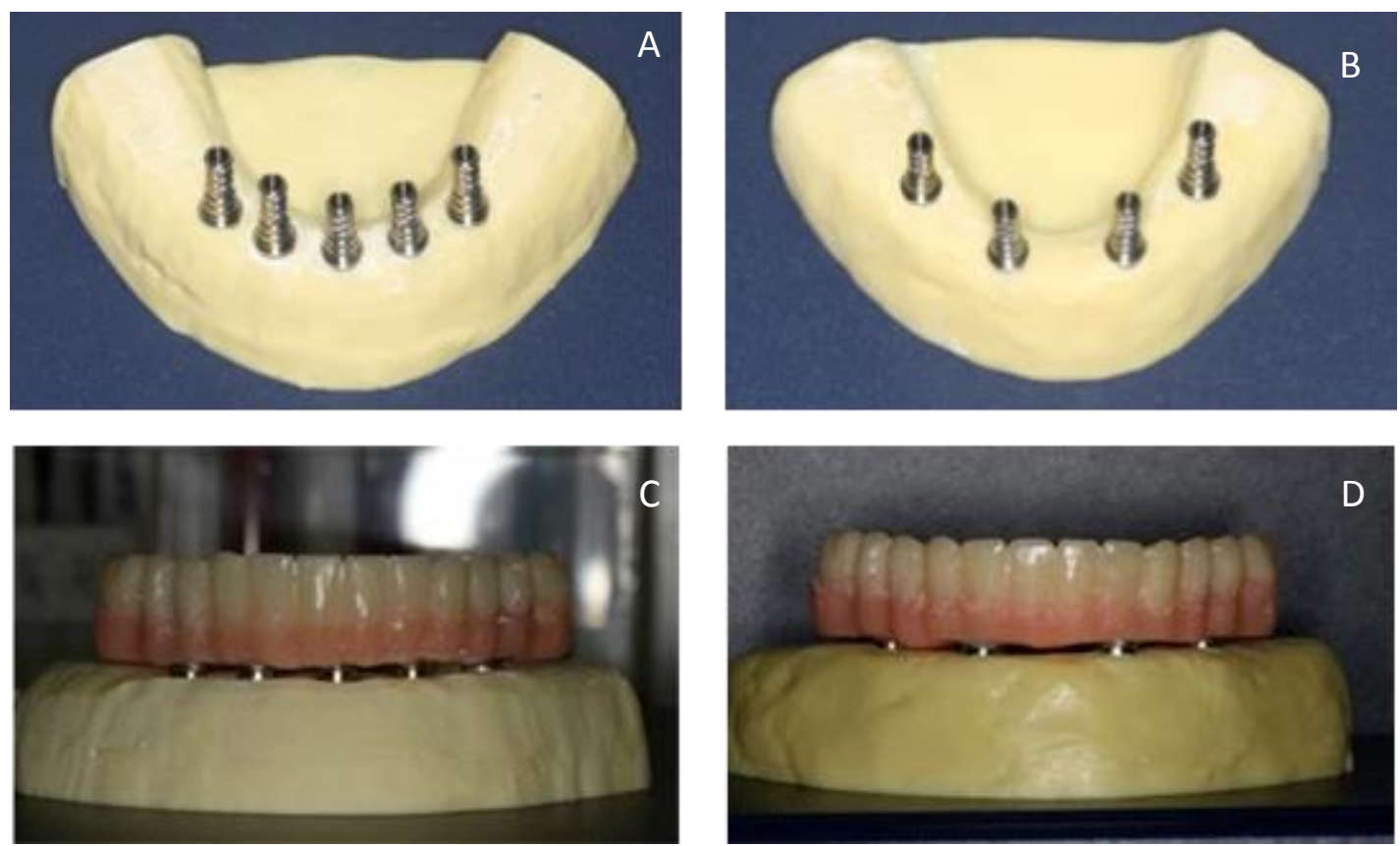

Figura 8. A) e B) - modelos de 5 e 4 implantes com cilindros de titânio posicionados; C) e D) Protótipos em resina acrílica para os dois grupos. 
Os protótipos confeccionados para os dois grupos eram idênticos, com diferença apenas no tamanho do cantilever. Para os grupos de 5 implantes, como os últimos implantes não têm inclinação para a distal, o cantilever ficou mais extenso: $15 \mathrm{~mm}$ (medida linear entre a borda mais distal dos últimos mini pilares e o final da extensão protética em resina); já nos grupos de 4 implantes, com a inclinação dos últimos implantes houve diminuição da extensão do cantilever: $12 \mathrm{~mm}$ (medidos da mesma maneira).

Entretanto, sabe-se da necessidade em reservar espaço para o recobrimento em resina em toda a superfície da infraestrutura, inclusive da extensão final da prótese. Nesta região especificamente, foi deixado o espaço de $3 \mathrm{~mm}$, para ambas as situações. Portanto, foi padronizado que a extensão do cantilever metálico deveria ser de $13 \mathrm{~mm}$ para os grupos de 5 implantes e $9 \mathrm{~mm}$ para os grupos de 4 implantes.

Após a confecção dos protótipos, iniciou-se a confecção das barras pelas duas técnicas propostas.

\subsection{Obtenção das barras em Co-Cr (CAD-CAM - Usinagem)}

Estas barras foram confeccionadas pela Neodent (Neodent Digital). Para isto foram enviados dois protótipos em resina previamente confeccionados (4 e 5 implantes) para guiar o desenho das infraestruturas. Também foram encaminhados 1 modelo de cada grupo.

1- Etapa CAD do sistema:

Nesta fase inicial foi determinado, virtualmente, o desenho da peça a ser confeccionada, observando todos os detalhes de contorno e espessura ideais. Em seguida foi realizado todo o planejamento virtual da futura prótese. A partir do scanner de mesa tridimensional do Neoshape (D-700, 3Shape A/S, Copenhagen, Dinamarca) foi determinado o tipo de prótese a ser confeccionada, especificamente uma prótese fixa mandibular implantossuportada de 12 elementos sobre as duas configurações propostas neste estudo, 5 implantes e 4 implantes.

O software para desenho das estruturas, 3Shape Dental Designer ${ }^{\text {TM }} 2010$ (3Shape A/S, Copenhagen, Dinamarca) desenhou virtualmente em 3D a barra. Obtidos os modelos virtuais 3D das barras, os mesmos foram salvos em arquivos tipo ST (Figura 9). 

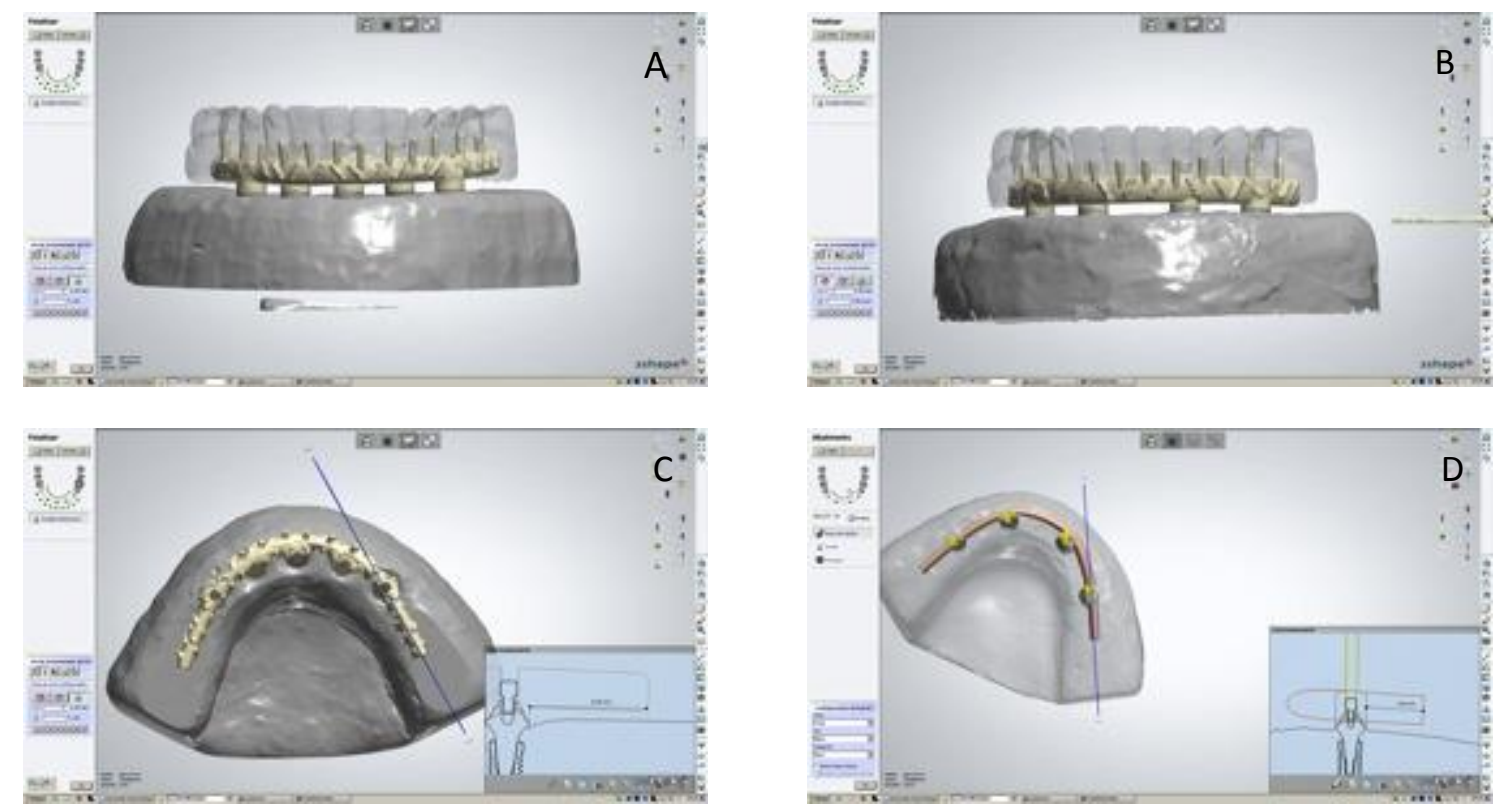

Figura 9. A) B) C) e D) - Desenhos das estruturas pelo sistema Neoshape através do software 3Shape Dental Designer ${ }^{\mathrm{TM}}$.

\section{2- Etapa CAM do sistema:}

Para a realização da etapa CAM do sistema, foi realizada a programação do software que opera a máquina de fresagem para a confecção das peças. Assim, foram determinadas todas as ferramentas que foram utilizadas pela fresadora de cinco eixos simultâneos Ultrasonic 20 linear (Sauer - DMG/MORI SEIKI USA, Hoffman Estates, IL, EUA) (figura 10), durante a fresagem, além de serem determinadas as etapas em que a mesma ocorreu.

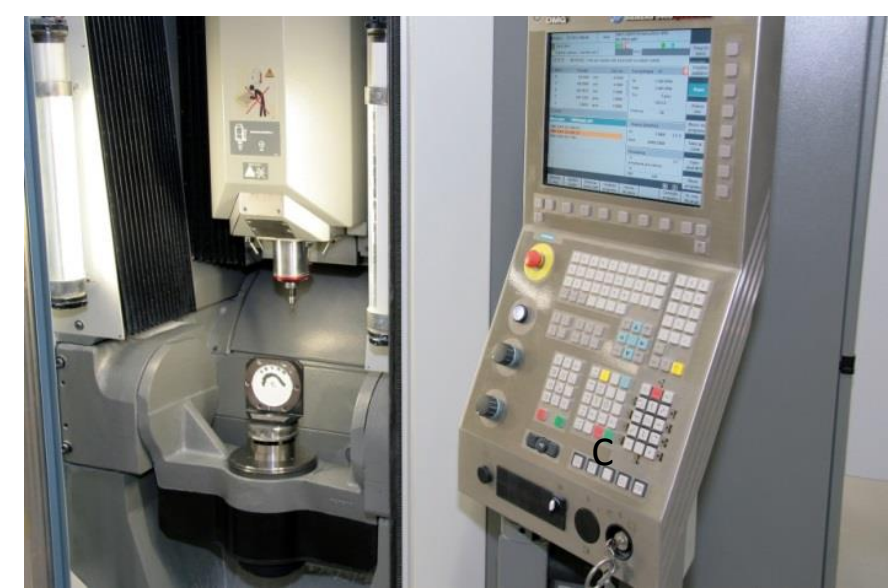

Figura 10. Fresadora utilizada para obtenção das barras 
Um teste piloto foi inicialmente realizado para a confecção das infraestruturas deste projeto, uma vez que as estruturas são bastante extensas e complexas, envolvendo todo o arco mandibular. Foi colocado um disco de acrílico na máquina a qual foi programada para operar em 4 etapas: $1 \mathrm{a}$ - fresagem grosseira no sentido da incisal para o terço médio da peça, $1 \mathrm{~b}$ fresagem grosseira no sentido do terço médio da peça para a região cervical; $2 \mathrm{a}$ - refinamento da fresagem no sentido da incisal para o terço médio, $2 \mathrm{~b}$ - refinamento da fresagem no sentido do terço médio para a região cervical; 3 - refinamento da região de adaptação entre a peça e o componente protético e, 4 - confecção do furo para a passagem do parafuso de retenção. Após a obtenção das peças, a adaptação das mesmas aos análogos dos pilares foi avaliada em microscópio óptico com aumento de 30X (Marcel Aubert SA CH250, Bienne, Suíça).

Depois de verificada a precisão de adaptação foram confeccionadas as peças em Co$\mathrm{Cr}$ (Figura 11). Foram obtidas 4 barras através da usinagem de discos de $\mathrm{Co}-\mathrm{Cr}$ (Figura 12).

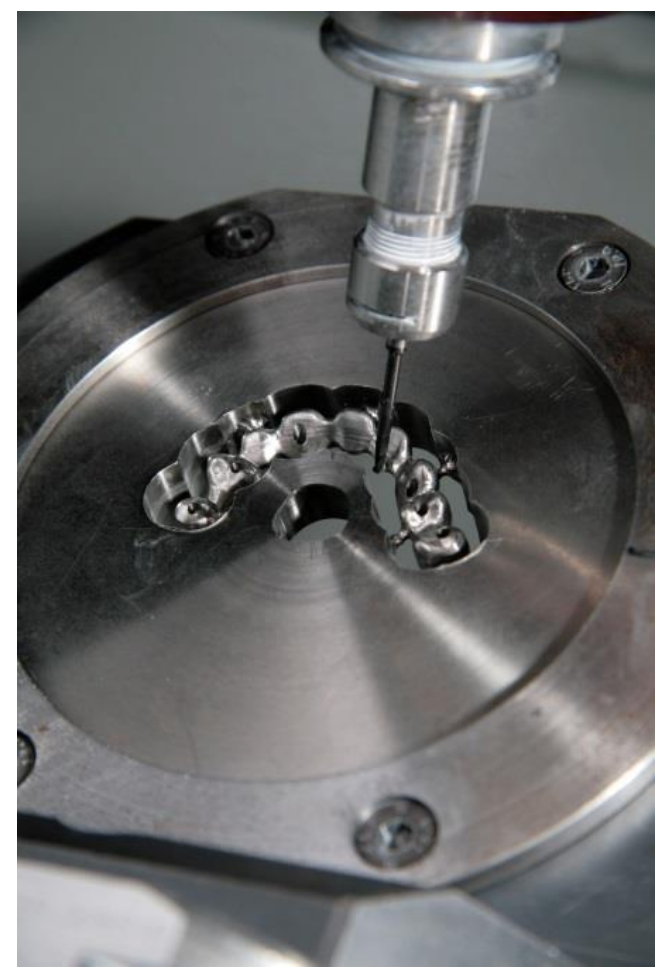

Figura 11. Fresagem das barras em $\mathrm{Co}-\mathrm{Cr}$ 

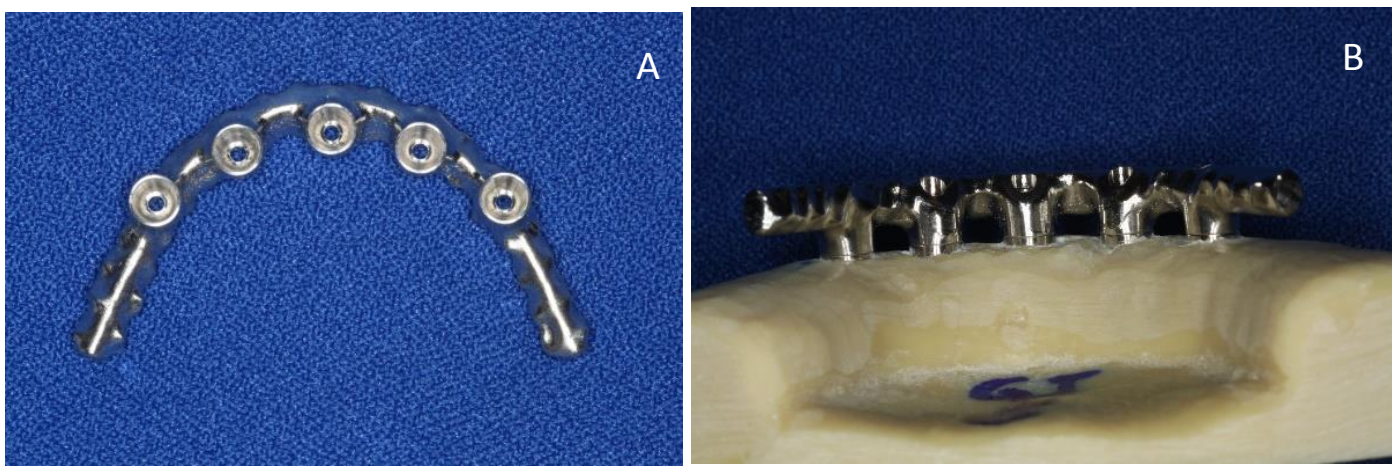

Figura 12. A) - Aspecto final das barras confeccionadas pelo sistema Neoshape, B) Assentamento da barra no respectivo modelo de trabalho.

\subsection{Obtenção das barras em Co-Cr (Método convencional)}

A confecção das barras neste grupo foi realizada por um técnico em prótese dentária. Para permitir uma padronização com outro grupo, algumas dimensões das barras usinadas foram respeitadas durante este enceramento.

Assim, nos modelos de trabalho, os cilindros para enceramento (Neodent, Curitiba, PR, Brasil) foram posicionados sobre os análogos, reduzidos em altura com disco de carborundum, as retenções destes componentes foram preenchidas com cera e os mesmos foram vaselinados, permitindo a confecção de coppings em resina acrílica Duralay (Duralay Reliance Dental MFG Co., Worth, EUA) sobre cada cilindro. Para a interligação dos cilindros foram utilizados segmentos de um padrão calcinável específico para a confecção de barras, cortados com disco de carborundum e fresas em baixa rotação. Estes segmentos devidamente dimensionados para cada espaço foram aderidos aos coppings previamente confeccionados com cola à base de cianoacrilato (Super Bonder ${ }^{\circledR}$, Loctite, São Paulo, SP, Brasil). (Figura 13).
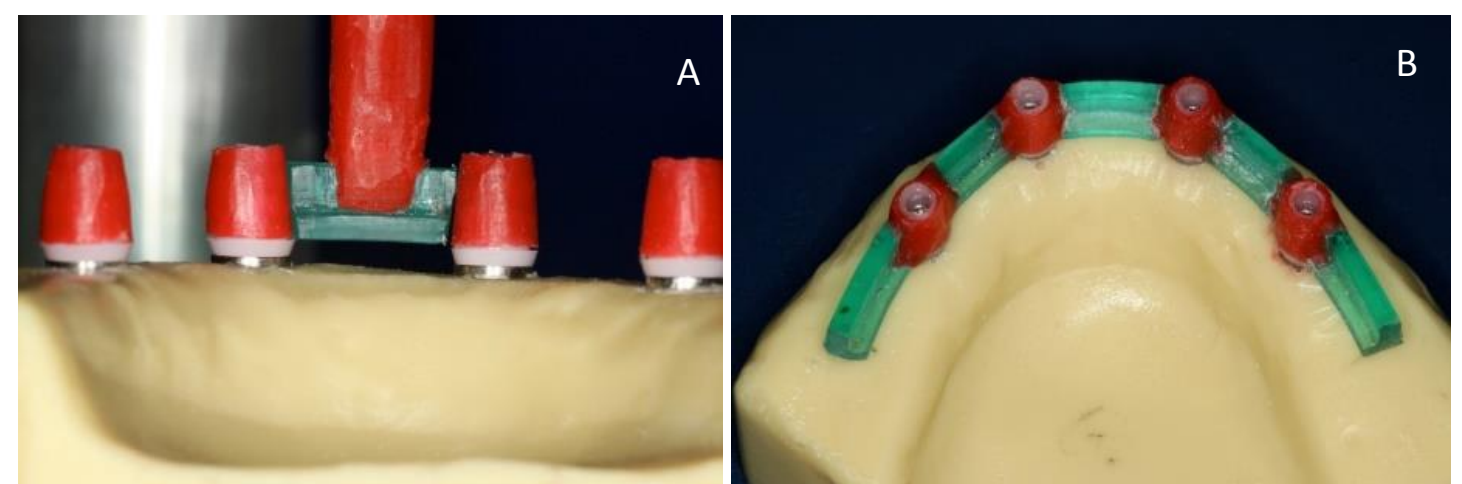

Figura 13. A) e B). Confecção das barras 
Após a confecção das barras para os grupos de 4 e 5 implantes, foi realizado um molde da barra modelo de 4 e 5 implantes utilizando silicone para laboratório Zetalabor (Zhermack S.p.A, Badia Polesine, Rovigo, Itália), possibilitando a replicação em resina acrílica Duralay das barras dentro dos padrões pré-estabelecidos (Figura 14).
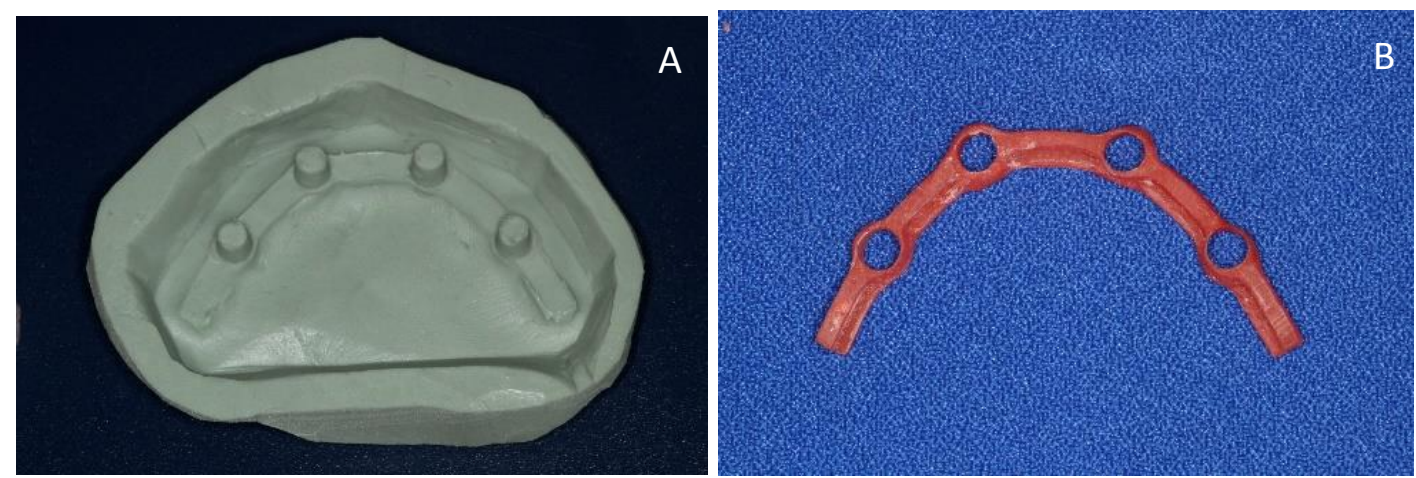

Figura 14. A) Molde em silicone denso para replicação das barras; B) - aspecto final das barras confeccionadas em resina acrílica Duralay.

Após obtenção dos padrões, todos foram levados a seus respectivos modelos de trabalho, posicionados sobre os cilindros calcináveis e fixados aos mesmos com cera fundida (Figura 15).
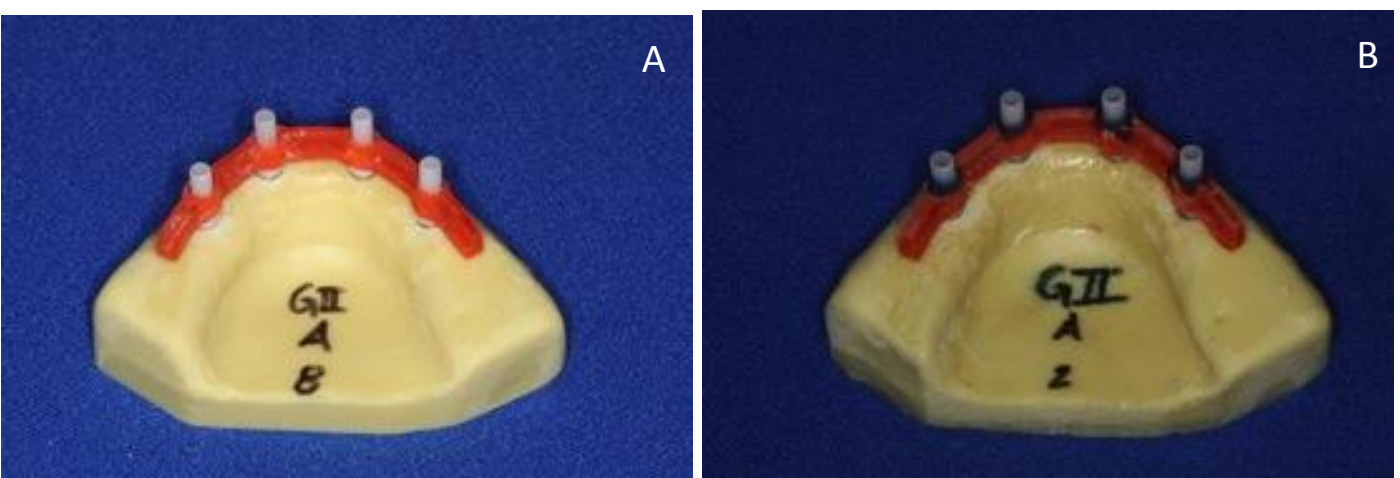

Figura 15. A) - Posicionamento dos padrões sobre os cilindros; B) fixação com cera

Os padrões foram armazenados em água destilada por 24 horas. Os padrões receberam os canais de alimentação em cera (Kota, São Paulo, SP, Brasil) para serem, então, incluídos no revestimento para fundição em Co-Cr. Para o processo de inclusão em revestimento, os padrões foram fixados às bases formadoras de cadinho, pulverizados com spray redutor de tensão de 
superfície (Antibolha Kota, São Paulo, SP, Brasil) e deixados secando em temperatura ambiente. Por sobre a base, foi encaixado um anel de inclusão de silicone (Figura 16).
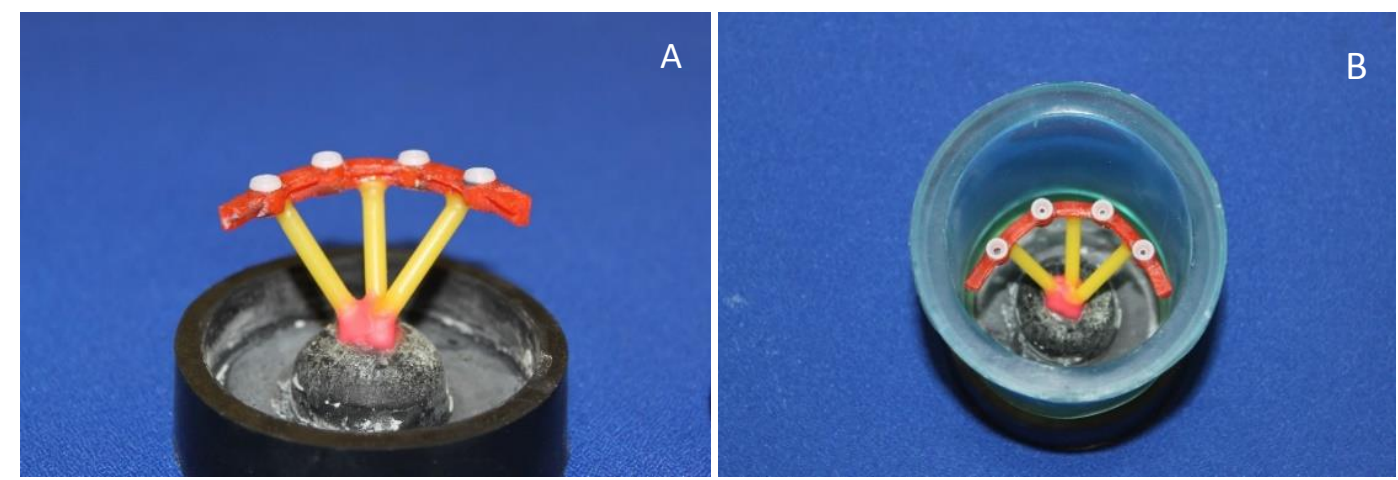

Figura 16. A) - Barras fixadas à base do cadinho; B) anel de inclusão em silicone encaixado para o futuro vazamento do revestimento.

O revestimento Heat Shock® (Polidental Ind. Com. Ltda., Cotia, SP, Brasil) foi manipulado usando $450 \mathrm{~g}$ de pó e $63 \mathrm{ml}$ de líquido. $\mathrm{O}$ revestimento foi espatulado mecanicamente a vácuo por 60 segundos em espatulador elétrico (Turbomix, EDG Equipamentos e Controles Ltda., São Carlos, SP, Brasil), depois vertido no anel sob vibração cuidadosa para preenchimento do mesmo.

$\mathrm{O}$ anel permaneceu sobre a bancada em temperatura ambiente até o início da reação de cristalização do revestimento. Após cerca de 40 minutos, a camada mais superficial do revestimento foi removida em recortador de gesso e o anel levado ao forno elétrico (EDG10PS, EDG Equipamentos e Controles Ltda.) para expansão do revestimento e eliminação da cera e resina (Figura 17).
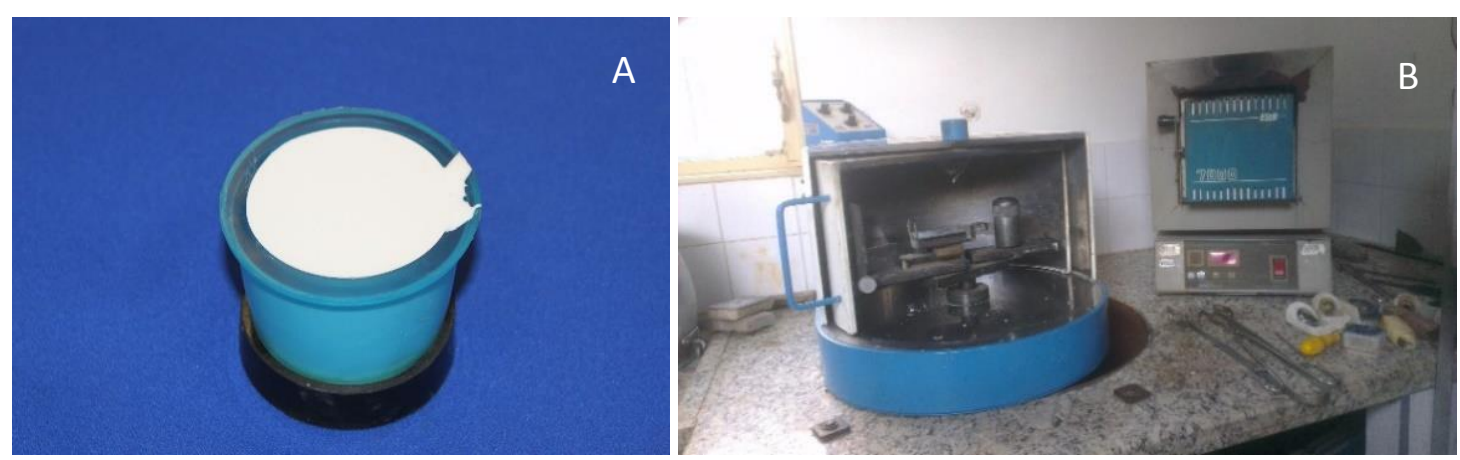

Figura 17. A) - Revestimento já vertido no anel de inclusão; B) - vista do forno EDG10P-S. 
As fundições foram realizadas por maçarico (gás/oxigênio) e a injeção da liga fundida foi realizada por uma máquina centrífuga (EDG Equipamentos e Controles Ltda). Após o processo de fundição e adequado resfriamento do revestimento, as barras foram desincluídas (Figura 18), e os condutos de alimentação foram seccionados com discos de carborundum. Em seguida, os corpos de prova foram jateados com óxido de alumínio (Polidental® Indústria e Comércio Ltda., São Paulo, SP, Brasil) de granulação de $100 \mu \mathrm{m}$, sob pressão de 80 lib/pol²
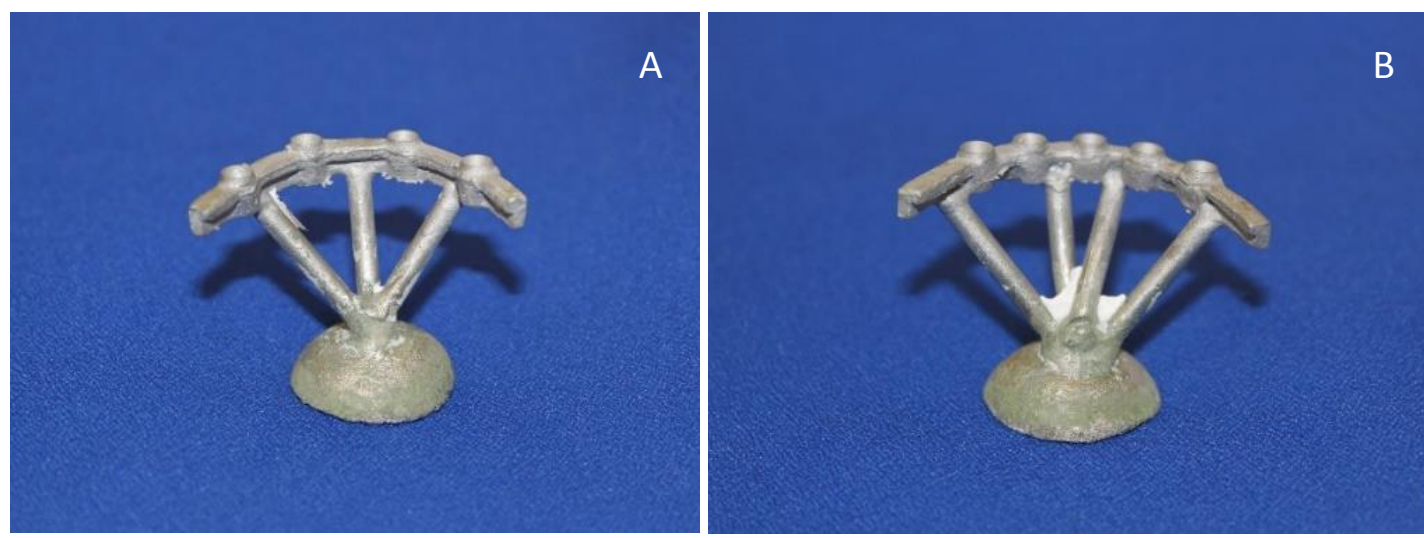

Figura 18. A) e B) - Aspecto das barras após desinclusão.

O acabamento consistiu apenas na remoção de pequenos nódulos e rebarbas com brocas de tungstênio em alta rotação e sob refrigeração constante (Figuras 19). As barras obtidas foram avaliadas em relação à adaptação e passividade sobre os pilares.
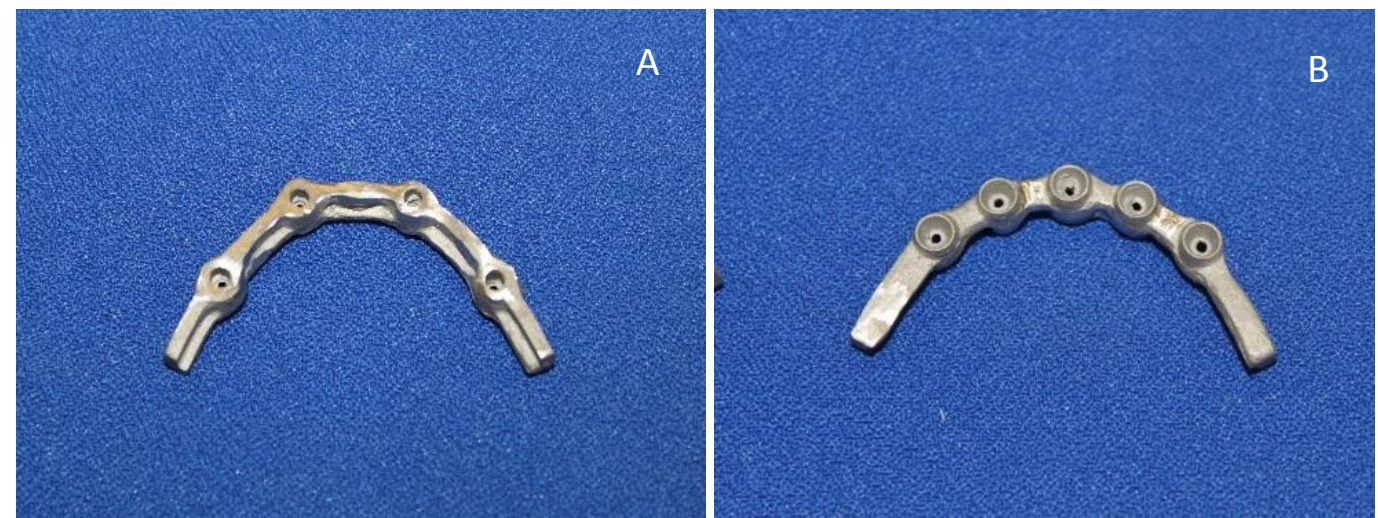

Figura 19. A) Vista Oclusal e B) Vista da interface da adaptação - Aspecto das barras após o acabamento. 
As barras obtidas por meio da confecção convencional apresentaram desadaptação e de ausência de passividade, necessitando de ponto de solda. No grupo de 4 implantes, a barra foi seccionada entre os dois implantes anteriores, e o grupo de 5 implantes, as barras foram seccionadas na região central, utilizando disco de carborundum (Figura 28), no local da secção da barra foi utilizada resina acrílica de polimerização rápida (Duralay Reliance Dental MFG Co., Worth, EUA), para unir as duas extremidades da barra seccionada. As barras foram posicionadas sobre revestimento específico (Easy-Stack, Talmax, Curitiba, PR, Brasil), a resina acrílica foi eliminada e as superfícies a serem soldadas foram limpas. As superfícies foram soldadas com maçarico utilizando fluxo e varetas de solda (Solda Fit, Talmax). Assim, todas as barras obtidas pelo processo de fundição convencional foram submetidas ao processo de soldagem, fazendo com que os grupos fossem homogêneos. Após o processo de soldagem, cada infraestrutura foi novamente avaliada em relação à passividade sobre os análogos nos modelos de trabalho, constatando melhora visual significante em todas as situações (Figura 20)
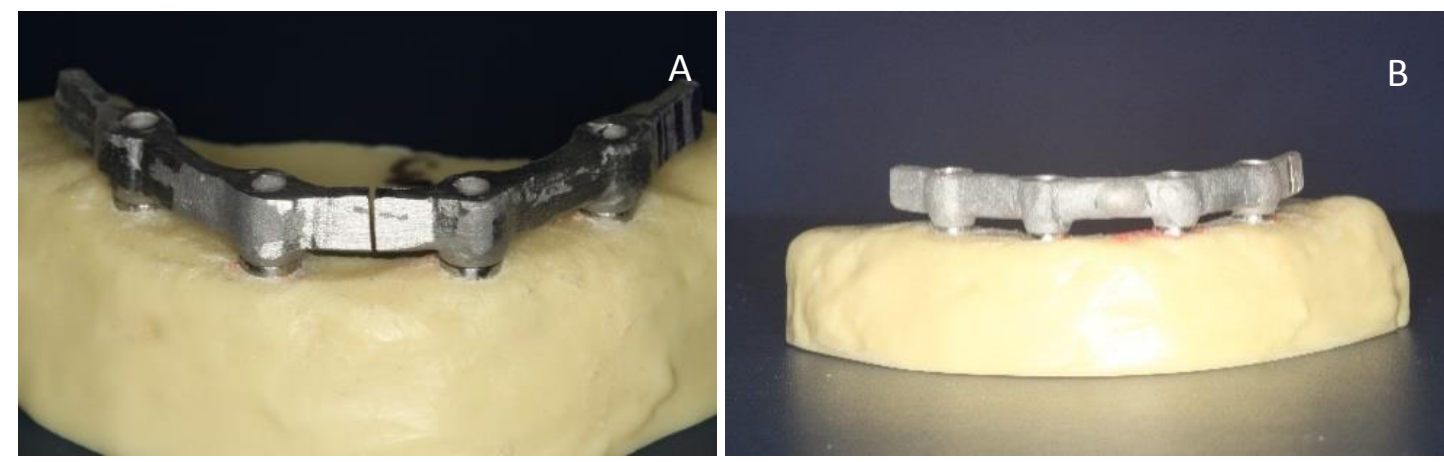

Figura 20. A) - Barra seccionada com disco de carborundum; B) aspecto final do ponto de solda

\subsection{Enceramento, montagem de dentes e acrilização das próteses}

Sobre o protótipo inicial da prótese, uma matriz de silicone por condensação para laboratório Zetalabor (Zhermack S.p.A, Badia Polesine, Rovigo, Itália), foi confeccionada para registrar o posicionamento dos dentes artificiais e possibilitar a reprodução e confecção das demais próteses. A superfície externa das muralhas em silicone e dos modelos em poliuretano foram picotados com discos de carborundum, criando retenções para permitir a inclusão na mufla (Figura 21). 
Para o processo de acrilização foram utilizados dois conjuntos de muflas (Vipi STG, Vipi, Pirassununga, SP, Brasil), um para cada grupo (4 e 5 implantes). Os modelos de trabalho foram posicionados no interior das bases das muflas e foi vazado gesso pedra tipo IV (Durone IV, Dentsply, Petrópolis, RJ, Brasil). Antes da presa do gesso, foi dado acabamento para obtenção de uma superfície extremamente lisa. Após a presa final, a superfície de gesso foi vaselinada e a partir daí as contra-muflas foram colocadas sobre as bases e fixadas com os quatro parafusos. O interior das contra-muflas foi preenchido com gesso pedra tipo IV, capturando as muralhas de silicone (Figura 22).

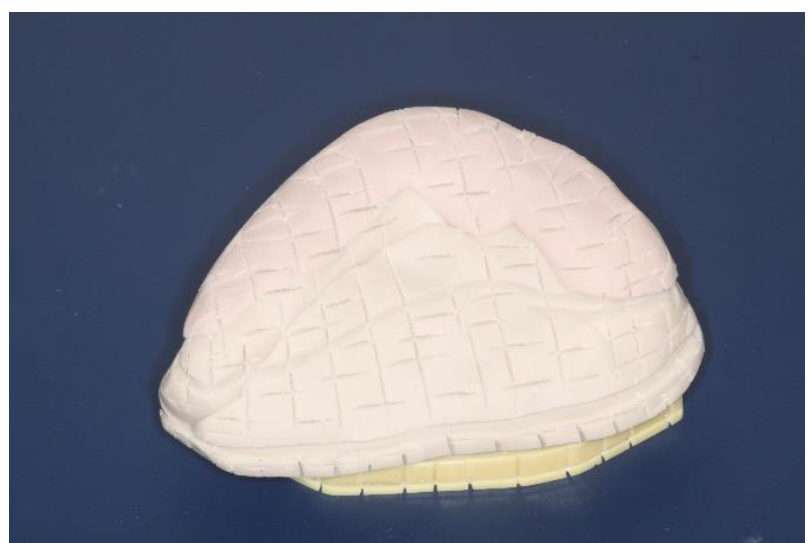

Figura 21. Retenções no modelo e da muralha em silicone para permitir inclusão na mufla.
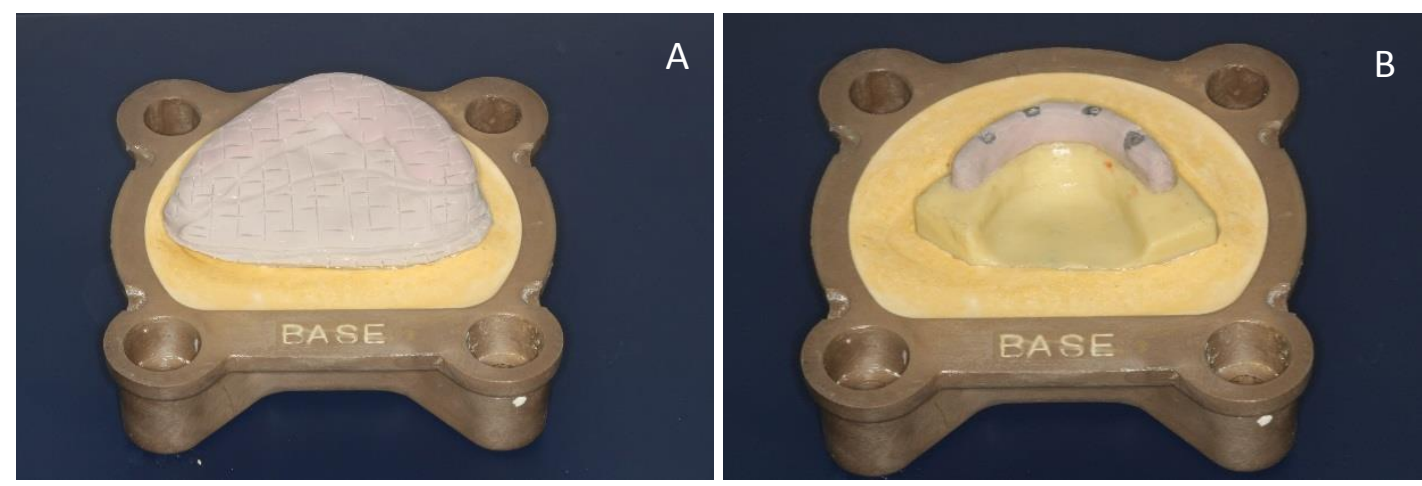

Figura 22. A) e B). Vista do modelo no interior da mufla

Com a inclusão das muflas concluída, teve início o processo de posicionamento dos dentes de estoque e acrilização das próteses utilizadas neste estudo. Portanto, na base da mufla, cada infraestrutura foi posicionada sobre o modelo de trabalho correspondente. Foram rosqueados os parafusos protéticos e sobre os mesmos, inseridas bolinhas de teflon (Brasfita®, 
Diadema, SP, Brasil), para proteger os orifícios da entrada de resina acrílica. As superfícies em poliuretano e gesso foram vaselinadas. Na contra-mufla, os dentes de estoque (Biotone ${ }^{\circledR}$, Dentisply, Petrópolis, RJ, Brasil) (figura 23) foram perfurados em sua base com broca esférica $\mathrm{n}^{\circ} 4$ para permitir melhor retenção da resina acrílica e inseridos dentro de seus respectivos espaços na muralha. A superfície de gesso na contra-mufla foi vaselinada (Figura 24).

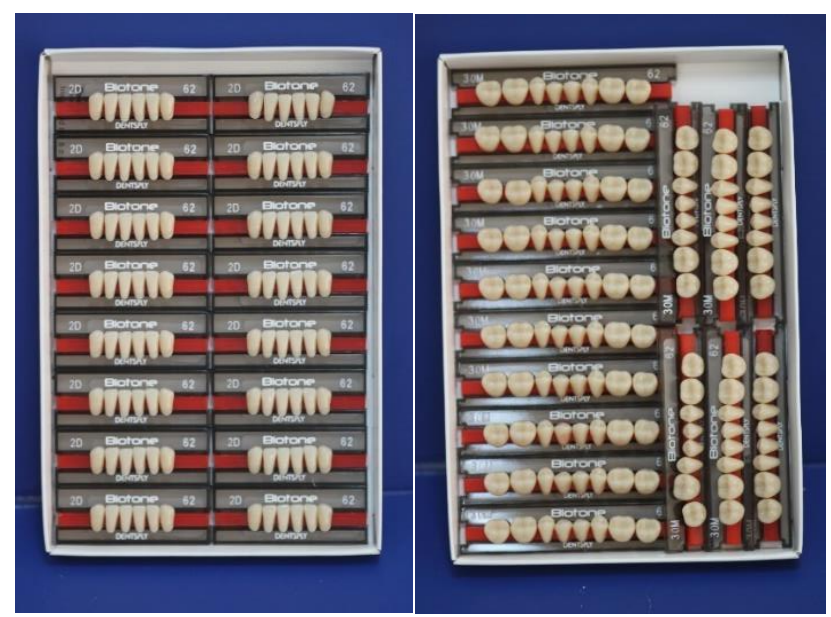

Figura 23. Dentes artificiais utilizados para confecção das próteses. A) - Dentes anteriores; B) Dentes posteriores

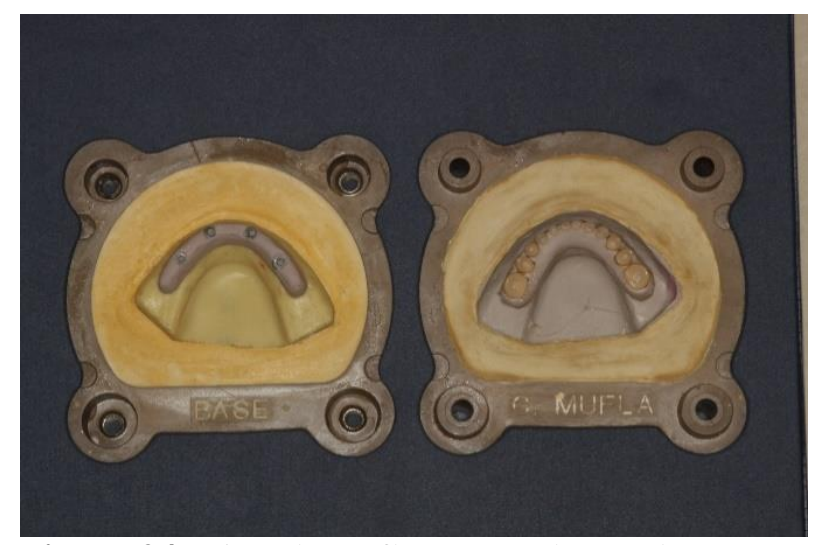

Figura 24. Vista da mufla com os dentes de estoque em posição

Para este estudo, foi utilizada resina acrílica incolor (Vipi Crill Plus, Vipi, Pirassununga, SP, Brasil) para permitir melhor visualização das infraestruturas e componentes da prótese. Foi manipulada resina acrílica termopolimerizável, de acordo com a instrução do 
fabricante. Após o material atingir a fase plástica, o mesmo foi aplicado no interior da mufla previamente isolada. As muflas foram fechadas e prensadas com $1000 \mathrm{Kgf}$, os excessos de resina foram removidos e antes da polimerização, a resina descansou por 20 minutos. Após este período as muflas foram apertadas com os quatro parafusos e levadas para a polimerização. Foi realizado o processo de polimerização termo-pneumático, colocando as muflas na polimerizadora e cobrindo-as com água. A polimerizadora foi fechada, ligada à rede elétrica e foi injetado ar comprimido (60 libras). Ao atingir $120^{\circ} \mathrm{C}$, desligou-se a polimerizadora até esfriar a $90^{\circ} \mathrm{C}$. Ao atingir esta temperatura, a polimerizadora foi novamente ligada até atingir $120^{\circ} \mathrm{C}$ e em seguida, a mesma foi desligada, deixando agora esfriar até $60^{\circ} \mathrm{C}$. A partir deste ponto, a mufla foi removida e iniciou-se a demuflagem, removendo os parafusos e separando a base e contra-mufla.

Para a remoção das próteses, foi utilizada broca esférica na direção dos parafusos protéticos até atingir as bolinhas de teflon. As mesmas foram removidas com explorador clínico e os parafusos protéticos foram desrosqueados. O acabamento das próteses foi feito com brocas, pedras e borrachas abrasivas diversas. Em seguida foi feito o polimento com escova de flanela e pedra-pomes em politriz (Figura 25).

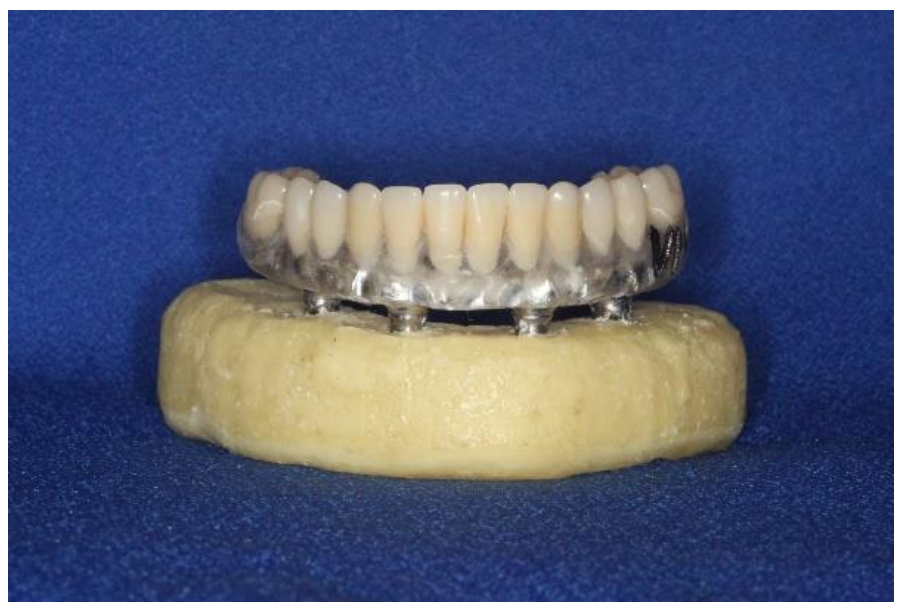

Figura 25. Aspecto final das próteses após acabamento e polimento 


\subsection{Análise por correlação de imagens digitais}

Para análise da distribuição de tensões ao redor dos implantes, foi utilizado o método de correlação de imagens digitais. Foram confeccionados modelos em poliuretano dos oito grupos estudados para esta análise.

O sistema completo da técnica de correlação de imagens (StrainMaster, LaVision Inc., Goettingen, Alemanha) inclui duas câmeras digitais CCD (Charged-coupled device) (Imager Intense, LaVision Inc.) com resolução de 1039 x 1395 pixels utilizadas para captura das imagens da superfície do modelo sob carregamento e um software específico (DaVis 8.1.2 LaVision Inc.) para análise das imagens e cálculo das tensões (Figura 26).

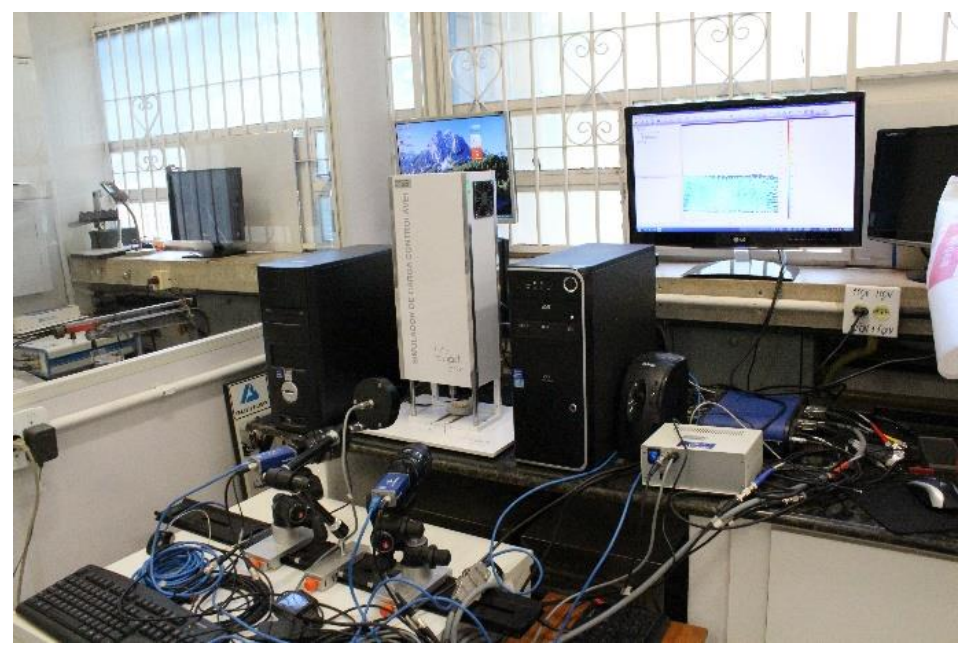

Figura 26. Técnica de correlação de imagens digitais (StrainMaster, LaVision Inc., Goettingen, Alemanha)

Os modelos para esta análise foram obtidos exatamente da mesma forma descrita anteriormente para confecção das barras, a única alteração é que foram posicionados implantes e mini pilares e não análogos nestes modelos. A superfície do modelo a ser analisada foi pintada com uma fina camada de tinta spray branca (ColorGin, Sherwin-Williams do Brasil, Taboão da Serra, SP), com pequenos pontos pretos também realizados com tinta spray que foram utilizados pelo sistema de correlação de imagens para facilitar o rastreamento de seu deslocamento e realizar corretamente os cálculos das tensões geradas na superfície do modelo (Li et al. 2009, Tiossi 2010). Sobre os modelos foram posicionadas as barras obtidas pelos dois diferentes métodos (Figura 27). 


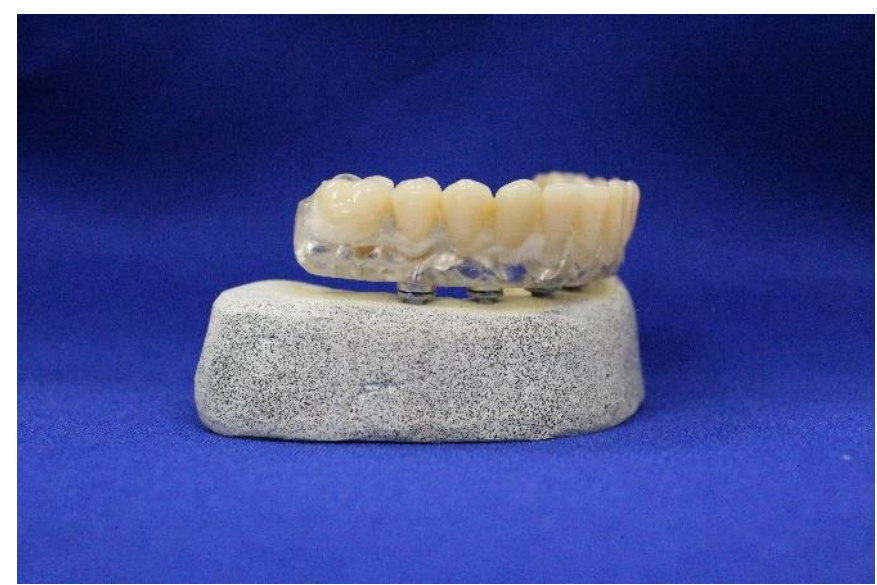

Figuras 27. Vista do modelo preparado para análise por correlação de imagens.

Para análise por correlação de imagens foi aplicada uma carga de $250 \mathrm{~N}$ com velocidade de 0,5 mm/min, utilizando um aplicador de carga (Biopdi, São Carlos, São Paulo, Brasil). A face do modelo após o preparo foi posicionada em frente às câmeras digitais e a carga puntiforme foi aplicada na região da fossa central do primeiro molar.

O modelo foi apoiado em dois pontos para sua base não ficasse em contato com a bancada do simulador de carga controlável, impedindo assim, que houvesse um apoio total do modelo evitando possíveis alterações na análise das tensões e também para simular a situação de metade do arco mandibular, a captura das imagens foi feita de uma vista lateral dos modelos, previamente a cada carregamento foi realizada uma calibração das imagens com uma placa padrão fornecida pelo fabricante do equipamento (LaVision Inc) (Figura 28).

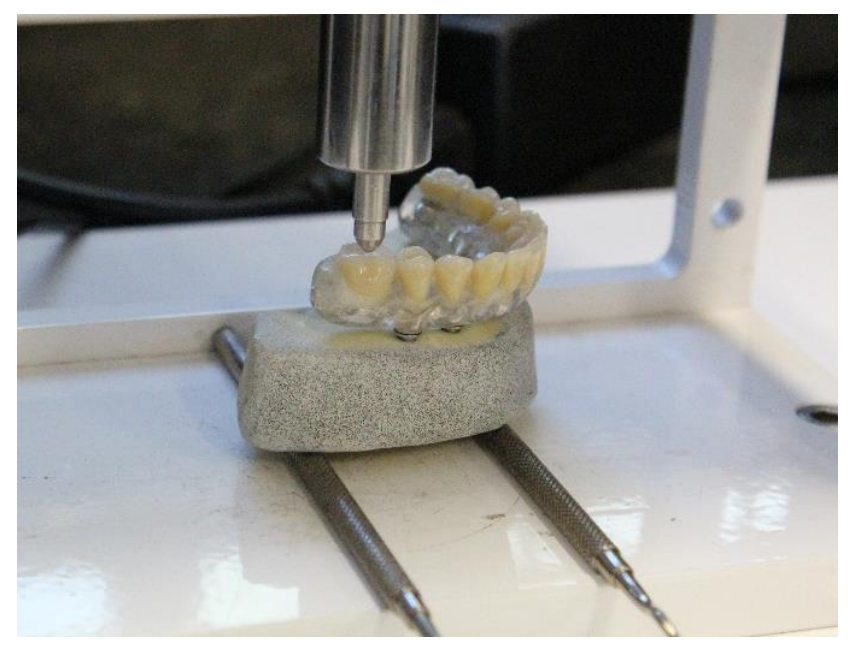

Figura 28. Aplicação de carga 
Para medir as tensões geradas na superfície do modelo após o carregamento, imagens da superfície pintada foram tiradas na frequência de $1,00 \mathrm{~Hz}$ até que a carga de $250 \mathrm{~N}$ fosse atingida. As tensões superficiais foram calculadas a partir dos deslocamentos pelo software de correlação de imagens (DaVis 8). Através desse método é possível detectar tensões horizontais $\left(\mathrm{E}_{\mathrm{xx})}\right.$.

Para determinação das regiões a serem analisadas, a ponta de aplicação de carga no último molar da prótese, foi utilizada como referência. A região Distal ao último implante $(\mathrm{C} 1$ e A1), compreendeu a distância entre o longo eixo da ponta aplicadora até a mensuração de $4 \mathrm{~mm}$ no sentido mésio distal, e $6 \mathrm{~mm}$ no sentido cervico apical, totalizando para as duas regiões (C1 e A1) 4x12 mm. O mesmo ocorreu para a região Mesial (C2 e A2), onde a partir da ponta de aplicação de carga, contados $4 \mathrm{~mm}$ da região Distal, $4 \mathrm{~mm}$ da região do implante e partir daí iniciou a marcação para a região Mesial, também com as dimensões de 4x12mm. (Figura 29).

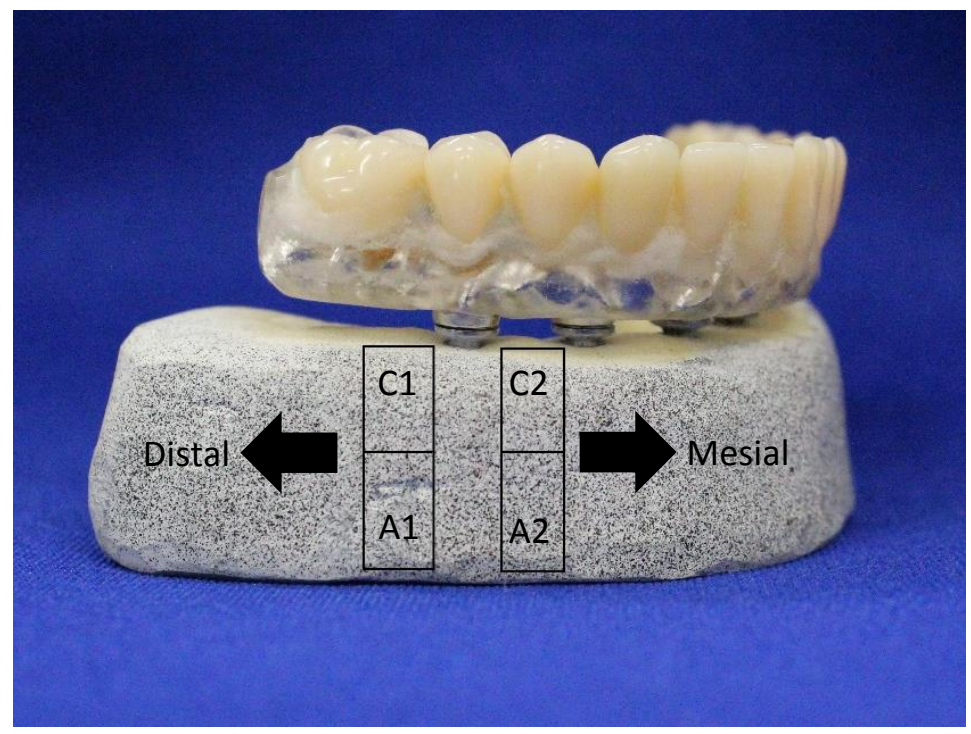

Figuras 29. Modelo de trabalho com as áreas de interesse para o estudo da distribuição de tensões.

Para verificar o correto funcionamento do sistema de análise de tensões por correlação de imagens, a mesma situação teve as tensões mensuradas por três vezes. As três mensurações foram comparadas estatisticamente entre si, para verificar a repetitividade e confiabilidade do método e dos resultados encontrados.

Todos os diferentes grupos foram analisados pelo sistema de correlação de imagens quantitativa e qualitativamente. Para a comparação quantitativa, foi utilizado Análise de Variância de 3 fatores para comparação entre cada grupo do estudo com o auxílio do software. SPSS for Windows (IBM SPSS software, IBM Corporation, NY, EUA). As tensões na direção horizontal $\left(E_{\mathrm{xx}}\right)$ foram usadas e calculadas para a comparação entre grupos. 
RESUltadOS 

Correlação de Imagens Digitais

As tensões horizontais (Exx) em microtensão $(\mu s)$, encontradas nas regiões de interesse para cada grupo são apresentadas nas imagens a seguir (Figuras 30 -37).

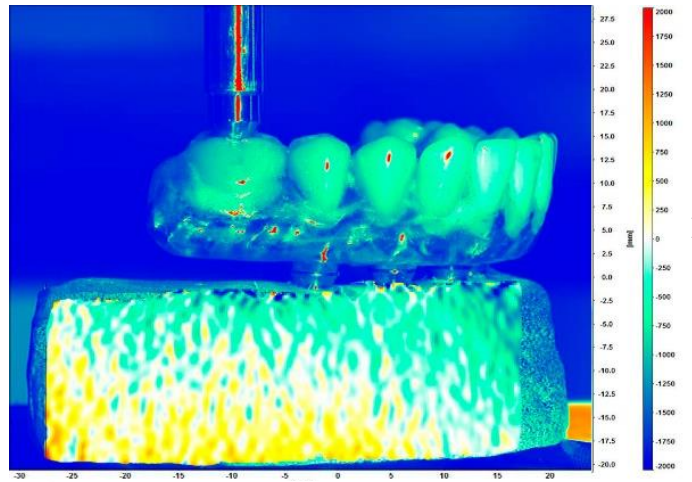

(mm)

Figura 30. G1 (5 Implantes HE - CAD/CAM)

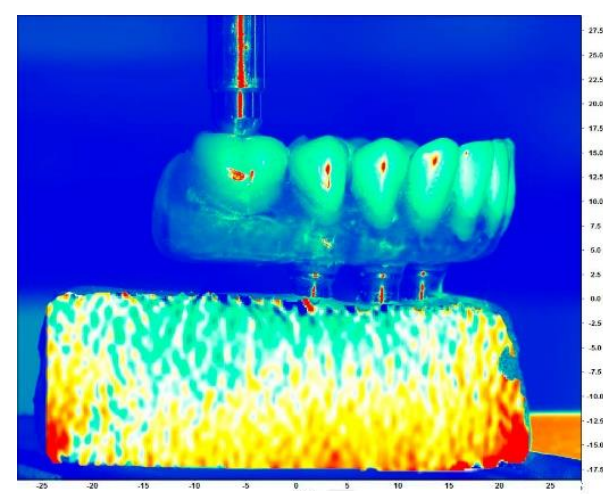

(mm)

Figura 32. G3 (5 Implantes HE - Convencional)

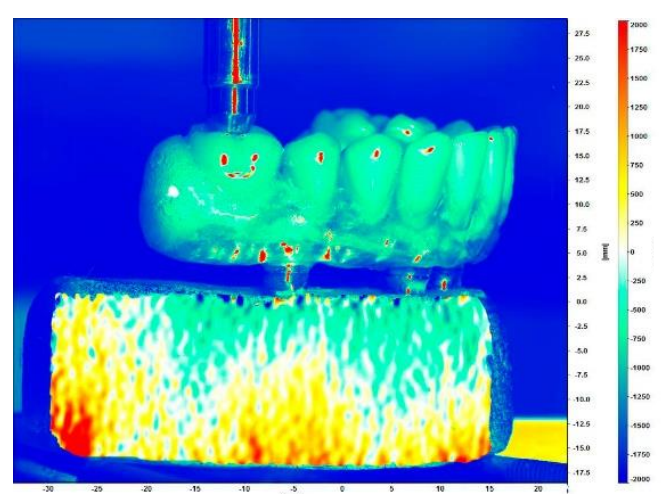

$(\mathrm{mm})$

Figura 34. G5 (4 Implantes HE - CAD/CAM)

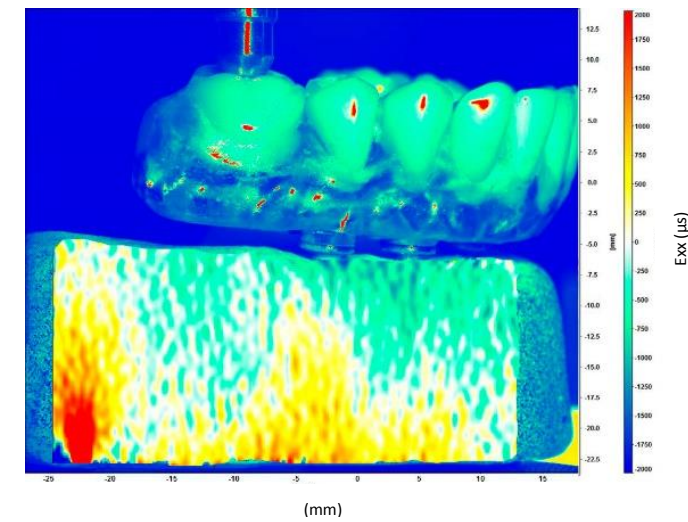

Figura 31. G2 (5 Implantes CM - CAD/CAM)

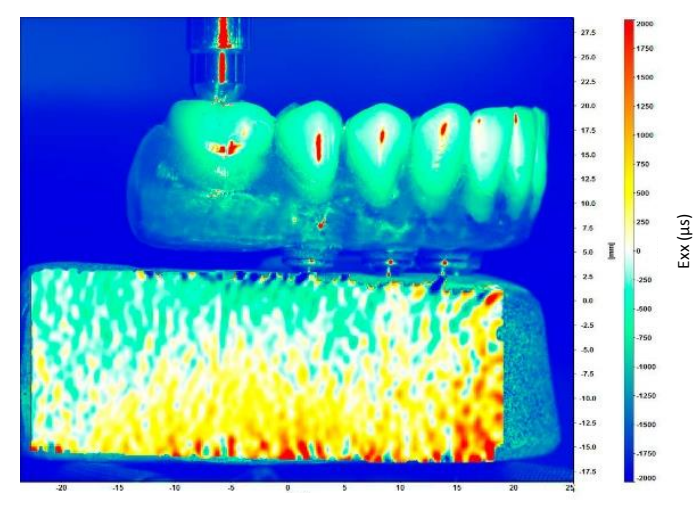

$(\mathrm{mm})$

Figura 33. G4 (5 Implantes CM - Convencional)

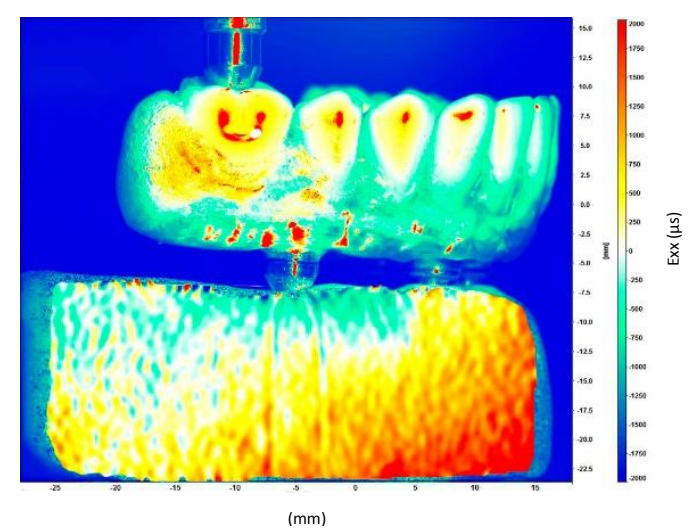

Figura 35. G6 (4 Implantes CM - CAD/CAM) 


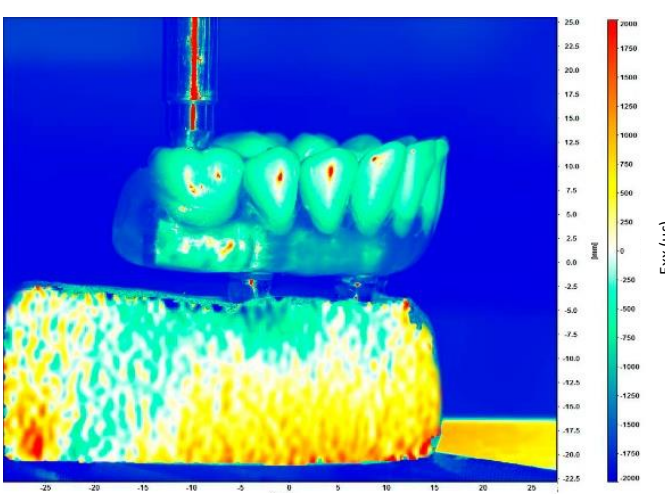

$(\mathrm{mm})$

Figura 36: G7 (4 Implantes HE - Convencional)

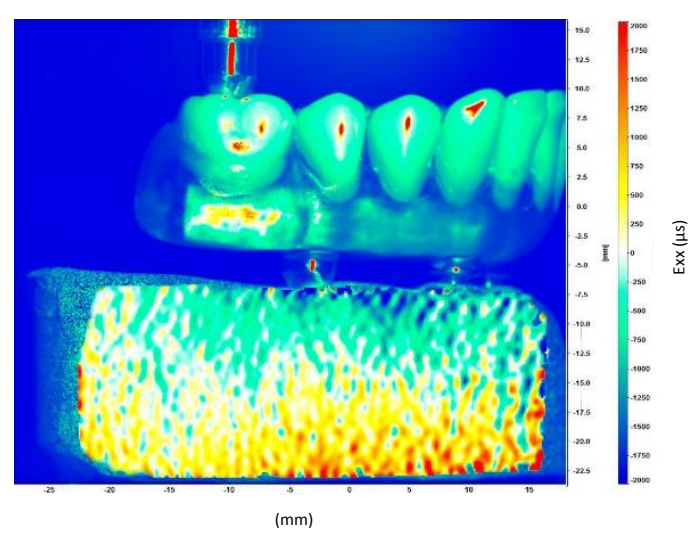

Figura 37: G8 (4 Implantes/ CM/ Convencional)

Pode-se observar que as imagens de cada grupo, apresentam tensões compressivas na região cervical dos modelos, representando nas imagens as cores frias, na região central dos modelos, representada pela cor branca, é a zona neutra e na região apical do modelo, observase as forças de tração, representadas pelas cores quentes, mais evidentes nos modelos de 4 implantes.

Os dados de microtensão ( $\mu \mathrm{s})$ para as regiões C1, A1, C2 e A2, são apresentados nas tabelas abaixo.

Tabela 01. Microtensão (Exx - $\mu$ s) observada na região C1 (cervical 1) - média (desvio-padrão), por número de implantes, conexão e tipo de barra.

\begin{tabular}{ccccc}
\hline & \multicolumn{2}{c}{ CM } & \multicolumn{2}{c}{ HE } \\
& CAD/CAM & Convencional & CAD/CAM & Convencional \\
\hline 5 implantes & $-608,28(240,97)$ & $-499,51(30,23)$ & $-398,72(53,40)$ & $-644,29(106,71)$ \\
4 implantes & $-269,07(61,09)$ & $-440,69(16,74)$ & $-444,86(67,32)$ & $-367,67(26,40)$ \\
\hline
\end{tabular}

Tabela 02. Microtensão (Exx - $\mu$ s) observada na região A1 (apical 1) - média (desvio-padrão), por número de implantes, conexão e tipo de barra.

\begin{tabular}{ccccc}
\hline & \multicolumn{2}{c}{ CM } & \multicolumn{2}{c}{ HE } \\
& CAD/CAM & Convencional & CAD/CAM & Convencional \\
\hline 5 implantes & $-48,77(46,87)$ & $269,19(56,95)$ & $100,23(138,65)$ & $15,77(44,88)$ \\
4 implantes & $301,19(48,10)$ & $154,52(78,36)$ & $165,81(51,75)$ & $197,13(15,10)$ \\
\hline
\end{tabular}


Tabela 03. Microtensão (Exx - $\mu$ s) na região C2 (cervical 2) - média (desvio-padrão), por número de implantes, conexão e tipo de barra.

\begin{tabular}{ccccc}
\hline & \multicolumn{2}{c}{ CM } & \multicolumn{2}{c}{ HE } \\
& CAD/CAM & Convencional & CAD/CAM & Convencional \\
\hline 5 implantes & $-753,16(86,80)$ & $-350,91(124,61)$ & $-329,64(59,35)$ & $-247,26(13,50)$ \\
4 implantes & $-406,38(18,98)$ & $-938,67(79,56)$ & $-499,86(111,78)$ & $-400,80(68,80)$ \\
\hline
\end{tabular}

Tabela 04. Microtensão (Exx - $\mu \mathrm{s})$ na região A2 (apical 2) - média (desvio-padrão), por número de implantes, conexão e tipo de barra.

\begin{tabular}{lcccc}
\hline & \multicolumn{2}{c}{ CM } & \multicolumn{2}{c}{ HE } \\
& CAD/CAM & Convencional & CAD/CAM & Convencional \\
\hline 5 implantes & $-150,03(92,70)$ & $112,05(44,09)$ & $-104,34(79,34)$ & $273,22(5,61)$ \\
4 implantes & $409,24(69,36)$ & $-10,69(61,38)$ & $-25,53(115,99)$ & $157,74(45,70)$ \\
\hline
\end{tabular}

Os gráficos abaixo (Figuras 38 a 45) ilustram o comportamento das tensões para cada grupo analisado. A região mencionada no gráfico como distal, é referente à porção cervicalapical (de C1 até A1) do último implante. A mesial, referente a porção cervical-apical (de C2 até A2) corresponde a região mesial ao último implante.

A extensão do gráfico é medida em mm, o que corresponde ao comprimento do implante $(11 \mathrm{~mm})$ mais uma margem de $2 \mathrm{~mm}$ na direção apical. As tensões são observadas em microtensão $(\mu \mathrm{s})$. 


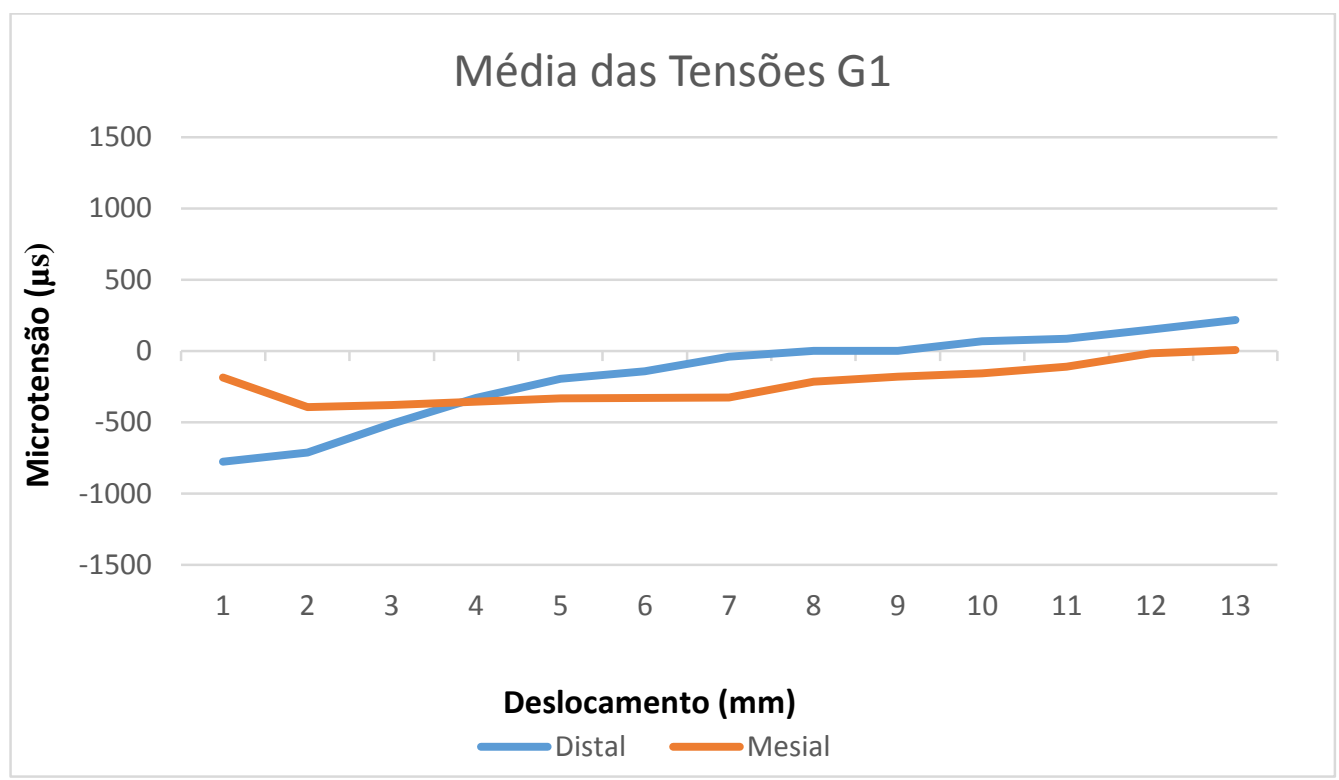

Figura 38. Tensões para o grupo G1, nas regiões distal e mesial

Para o grupo G1 (5 implantes - HE - CAD/CAM), pode-se observar forças compressivas na região cervical mesial e distal, mudando de comportamento ao longo do gráfico, apresentando discretas forças de tração próximas a região apical para a região distal.

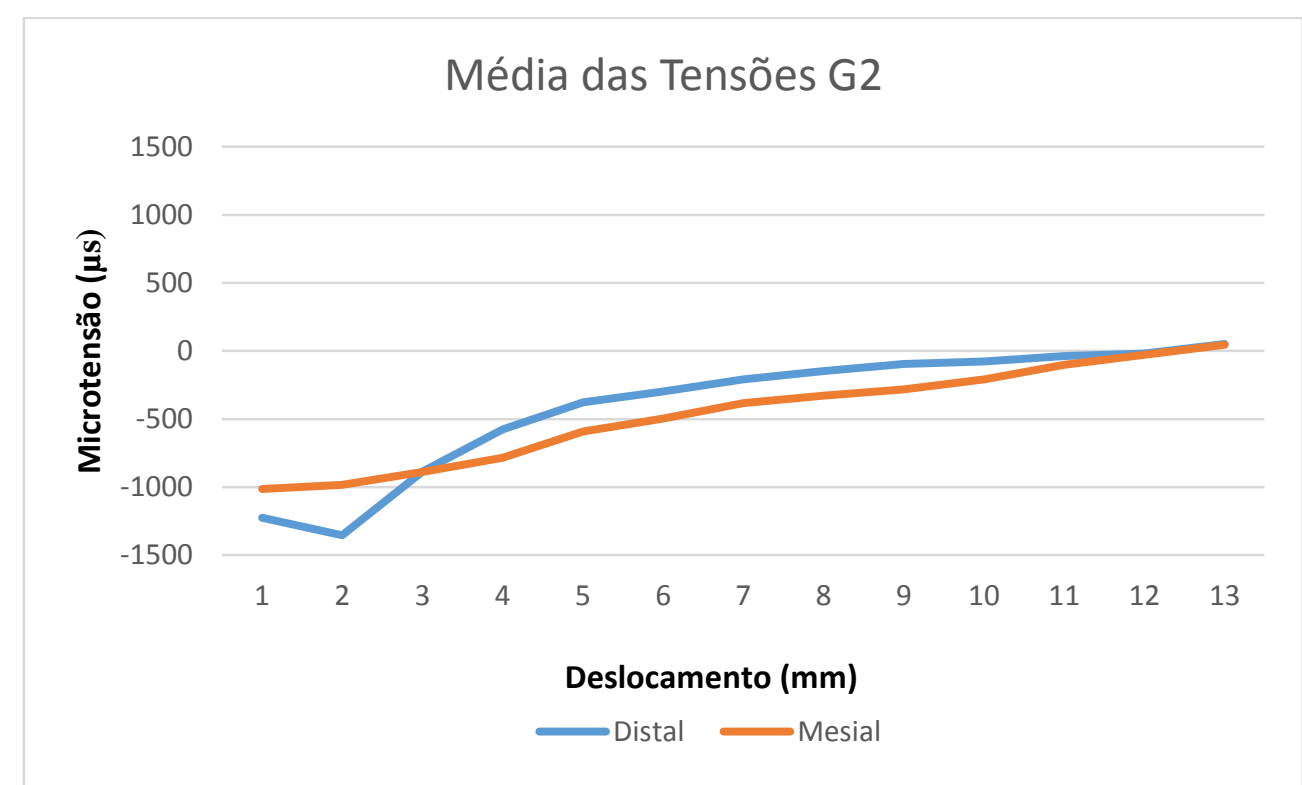

Figura 39. Tensões para o grupo G2, nas regiões distal e mesial

Para o grupo G2 (5 implantes - CM - CAD/CAM), pode-se observar comportamento semelhante ao grupo G1, com predominância das forças de compressão, principalmente na região cervical distal. 


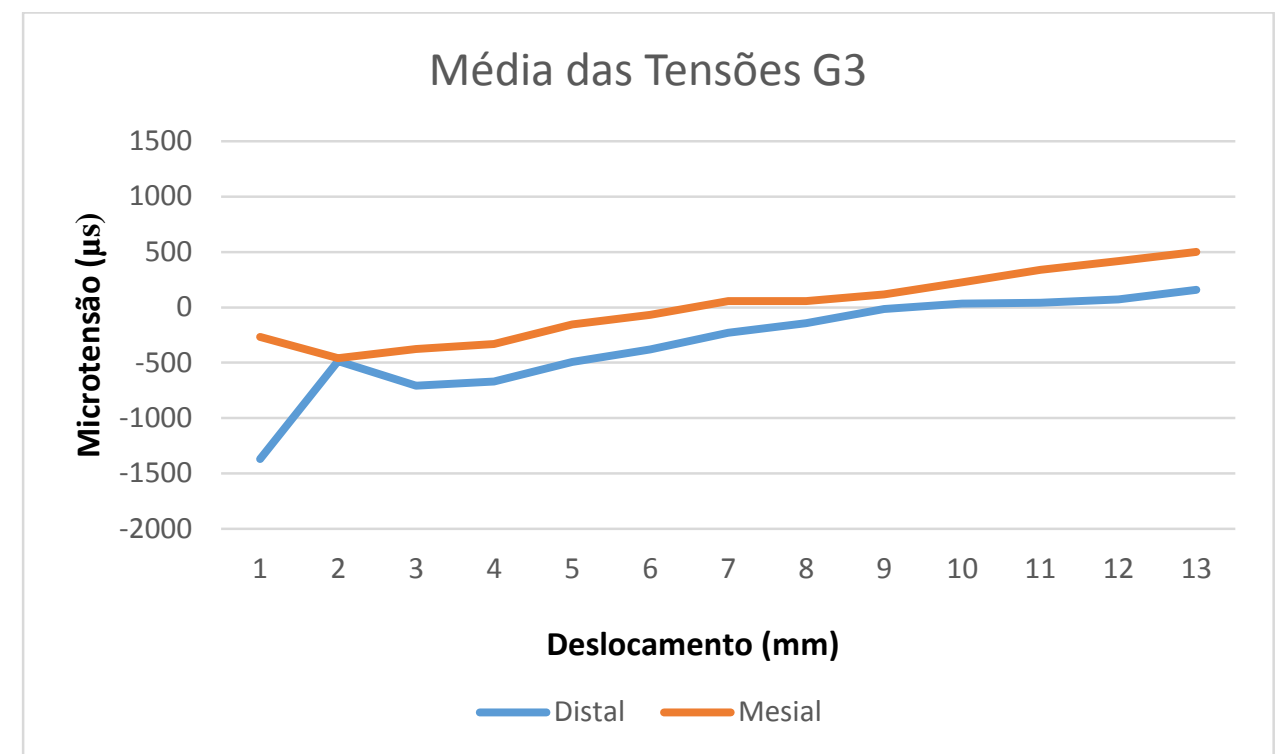

Figura 40. Tensões para o grupo G3, nas regiões distal e mesial

Para o grupo G3 (5 implantes - HE - Convencional), pode-se observar na região cervical distal e mesial forças compressivas, mudando de comportamento ao longo do gráfico, apresentando forças de tração próximas a apical principalmente na mesial, destaca-se a predominância das forças de compressão na região cervical distal.

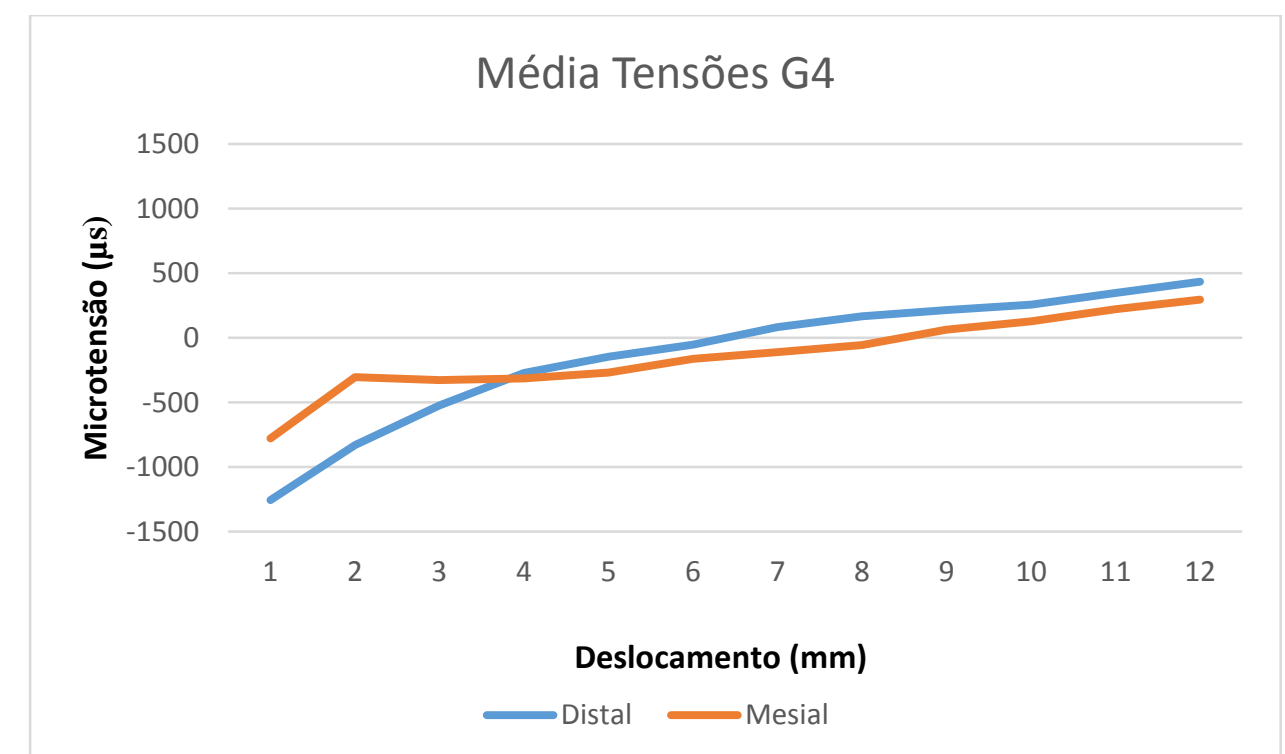

Figura 41. Tensões para o grupo G4, nas regiões distal e mesial

Para o grupo G4 (5 implantes - CM - Convencional), pode-se observar na região cervical distal e mesial forças compressivas, mudando de comportamento ao longo do gráfico, apresentando forças de tração próximas a região apical, 
De maneira geral pode-se observar comportamento semelhante para os grupos com 5 implantes, predominando as forças compressivas na região cervical.

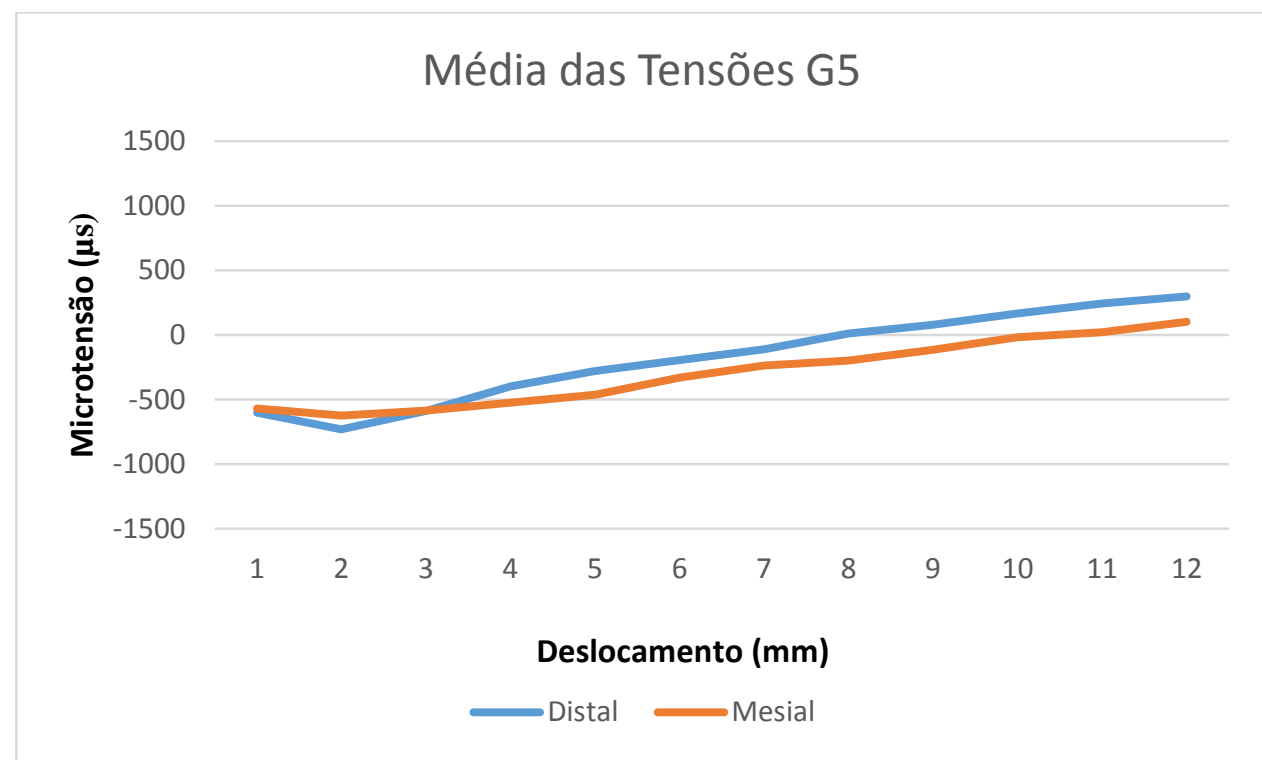

Figura 42. Gráfico das tensões para o grupo G5, nas regiões distal e mesial

Para o grupo G5 (4 implantes - HE-CAD/CAM), pode-se observar na região cervical distal e mesial forças compressivas muito semelhantes, mudando de comportamento ao longo do gráfico, apresentando forças de tração próximas a região apical.

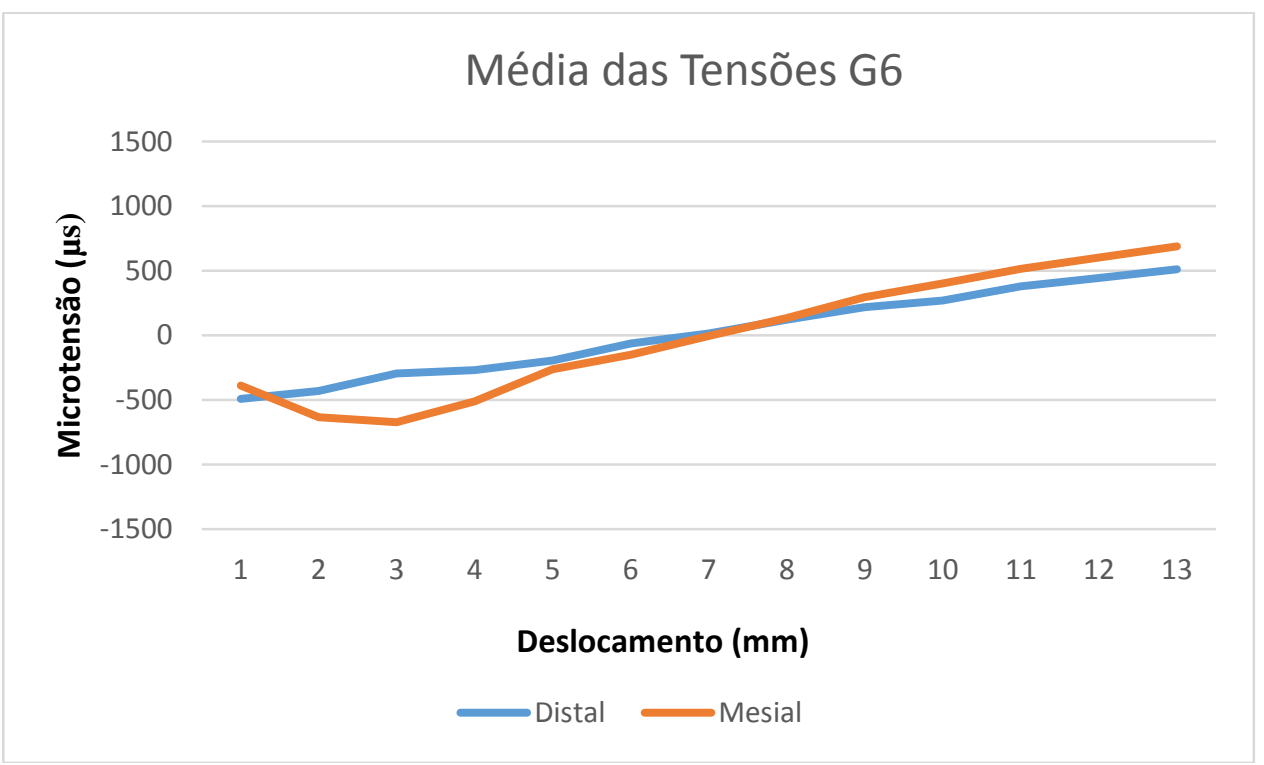

Figura 43. Tensões para o grupo G6, nas regiões distal e mesial 
Para o grupo G6 (4 implantes - CM - CAD/CAM), pode-se observar na região cervical distal e mesial forças compressivas, mudando de comportamento ao longo do gráfico, apresentando forças de tração próximas a região apical para as duas regiões.

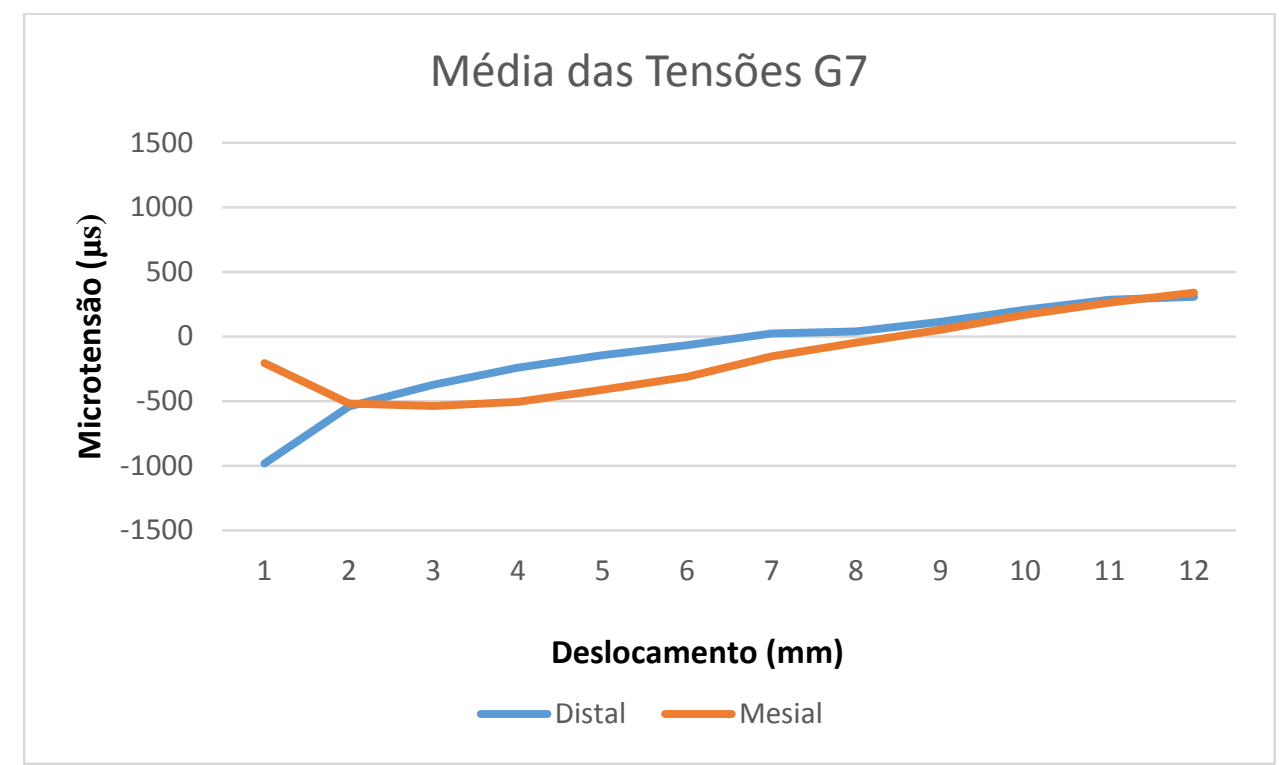

Figura 44. Tensões para o grupo G7, nas regiões distal e mesial

Para o grupo G7 (4 implantes - HE - Convencional), pode-se observar comportamento semelhante ao G6, mas as forças de tração foram de menor intensidade.

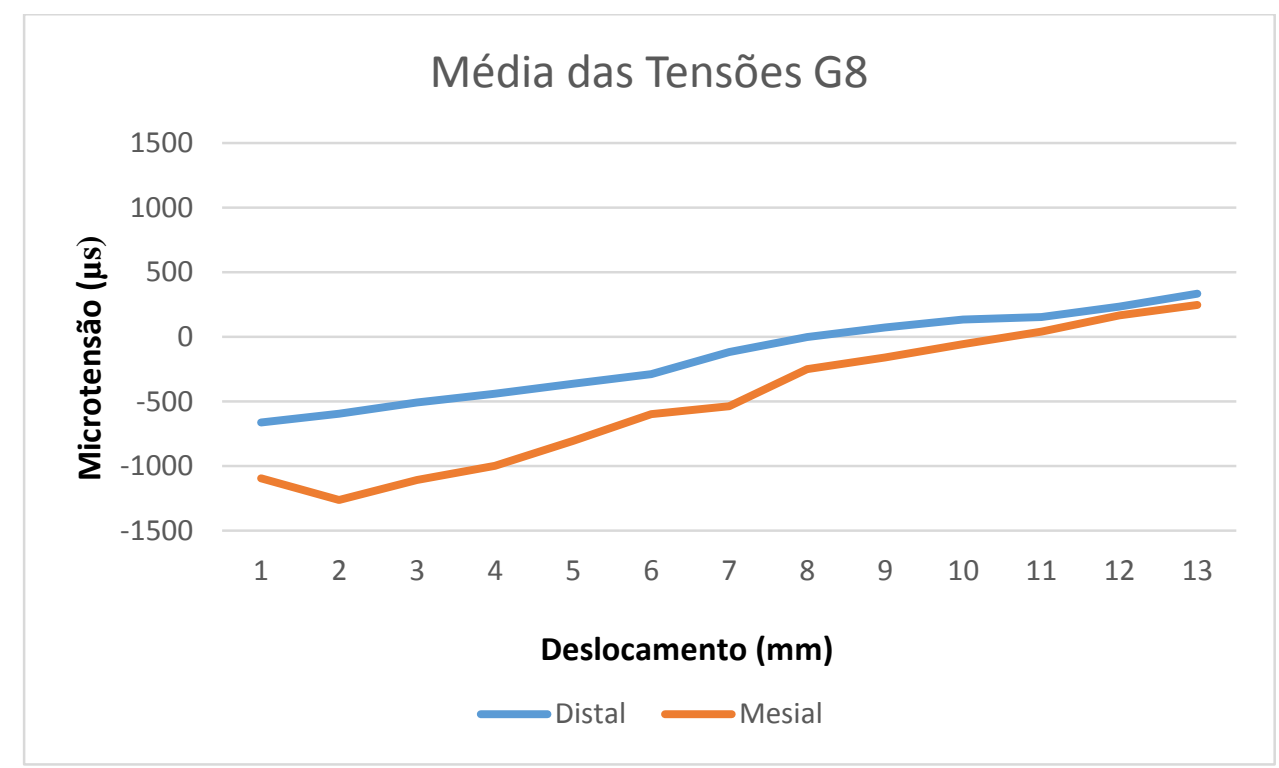

Figura 45. Tensões para o grupo G8, nas regiões distal e mesial 
Para o grupo G8 (4 implantes - CM - Convencional), pode-se observar na região cervical distal e mesial forças compressivas mais intensas que nos 3 grupos anteriores, mudando de comportamento ao longo do gráfico, apresentando uma proximidade nos valores de tensões de tração na região apical, tanto para área distal quanto para a mesial.

Os resultados obtidos foram analisados estatisticamente para cada região, sendo encontradas diferenças estatisticamente significantes para comparação entre o número de implantes para a região C1 (Tabela 5), para as demais comparações (conexão e barra) não foram encontradas diferenças significantes.

Tabela 05. Comparação das tensões horizontais $(E x x-\mu s)$ na região $\mathrm{C} 1$ com diferentes números de implantes.

\begin{tabular}{|c|c|c|c|c|}
\hline \multirow{2}{*}{$\begin{array}{c}\text { Comparação } \\
\text { ( } \mathrm{N}^{\mathrm{o}} \text { de implantes) }\end{array}$} & \multirow{2}{*}{$\begin{array}{c}\text { Diferença } \\
\text { entre as } \\
\text { médias }\end{array}$} & \multirow{2}{*}{$\mathrm{p}$-valor } & \multicolumn{2}{|c|}{ Intervalo de confiança } \\
\hline & & & Limite Inferior & Limite Superior \\
\hline $4 \times 5$ & 157,12 & 0,002 & 69,26 & 244,99 \\
\hline
\end{tabular}

Houve diferença significante na distribuição de tensões na região $\mathrm{C} 1$, entre o número de implantes, comparados isoladamente, sendo que os maiores valores de tensão foram obtidos com 4 implantes.

Foram analisadas também a interação entre os fatores número*conexão*barra para região $\mathrm{C} 1$ esta interação foi estatisticamente significante $(\mathrm{p}=0,002)$. As interações são apresentadas nas tabelas abaixo.

Tabela 06. Comparação entre número de implantes $(4$ x 5) considerando cada conexão e tipo de barra para a região $\mathrm{C} 1$.

\begin{tabular}{|c|c|c|c|c|c|}
\hline \multirow{2}{*}{ Conexão } & \multirow{2}{*}{ Barra } & \multirow{2}{*}{$\begin{array}{c}\text { Diferença } \\
\text { entre as } \\
\text { médias }\end{array}$} & \multirow{2}{*}{ p-valor } & \multicolumn{2}{|c|}{ Intervalor de confiança } \\
\hline & & & & Limite Inferior & Limite Superior \\
\hline \multirow{2}{*}{$\mathrm{CM}$} & $\mathrm{CAD} / \mathrm{CAM}$ & 339,21 & 0,001 & 163,48 & 514,94 \\
\hline & Convencional & 58,82 & 0,488 & $-116,91$ & 234,55 \\
\hline \multirow{2}{*}{$\mathrm{HE}$} & CAD/CAM & $-46,14$ & 0,585 & $-221,87$ & 129,59 \\
\hline & Convencional & 276,61 & 0,004 & 100,88 & 452,35 \\
\hline
\end{tabular}


Houve diferença significante na distribuição de tensões na região $\mathrm{C} 1$, entre 4 e 5 implantes, com conexão CM e barra CAD/CAM, assim, como entre 4 e 5 implantes, com conexão HE e barra Convencional.

Tabela 07. Comparação entre as conexões (CM X HE) considerando cada número de implantes e tipos de barra para a região $\mathrm{C} 1$.

\begin{tabular}{cccccc}
\hline $\begin{array}{c}\text { Número } \\
\text { de }\end{array}$ & Barra & $\begin{array}{c}\text { Diferença } \\
\text { entre as } \\
\text { médias }\end{array}$ & p-valor & Limite Inferior & Limite Superior \\
\hline \multirow{2}{*}{4} & CAD/CAM & 175,78 & $<0,05$ & 0,51 & 351,52 \\
& Convencional & $-73,02$ & 0,391 & $-248,75$ & 102,71 \\
\multirow{2}{*}{5} & CAD/CAM & $-209,57$ & 0,022 & $-385,30$ & $-33,83$ \\
& Convencional & 144,77 & 0,100 & $-30,96$ & 320,51 \\
\hline
\end{tabular}

Houve diferença significante na distribuição de tensões na região $\mathrm{C}$ 1, entre as conexões HE e CM, utilizando 4 implantes e barra CAD CAM, assim como utilizando 5 implantes e barra CAD/CAM.

Tabela 08. Comparação entre barras CAD/CAM e convencional, considerando número de implantes e conexões para a região $\mathrm{C} 1$.

\begin{tabular}{cccccc}
\hline $\begin{array}{c}\text { Número } \\
\text { de } \\
\text { implantes }\end{array}$ & Conexão & $\begin{array}{c}\text { Diferença } \\
\text { entre as } \\
\text { médias }\end{array}$ & p-valor & Limite Inferior & Limite Superior \\
\hline \multirow{2}{*}{4} & CM & 171,62 & $<0,05$ & $-4,12$ & 374,35 \\
& HE & $-77,19$ & 0,366 & $-252,92$ & 98,55 \\
\multirow{2}{*}{5} & CM & $-108,77$ & 0,208 & $-284,51$ & 66,96 \\
& HE & 245,57 & 0,009 & 69,83 & 421,30 \\
\hline
\end{tabular}

Houve diferença significante na distribuição de tensões na região $\mathrm{C}$, entre as barras CAD/CAM e Convencional, utilizando 5 implantes com conexão HE. 
Foram encontradas diferenças estatisticamente significantes para comparação entre o número de implantes para a região A1 (Tabela 9), para as demais comparações (conexão e barra) não foram encontradas diferenças significantes.

Tabela 09. Comparação das tensões horizontais $(E x x$ - $\mu$ s) para a região A1 com diferentes números de implantes (4 X 5).

\begin{tabular}{|c|c|c|c|c|}
\hline \multirow{2}{*}{$\begin{array}{c}\text { Comparação } \\
\mathrm{N}^{\mathrm{o}} \text { de implantes }\end{array}$} & \multirow{2}{*}{$\begin{array}{c}\text { Diferença entre as } \\
\text { médias }\end{array}$} & \multirow{2}{*}{ p- valor } & \multicolumn{2}{|c|}{ Intervalo de confiança } \\
\hline & & & Limite Inferior & Limite Superior \\
\hline $4 \times 5$ & 120,55 & 0,01 & 60,88 & 180,23 \\
\hline
\end{tabular}

Houve diferença significante na distribuição de tensões na A1, entre o número de implantes.

Foram analisadas também a interação entre os fatores número*conexão*barra para região A1 esta interação foi estatisticamente significante $(\mathrm{p}<0,05)$.

Tabela 10. Comparação entre número de implantes (4 X 5) considerando cada conexão e tipo de barra para a região A1.

\begin{tabular}{|c|c|c|c|c|c|}
\hline \multirow{2}{*}{ Conexão } & \multirow{2}{*}{ Barra } & \multirow{2}{*}{$\begin{array}{l}\text { Diferença entre } \\
\text { as médias }\end{array}$} & \multirow{2}{*}{ p-valor } & \multicolumn{2}{|c|}{ Intervalor de confiança } \\
\hline & & & & Limite Inferior & Limite Superior \\
\hline \multirow{2}{*}{$\mathrm{CM}$} & $\mathrm{CAD} / \mathrm{CAM}$ & 349,96 & $<0,05$ & 230,60 & 469,31 \\
\hline & Convencional & 114,67 & 0,59 & $-234,03$ & 4,68 \\
\hline \multirow{2}{*}{$\mathrm{HE}$} & $\mathrm{CAD} / \mathrm{CAM}$ & 65,57 & 0,261 & $-53,78$ & 184,93 \\
\hline & Convencional & 181,36 & 0,005 & 62,00 & 300,71 \\
\hline
\end{tabular}

Houve diferença significante na distribuição de tensões na região A1, entre as o número de 4 e 5 implantes, com conexão $\mathrm{CM}$ e barra CAD/CAM e conexão $\mathrm{HE}$ e barra convencional. 
Tabela 11. Comparação entre as conexões (CM X HE) considerando cada número de implantes e tipos de barra para a região A1.

\begin{tabular}{cccccc}
\hline $\begin{array}{c}\text { Número } \\
\text { de } \\
\text { implantes }\end{array}$ & Barra & $\begin{array}{c}\text { Diferença } \\
\text { entre as } \\
\text { médias }\end{array}$ & p-valor & Limite Inferior & Limite Superior \\
\hline \multirow{2}{*}{4} & CAD/CAM & 135,38 & 0,029 & 16,03 & 254,74 \\
& Convencional & 42,61 & 0,460 & $-161,97$ & 76,74 \\
& CAD/CAM & 149,00 & 0,018 & $-268,36$ & $-29,65$ \\
5 & Convencional & 253,42 & $<0,05$ & 134,06 & 372,77 \\
\hline
\end{tabular}

Houve diferença significante na distribuição de tensões na região $\mathrm{A} 1$, entre as conexões CM e HE, com 4 implantes e barra CAD/CAM, e com 5 implantes com barra CAD/CAM, e barra convencional.

Tabela 12. Comparação entre as barras $\mathrm{CAD} / \mathrm{CAM}$ e convencional, considerando número de implantes e tipo de conexão.

\begin{tabular}{cccccc}
\hline $\begin{array}{c}\text { Número de } \\
\text { implantes }\end{array}$ & Barra & $\begin{array}{c}\text { Diferença } \\
\text { entre as } \\
\text { médias }\end{array}$ & p-valor & $\begin{array}{c}\text { Intervalo de confiança } \\
\text { Limite }\end{array}$ & Limite Superior \\
\hline \multirow{2}{*}{4} & CM & 146,67 & 0,019 & 27,31 & 266,02 \\
& HE & $-31,32$ & 0,586 & $-150,68$ & 88,03 \\
\multirow{2}{*}{5} & CM & $-317,96$ & $<0,05$ & $-437,32$ & $-198,61$ \\
& HE & 84,46 & 0,153 & $-34,90$ & 203,81 \\
\hline
\end{tabular}

Houve diferença significante na distribuição de tensões na região A1, entre as barras CAD/CAM e Convencional, com 4 implantes e conexão CM, e com 5 implantes com conexão CM.

Foram encontradas diferenças estatisticamente significantes para comparação entre o número de implantes e conexão para a região C2 (Tabela 13), para a comparação entre as barras não foram encontradas diferenças significantes. 
Tabela 13. Comparação das tensões horizontais $(\operatorname{Exx}-\mu$ s) entre o número de implantes para a região C2.

\begin{tabular}{|c|c|c|c|c|}
\hline \multirow[b]{2}{*}{$\begin{array}{c}\text { Comparação } \\
\mathrm{N}^{\mathrm{o}} \text { de implantes }\end{array}$} & \multirow{2}{*}{$\begin{array}{c}\text { Diferença } \\
\text { entre as } \\
\text { médias }\end{array}$} & \multirow[b]{2}{*}{ p- valor } & \multicolumn{2}{|c|}{ Intervalo de confiança } \\
\hline & & & $\begin{array}{l}\text { Limite } \\
\text { Inferior }\end{array}$ & $\begin{array}{l}\text { Limite } \\
\text { Superior }\end{array}$ \\
\hline $4 \times 5$ & 141,18 & 0,001 & $-210,07$ & $-72,30$ \\
\hline
\end{tabular}

Houve diferença significante na distribuição de tensões na região C2, entre o número de implantes.

Tabela 14. Comparação das tensões horizontais (Exx - $\mu$ s) entre as conexões para a região C2.

\begin{tabular}{ccccc}
\hline \multirow{2}{*}{ Comparação } & $\begin{array}{c}\text { Diferença entre } \\
\text { as médias }\end{array}$ & p- valor & $\begin{array}{l}\text { Intervalo de confiança } \\
\text { Limite } \\
\text { Inferior }\end{array}$ & $\begin{array}{c}\text { Limite } \\
\text { Superior }\end{array}$ \\
\hline CM X HE & 242,89 & $<0,05$ & $-311,78$ & $-174,00$ \\
\hline
\end{tabular}

Houve diferença significante na distribuição de tensões na região C2, entre o tipo de conexão dos implantes

Foi analisada também a interação entre os fatores número*conexão*barra para região $\mathrm{C} 2$ esta interação foi estatisticamente significante $(\mathrm{p}<0,05)$.

Tabela 15. Comparação entre número de implantes (4 X 5) considerando cada conexão e tipo de barra para a região $\mathrm{C} 2$.

\begin{tabular}{cccccc}
\hline \multirow{2}{*}{ Conexão } & Barra & $\begin{array}{c}\text { Diferença } \\
\text { entre as } \\
\text { médias }\end{array}$ & p-valor & \multicolumn{2}{c}{ Intervalor de confiança } \\
& CAD/CAM & $346,78^{*}$ & $<0,05$ & 209,00 & 484,55 \\
CM & Convencional & $-587,76$ & $<0,05$ & $-725,53$ & $-449,98$ \\
& CAD/CAM & $-170,22$ & 0,019 & $-308,00$ & $-32,45$ \\
\multirow{2}{*}{$\mathrm{HE}$} & Convencional & $-153,53$ & 0,031 & $-291,31$ & $-15,76$ \\
\hline
\end{tabular}


Houve diferença significante na distribuição de tensões na região $C 2$, entre 4 e 5 implantes, com ambas as conexões, $\mathrm{HE}$ e CM, e ambas as barras, CAD/CAM e Convencional.

Tabela 16. Comparação entre as conexões (CM X HE) considerando cada número de implantes e tipos de barra para a região $\mathrm{C} 2$.

\begin{tabular}{|c|c|c|c|c|c|}
\hline \multirow{2}{*}{$\begin{array}{c}\text { Número } \\
\text { de } \\
\text { implantes }\end{array}$} & \multicolumn{3}{|c|}{ Diferença } & \multicolumn{2}{|c|}{ Intervalor de confiança } \\
\hline & Barra & $\begin{array}{l}\text { entre as } \\
\text { médias }\end{array}$ & $\mathrm{p}$-valor & Limite Inferior & Limite Superior \\
\hline \multirow{2}{*}{4} & CAD/CAM & 93,48 & 0,170 & $-44,29$ & 231,25 \\
\hline & Convencional & 537,87 & $<0,05$ & $-675,65$ & $-400,10$ \\
\hline \multirow{2}{*}{5} & CAD/CAM & 423,52 & $<0,05$ & $-561,29$ & $-285,75$ \\
\hline & Convencional & 103,65 & 0,130 & $-241,42$ & 34,12 \\
\hline
\end{tabular}

Houve diferença significante na distribuição de tensões na região $C 2$, para as conexões CM e HE, com 4 implantes e barra Convencional, e 5 implantes com barra CAD/CAM.

Tabela 17. Comparação entre as barras (CAD/CAM X Convencional), considerando cada número de implantes e tipo de conexão para a região $\mathrm{C} 2$.

\begin{tabular}{|c|c|c|c|c|c|}
\hline \multirow{2}{*}{$\begin{array}{l}\text { Número de } \\
\text { Implantes }\end{array}$} & \multirow{2}{*}{ Barra } & \multirow{2}{*}{$\begin{array}{c}\text { Diferença } \\
\text { entre as } \\
\text { médias }\end{array}$} & \multirow{2}{*}{ p-valor } & \multicolumn{2}{|c|}{ Intervalor de confiança } \\
\hline & & & & Limite Inferior & Limite Superior \\
\hline \multirow{2}{*}{4} & $\mathrm{CM}$ & 532,29 & $<0,05$ & 394,51 & 670,06 \\
\hline & $\mathrm{HE}$ & 99,07 & 0,147 & $-236,84$ & 38,71 \\
\hline \multirow{2}{*}{5} & $\mathrm{CM}$ & $-402,245$ & $<0,05$ & $-540,02$ & $-264,47$ \\
\hline & $\mathrm{HE}$ & $-82,38$ & 0,223 & $-220,15$ & 55,40 \\
\hline
\end{tabular}

Houve diferença significante na distribuição de tensões na região C2, entre as barras CAD/CAM e Convencional, com 4 implantes e conexão CM, e 5 implantes com conexão CM.

Foram encontradas diferenças estatisticamente significantes para comparação entre o número de implantes e tipo de barra para a região A2 (Tabelas 18 e 19), para a comparação entre as conexões não foram encontradas diferenças significantes. 
Tabela 18. Comparação das tensões horizontais $(\operatorname{Exx}-\mu$ s) entre o número de implantes para a região A2.

\begin{tabular}{ccccc}
\hline Comparação & $\begin{array}{c}\text { Diferença } \\
\text { entre as } \\
\text { médias }\end{array}$ & p- valor & Limite Inferior & Limite Superior \\
\hline 4 X 5 & 99,97 & 0,004 & 38,02 & 161,92 \\
\hline
\end{tabular}

Houve diferença significante na distribuição de tensões na região A2, entre 4 e 5 implantes.

Tabela 19. Comparação das tensões horizontais (Exx - $\mu$ s) entre os tipos de barra para a região A2.

\begin{tabular}{ccccc}
\hline Comparação & $\begin{array}{c}\text { Diferença } \\
\text { entre as } \\
\text { médias }\end{array}$ & p- valor & \multicolumn{2}{c}{ Intervalo de confiança } \\
& 100,75 & 0,003 & $-162,70$ & Limite Inferior \\
\hline $\begin{array}{l}\text { CAD/CAM X } \\
\text { Convencional }\end{array}$ & 100 Superior \\
\hline
\end{tabular}

Houve diferença significante na distribuição de tensões na região A2, entre os tipos de barras.

Foram analisadas também a interação entre os fatores número*conexão*barra para região A2 esta interação foi estatisticamente significante $(\mathrm{p}<0,001)$.

Tabela 20. Comparação entre número de implantes (4 X 5) considerando cada conexão e tipo de barra para a região $\mathrm{A} 2$.

\begin{tabular}{|c|c|c|c|c|c|}
\hline \multirow{2}{*}{$\begin{array}{c}\mathrm{N}^{\mathrm{o}} \mathrm{de} \\
\text { Implantes }\end{array}$} & \multirow{2}{*}{ Conexão } & \multirow{2}{*}{$\begin{array}{c}\text { Diferença } \\
\text { entre as } \\
\text { médias }\end{array}$} & \multirow{2}{*}{$\mathrm{p}$-valor } & \multicolumn{2}{|c|}{ Intervalor de confiança } \\
\hline & & & & Limite Inferior & Limite Superior \\
\hline \multirow{2}{*}{4} & $\mathrm{CM}$ & 419,94 & $<0,05$ & 296,05 & 543,84 \\
\hline & $\mathrm{HE}$ & $-183,28$ & 0,006 & $-307,18$ & $-59,38$ \\
\hline \multirow{2}{*}{5} & $\mathrm{CM}$ & $-262,09$ & $<0,05$ & $-385,98$ & $-138,19$ \\
\hline & $\mathrm{HE}$ & $-377,57$ & $<0,05$ & $-501,46$ & $-253,67$ \\
\hline
\end{tabular}


Houve diferença significante na distribuição de tensões na região A2, entre 4 e 5 implantes, com conexão CM e barra CAD/CAM.

Tabela 21. Comparação entre as conexões (CM X HE) considerando cada número de implantes e tipos de barra para a região A2.

\begin{tabular}{ccccccc}
\hline \multirow{2}{*}{ Conexão } & Barra & $\begin{array}{c}\text { Diferença } \\
\text { entre as } \\
\text { médias }\end{array}$ & p-valor & \multicolumn{2}{c}{ Intervalor de confiança } \\
& CAD/CAM & 559,28 & $<0,05$ & 435,38 & Limite Inferior & Limite Superior \\
\hline \multirow{2}{*}{ CM } & Convencional & $-122,75$ & 0,052 & $-246,65$ & 1,15 \\
& CAD/CAM & 78,81 & 0,196 & $-45,08$ & 202,71 \\
\multirow{2}{*}{$\mathrm{HE}$} & Convencional & $-115,47$ & 0,066 & $-239,37$ & 8,43 \\
\hline
\end{tabular}

Houve diferença significante na distribuição de tensões na região A2, entre os tipos de conexão, com 4 implantes e barra CAD/CAM e com barra Convencional, e 5 implantes, com barra convencional.

Tabela 22. Comparação entre as barras (CAD/CAM X Convencional), considerando cada número de implantes e tipo de conexão para a região A2.

\begin{tabular}{|c|c|c|c|c|c|}
\hline \multirow{2}{*}{$\begin{array}{c}\text { Comparação } \\
\left(\mathrm{N}^{\mathrm{o}} \text { de }\right. \\
\text { Implantes })\end{array}$} & \multirow{2}{*}{ Barra } & \multirow{2}{*}{$\begin{array}{c}\text { Diferença } \\
\text { entre as } \\
\text { médias }\end{array}$} & \multirow{2}{*}{$\begin{array}{c}\text { p- } \\
\text { valor }\end{array}$} & \multicolumn{2}{|c|}{ Intervalor de confiança } \\
\hline & & & & Limite Inferior & Limite Superior \\
\hline \multirow{2}{*}{4} & $\mathrm{CAD} / \mathrm{CAM}$ & 434,78 & $<0,05$ & 310,88 & 558,68 \\
\hline & Convencional & $-168,44$ & 0,011 & $-292,34$ & $-44,54$ \\
\hline \multirow{2}{*}{5} & CAD/CAM & 45,69 & 0,446 & $-169,59$ & 78,21 \\
\hline & Convencional & $-161,17$ & 0,014 & $-285,07$ & $-37,27$ \\
\hline
\end{tabular}

Houve diferença significante na distribuição de tensões na região A2, entre os tipos de barra, com 4 implantes e conexão CM e HE, e para 5 implantes com conexão CM e HE. 

DISCUSSÃO 

As próteses totais implantossuportadas, mais conhecidas como próteses protocolo, têm conquistado cada dia mais seu espaço no tratamento reabilitador de pacientes edêntulos totais, pois se trata de uma forma de tratamento que atende os quesitos funcionais e estéticos. $O$ grande desafio proposto por essa opção de tratamento está na configuração ideal, que ainda é muito discutida tanto pela parte clínica quanto científica. A melhor maneira de minimizar a concentração de tensões ao longo dos implantes e dos tecidos adjacentes ainda é o foco principal das pesquisas.

Desde o início da utilização das próteses totais mandibulares implantossuportadas, preconizadas nos primeiros estudos de Branemark (Branemark et al., 1969; Branemark et al., 1977, Adell et al., 1981), nos quais foi proposto um protocolo reabilitador contendo de cinco a seis implantes instalados na região interforaminal, suportando uma prótese total fixa com extensões distais em cantiléver (Branemark, 1985; Naini, 2011), proporcionando aos pacientes edêntulos maior comodidade e estabilidade se comparado às próteses totais mandibulares convencionais, muito se tem pesquisado sobre qual a melhor configuração para o sucesso em longo prazo desse tipo de tratamento. Atualmente tem sido preconizado a diminuição do número dos implantes, fato esse que vem sendo difundido na implantodontia atual. Em 2003, Maló, preconizou a técnica “All-on-four”, que consiste na instalação de 4 implantes na região interforaminal, 2 anteriores posicionados axialmente, e 2 distais instalados com inclinação de $30^{\circ}$, minimizando o tamanho do cantiléver (Maló, 2005; Patzelt et al., 2014). Apesar dessas duas configurações de tratamento estarem bem sedimentadas na literatura, é necessária uma investigação mais apurada a respeito do comportamento biomecânico. Esse é o fator determinante no resultado final e sucesso em longo prazo do tratamento com próteses totais mandibulares implantossuportadas.

Um dos objetivos deste trabalho foi verificar a influência do número de implantes na concentração de tensões. Pelos resultados obtidos observou-se maior concentração de tensões nos grupos de 4 implantes quando comparados com os grupos de 5 implantes. Essa concentração de tensões esteve presente nas 4 regiões de interesse do estudo, especialmente nas regiões apicais dos modelos, onde podemos observar, nas imagens da análise por correlação digital, zonas com cores quentes, indicando a ocorrência de tensões de tração. Isto também é visto no estudo de Ogawa (2010), no qual foram utilizados extensômetros ligados aos pilares dos implantes, com carga de $50 \mathrm{~N}$ na região próxima aos medidores, porém os implantes foram posicionados de forma reta e não angulada, mostrando, também, que na medida em que se aumenta o número de implantes, menor é a concentração de tensão nos mesmos. Em estudo in vivo anterior realizado por Duyck (2000), o comportamento se repete, utilizando extensômetros 
ligados aos pilares, com cargas de 50N, também foi constatada diminuição na concentração de tensões com o aumento do número de implantes. Já o estudo de Fazi et al. (2011) demonstrou que os implantes inclinados distalmente em $34^{\circ}$ resultaram em redução favorável de tensões ao osso, implante e infraestrutura, porém foi utilizada a metodologia de elementos finitos com várias simplificações no desenho de implante, pilar e parafusos, e a estrutura protética tinha somente o componente metálico, sem abertura para os parafusos e rigidamente conectada aos implantes assumindo perfeita passividade, o que de certa forma pode explicar a diferença de resultados. No estudo de Francetti et al. (2015) não foram encontradas diferenças no padrão de distribuição de tensão em próteses com 5 implantes ou "All-on-4".

Outro fator importante a se ressaltar na concentração de tensões é o tamanho do cantiléver das próteses. Vários estudos como os de Rangert et al. (1989); Jemt, (1991); Naert et al. (1992); Van Zyl et al. (1995); Sertgoz \& Guvener, (1996); Jacques et al. (2009), têm mostrado que a taxa de sobrevivência desses tratamentos é maior, em próteses com cantiléver de $15 \mathrm{~mm}$ ou menos, mas isso não é um fator que deve ser levado em conta separadamente, e o número de implantes e sua distribuição no osso alveolar também são fatores a serem considerados. Seguindo essa linha de raciocínio, nesse trabalho, nos grupos com configuração de 5 implantes as próteses tiveram cantiléver de $15 \mathrm{~mm}$, e para o grupo de 4 implantes as próteses tiveram o cantiléver de $12 \mathrm{~mm}$, ficando dentro do tamanho considerado adequado por Jacques et al. (2009). O fato do grupo de 4 implantes proporcionar aumento da concentração de tensão, apesar de ter menor cantiléver, pode ser devido ao fato de apresentar, na sua configuração, implantes inclinados em $30^{\circ}$. A maior concentração de tensão aconteceu na região A2, onde houve a maior concentração de tensões de tração. As regiões de compressão citadas durante esse trabalho, são localizadas nas áreas cervicais do modelo, representadas por cores frias, onde se constatou uniformidade nos grupos estudados independentemente do número de implantes, o que pode ser visualizado nas imagens capturadas pelo software de correlação de imagens digitais.

Neste estudo foram analisadas as áreas diretamente relacionadas ao implante distal. Vários artigos na literatura (Rubo e Souza, 2008; Suedam, 2009, Jacques et al., 2009) apontam que em próteses com cantilever, os implantes mais distais representam o fulcro e, portanto, estão sujeitos a cargas. Migliorança (2008) demonstrou em estudo que a maior parte da força aplicada nas extensões distais das próteses protocolo é absorvida pelo implante mais posterior, independentemente do número de implantes utilizado. Todos estes fatores justificam a escolha do implante mais posterior para as análises. 
Outro fator importante para a distribuição de tensões, é o tipo de plataforma dos implantes. Para esse estudo foi utilizada a plataforma hexágono externo, que atualmente ainda é o tipo de conexão mais usada para esse tipo de tratamento. Entretanto, muitos estudos têm sido realizados e mostram que o hexágono externo apresenta pouca eficácia quando submetido a cargas fora de seu longo eixo (Weinberg, 1993), e devido a esse inconveniente, muitos autores têm contraindicado o hexágono externo frente a sobrecargas (Merz et al., 2000; Maeda et al., 2006). Também foi utilizada nesse estudo a conexão cone Morse, conexão que vem sendo proposta e muito utilizada para minimizar as perdas ósseas na região cervical. A literatura ainda é escassa a respeito de prótese totais implantossuportadas utilizando conexões internas. Pôde ser observado nesse trabalho, que não houveram grandes diferenças em relação à concentração de tensões quando comparados os tipos de conexão, sendo que a única região de interesse que apresentou diferença significativa foi a região $\mathrm{C} 2$, com maior concentração de tensões para a conexão cone Morse. Este fato também pode ser visto no estudo Goiato et al. (2013), que compararam conexões internas e externas através do método de fotoelasticidade. Em testes de próteses unitárias e fixas de 3 elementos os autores mostraram que as próteses unitárias com conexão cone Morse distribuem melhor as tensões em comparação à conexão hexágono externo, mas quando testadas as próteses fixas unidas, o comportamento é antagônico, com a conexão hexágono externo apresentando melhor transmissão das tensões em comparação à conexão cone Morse. Segundo os autores, quando implantes cone Morse são esplintados existe aumento de tensão devido à inclinação dos implante, pois clinicamente é muito difícil obter o absoluto paralelismo dos implantes.

Atualmente a confecção da maioria das barras que compõem as próteses totais mandibulares implantossuportadas ainda ocorre através do método convencional de fundição, sendo a liga de Co-Cr, a liga padrão de escolha (Hulterström \& Nilsson, 1994; Goodacre, 1999). O método de fundição convencional está muito bem sedimentado, mas apresenta inconvenientes próprios inerentes à técnica, o que pode proporcionar desajuste ou assentamento inadequado da prótese (Jemt et al., 1995; Cariello, 2009). Em busca de melhor adaptação protética, foi incorporado à odontologia o uso do CAD/CAM (Beuer, 2008; Harder, 2009), sendo que esse processo computadorizado reduz os passos para a confecção de barras, diminuindo assim as chances de distorção do material, proporcionada pela fundição convencional (Carr et al., 1996; Kapos et al., 2009; Ichi, 2010).

Nesse estudo foram comparadas barras confeccionadas pelo método convencional e pelo sistema CAD/CAM, e através das imagens obtidas pôde ser observada maior concentração de tensão de tração nos grupos que apresentam 5 implantes que utilizaram barra confeccionada 
pelo método convencional. Esse aumento de tensão é justificável pelo processo crítico de fundição, principalmente nas barras de 5 implantes que têm maior extensão e maior número de implantes, sendo, portanto, mais crítica a adaptação passiva da barra sobre todos os pilares, mesmo após o procedimento de soldagem. Cariello (2009) ressaltou que a confecção de próteses extensas é passível de maior distorção. Alguns trabalhos (Paniz et al., 2013; Alfadda, 2014) apontam que as estruturas fresadas pelo sistema CAD/CAM apresentam melhor adaptação marginal e passividade quando comparadas a barras obtidas por fundição convencional, fato este que resultaria em melhor distribuição de tensão. Através das imagens obtidas neste estudo foi possível verificar que para o grupo com 4 implantes a transmissão de tensões entre as barras convencional e CAD/CAM foi semelhante. Sendo assim, a obtenção de barras pelo sistema CAD/CAM é vantajosa por proporcionar melhor adaptação e boa distribuição de tensão, porém o custo elevado ainda limita a popularização do seu uso. Há que considerar, no entanto, todo o rigor técnico mantido em cada fase da obtenção das barras convencionais deste trabalho, o que nem sempre é observado na rotina de laboratórios protéticos comerciais.

Muitos trabalhos publicados anteriormente, como o trabalho de Frost (2003), sugerem que tensões entre 200 e $400 \mu$ s tendem a não causar danos na densidade óssea, assim como valores entre 4000 e $25.000 \mu$ s, podem causar danos microscópicos à estrutura óssea. Em 1992, o mesmo autor sugeriu que valores acima de $4.000 \mu$ s indicam sobrecarga à estrutura óssea, gerando, assim, um processo patológico. Outro trabalho realizado por Duyck, em 2001, utilizando método de elementos finitos, sugeriu que o valor limite para o início da indução de reabsorção óssea é de 4.200 s, não diferenciando do estudo anterior de Frost, em 1992. Em 2001, o trabalho publicado por Melsen \& Land, de um estudo feito em macacos, mostrou que os limites de tensão para que ocorra a reabsorção óssea estavam entre 3.400 e $6.600 \mu \mathrm{s}$, limites consideravelmente mais altos em relação a outros estudos na mesma linha de pesquisa. As informações citadas pelos estudos anteriores podem ser comparadas a esse estudo, no qual foi observado que as tensões nas quatro regiões de interesse não apresentaram valores que representem risco de início de processos de reabsorção óssea. Nas áreas de maior concentração de tensão de tração, regiões A1 e A2, o maior valor médio registrado no estudo foi de 409,24 $\mu$ s para a região $\mathrm{A} 2$, e as tensões de compressão localizadas na região $\mathrm{C} 1$ e $\mathrm{C} 2$, tiveram registro de tensão máxima de $-938,67 \mu$ s para a região $C 2$.

Os resultados do presente estudo trazem implicações clínicas importantes e sugerem que a partir das configurações propostas, quanto ao número de implantes, pode-se sugerir como melhor opção a configuração de 5 implantes, pois esta apresenta melhor transmissão das tensões, porém os valores de tensão encontrados para as próteses confeccionadas com 4 
implantes também estão dentro dos limites de tensão considerados adequados, podendo ser utilizadas clinicamente com segurança, e que, segundo Mericske-Stern (2000) e Attard et al. (2005) seriam vantajosas, pois o uso de menor número de implantes, em posições estratégicas, pode proporcionar distribuição favorável de forças associada ao menor custo total do tratamento. A determinação do número ideal de implantes para suportar uma prótese total implantossuportada deve ser baseada numa análise biomecânica de vários fatores, como: os locais dos implantes na mandíbula; a qualidade e quantidade de osso no qual eles serão colocados; as cargas que se desenvolverão sobre os implantes, entre outros. Em geral, a determinação do número ótimo de implantes para utilização em um paciente deve responder a uma questão biomecânica inerente a cada situação clínica individual (Brunski, 2014). Quanto ao tipo de conexão, não houveram diferenças significativas em relação à distribuição de tensões, e quanto ao método de confecção das barras, a que melhor apresentou comportamento biomecânico foram as barras confeccionadas pelo sistema CAD/CAM.

Neste estudo, as comparações têm relevância porque os modelos utilizados são iguais, representando uma mesma condição "clínica" de mandíbula a ser reabilitada, e as variações se deram quanto ao tipo de implante (CM ou HE), número de implantes (4 ou 5) e método de obtenção da barra protética (convencional ou CAD/CAM). Depois, cada situação recebeu o mesmo padrão de aplicação de força: $250 \mathrm{~N}$ na fossa central do molar em cantiléver. Essa força, aplicada de forma pontual, simulando um contato prematuro na região, exacerba as tensões encontradas. Assim, pode-se sugerir que em uma oclusão corretamente balanceada, certamente as tensões de compressão e tração serão menores. Com essas considerações, em condições normais, desde que todas as configurações analisadas apresentaram valores de tensão dentro dos limites considerados favoráveis à manutenção óssea, todas podem ser indicadas clinicamente com segurança. A decisão final do clínico será tomada levando em conta aqueles fatores que não puderam ser representados neste trabalho, dadas as limitações normais de um trabalho in vitro.

Outros trabalhos, simulando condições diferentes daquelas reproduzidas neste estudo, devem ser realizados para completar o entendimento da biomecânica das próteses protocolo e suas variações, colaborando para a tomada de decisão do clínico seja mais segura e proporcione maior e melhor longevidade aos tratamentos realizados, aumentando o sucesso obtido e os índices de satisfação de pacientes e profissionais, objetivo final de todos nós. 

CONClUSÃo 

Dentro das limitações da metodologia aplicada no presente estudo e com base nos resultados obtidos, pode-se concluir que:

1. Houve diferença significante na distribuição de tensões entre as próteses obtidas com 4 e 5 implantes para todas as regiões analisadas;

2. Não houve diferença significativa na concentração de tensões entre as conexões HE e CM, exceto para a região $\mathrm{C} 2$, onde a conexão $\mathrm{CM}$ apresentou maiores valores de tensão;

3. Houve diferença estatisticamente significante entre as barras convencional e $\mathrm{CAD} / \mathrm{CAM}$ na região A2. As barras convencionais apresentaram maior concentração de tensões de tração nas próteses com 5 implantes. 

REFERÊNCIAS 

Adell R, Lekholm U, Rockler B, Branemark PI. A 15-year study of osseointegrated implants in the treatment of the edentulous jaw. International journal of oral surgery. $1981 \mathrm{Dec} ; 10(6)$ :387416.

Akca K, Cehreli MC, Iplikcioglu H. A comparison of three-dimensional finite element stress analysis with in vitro strain gauge measurements on dental implants. The International journal of prosthodontics. 2002 Mar-Apr;15(2):115-21.

Albrektsson T, Zarb G, Worthington P, Eriksson AR. The long-term efficacy of currently used dental implants: a review and proposed criteria of success. The International journal of oral \& maxillofacial implants. 1986 Summer;1(1):11-25.

Alfadda SA. Vertical marginal gap evaluation of conventional cast and computer numeric controlled-milled titanium full-arch implant-supported frameworks. The International journal of prosthodontics. 2014 Nov-Dec; 27(6):517-22.

Asvanund P. A strain gauge analysis comparing external and internal implant-abutment connections. Implant dentistry. 2014 Apr;23(2):206-11.

Attard NJ, Zarb GA, Laporte A. Long-term treatment costs associated with implant-supported mandibular prostheses in edentulous patients. The International journal of prosthodontics. 2005 Mar-Apr;18(2):117-23.

Attard NJ, Zarb GA. Long-term treatment outcomes in edentulous patients with implant-fixed prostheses: the Toronto study. The International journal of prosthodontics. 2004 JulAug;17(4):417-24.

Babbush CA. ITI endosteal hollow cylinder implant systems. Dental clinics of North America. 1986 Jan;30(1):133-49.

Becker W, Becker BE. Replacement of maxillary and mandibular molars with single endosseous implant restorations: a retrospective study. The Journal of prosthetic dentistry. 1995 Jul;74(1):51-5. 
Beuer F, Schweiger J, Edelhoff D. Digital dentistry: an overview of recent developments for CAD/CAM generated restorations. British dental journal. 2008 May 10;204(9):505-11.

Bonnet AS, Postaire M, Lipinski P. Biomechanical study of mandible bone supporting a fourimplant retained bridge: finite element analysis of the influence of bone anisotropy and foodstuff position. Medical engineering \& physics. 2009 Sep;31(7):806-15.

Branemark PI, Adell R, Albrektsson T, Lekholm U, Lundkvist S, Rockler B. Osseointegrated titanium fixtures in the treatment of edentulousness. Biomaterials. 1983 Jan;4(1):25-8.

Branemark PI, Adell R, Breine U, Hansson BO, Lindstrom J, Ohlsson A. Intra-osseous anchorage of dental prostheses. I. Experimental studies. Scandinavian journal of plastic and reconstructive surgery. 1969;3(2):81-100.

Branemark PI, Engstrand P, Ohrnell LO, Grondahl K, Nilsson P, Hagberg K, et al. Branemark Novum: a new treatment concept for rehabilitation of the edentulous mandible. Preliminary results from a prospective clinical follow-up study. Clinical implant dentistry and related research. 1999;1(1):2-16.

Branemark PI, Hansson BO, Adell R, Breine U, Lindstrom J, Hallen O, et al. Osseointegrated implants in the treatment of the edentulous jaw. Experience from a 10-year period. Scandinavian journal of plastic and reconstructive surgery Supplementum. 1977; 16:1-132.

Brånemark P-I, Zarb GA, Albrektsson T. Tissue-integrated prostheses: osseointegration in clinical dentistry: Quintessence; 1985.

Branemark PI. Osseointegration and its experimental background. The Journal of prosthetic dentistry. 1983 Sep;50(3):399-410.

Brunski JB. Biomechanical aspects of the optimal number of implants to carry a crossarch full restoration. Eur J Oral Implantol. 2014 Summer;7 Suppl 2:S111-31

Brunski JB. Biomechanical factors affecting the bone-dental implant interface. Clinical materials. 1992;10(3):153-201. 
Brunski JB. In vivo bone response to biomechanical loading at the bone/dental-implant interface. Advances in dental research. 1999 Jun;13:99-119.

Cariello MP. Analise fotoelastica e extensometrica das tensoes induzidas por estruturas de protese sobre implantes fabricadas pelas tecnicas monobloco, soldagem de borda e metodo CAD/CAM. Piracicaba: Faculdade de Odontologia de Piracicaba, Universidade Estadual de Campinas, 2009.

Carr AB, Gerard DA, Larsen PE. The response of bone in primates around unloaded dental implants supporting prostheses with different levels of fit. The Journal of prosthetic dentistry. 1996 Nov;76(5):500-9.

Cehreli MC, Akca K, Iplikcioglu H, Sahin S. Dynamic fatigue resistance of implant-abutment junction in an internally notched morse-taper oral implant: influence of abutment design. Clinical oral implants research. 2004 Aug;15(4):459-65.

Chun HJ, Shin HS, Han CH, Lee SH. Influence of implant abutment type on stress distribution in bone under various loading conditions using finite element analysis. The International journal of oral \& maxillofacial implants. 2006 Mar-Apr;21(2):195-202.

Coelho Goiato M, Pesqueira AA, Falcon-Antenucci RM, Dos Santos DM, Haddad MF, Bannwart LC, et al. Stress distribution in implant-supported prosthesis with external and internal implant-abutment connections. Acta odontologica Scandinavica. 2013 Mar;71(2):2838.

Duyck J, Ronold HJ, Van Oosterwyck H, Naert I, Vander Sloten J, Ellingsen JE. The influence of static and dynamic loading on marginal bone reactions around osseointegrated implants: an animal experimental study. Clinical oral implants research. 2001 Jun;12(3):207-18.

Duyck J, Van Oosterwyck H, Vander Sloten J, De Cooman M, Puers R, Naert I. Magnitude and distribution of occlusal forces on oral implants supporting fixed prostheses: an in vivo study. Clinical oral implants research. 2000 Oct;11(5):465-75.

Ekelund JA, Lindquist LW, Carlsson GE, Jemt T. Implant treatment in the edentulous mandible: a prospective study on Branemark system implants over more than 20 years. The International journal of prosthodontics. 2003 Nov-Dec;16(6):602-8. 
Fazi G, Tellini S, Vangi D, Branchi R. Three-dimensional finite element analysis of different implant configurations for a mandibular fixed prosthesis. The International journal of oral \& maxillofacial implants. 2011 Jul-Aug;26(4):752-9.

Fernandes CP, Glantz PO, Svensson SA, Bergmark A. Reflection photoelasticity: a new method for studies of clinical mechanics in prosthetic dentistry. Dental materials : official publication of the Academy of Dental Materials. 2003 Mar;19(2):106-17.

Ford TG. The heat-activated solderless passivation (HASP) technique for correcting nonpassive-fitting bars without soldering. Implant dentistry. 2003;12(1):11-7.

Francetti L, Cavalli N, Villa T, La Barbera L, Taschieri S, Corbella S, Del Fabbro M. Biomechanical in vitro evaluation of two full-arch rehabilitations supported by four or five implants The International journal of oral \& maxillofacial implants. 2015 Mar-Apr;30(2):41926.

Friberg B, Jemt T. Rehabilitation of edentulous mandibles by means of osseointegrated implants: a 5-year follow-up study on one or two-stage surgery, number of implants, implant surfaces, and age at surgery. Clinical implant dentistry and related research. 2015 Jun;17(3):413-24.

Frost HM. Bone's mechanostat: a 2003 update. The anatomical record Part A, Discoveries in molecular, cellular, and evolutionary biology. 2003 Dec;275(2):1081-101.

Frost HM. Perspectives: bone's mechanical usage windows. Bone and mineral. 1992 Dec;19(3):257-71.

Goodacre CJ, Kan JY, Rungcharassaeng K. Clinical complications of osseointegrated implants. The Journal of prosthetic dentistry. 1999 May;81(5):537-52.

Hansson S. Implant-abutment interface: biomechanical study of flat top versus conical. Clinical implant dentistry and related research. 2000;2(1):33-41. 
Harder S, Kern M. Survival and complications of computer aided-designing and computeraided manufacturing vs. conventionally fabricated implant-supported reconstructions: a systematic review. Clinical oral implants research. 2009 Sep;20 Suppl 4:48-54.

Hecker DM, Eckert SE. Cyclic loading of implant-supported prostheses: changes in component fit over time. The Journal of prosthetic dentistry. 2003 Apr;89(4):346-51.

Hemmings KW, Schmitt A, Zarb GA. Complications and maintenance requirements for fixed prostheses and overdentures in the edentulous mandible: a 5-year report. The International journal of oral \& maxillofacial implants. 1994 Mar-Apr;9(2):191-6.

Hulterstrom M, Nilsson U. Cobalt-chromium as a framework material in implant-supported fixed prostheses: a preliminary report. The International journal of oral \& maxillofacial implants. 1991 Winter;6(4):475-80.

Ichi AL. Análise da viabilidade da aplicação da tecnologia CAD-CAM por prototipagem rápida na confecção de estrutura metálica da prótese parcial removível comparando-a ao método convencional (tese), São Paulo: Faculdade de Odontologia da Universidade de São Paulo, 2010.

Inoue RT, Inoue, N.J., Inoue, L.T. Resolução protética em implante com conexão cone Morse, de único estágio cirúrgico, utilizando-se pilar sólido sem e com preparo. Implant News. 2006:625-32.

Isidor F. Loss of osseointegration caused by occlusal load of oral implants. A clinical and radiographic study in monkeys. Clinical oral implants research. 1996 Jun;7(2):143-52.

Jacques LB, Moura MS, Suedam V, Souza EA, Rubo JH. Effect of cantilever length and framework alloy on the stress distribution of mandibular-cantilevered implant-supported prostheses. Clinical oral implants research. 2009 Jul;20(7):737-41.

Jemt T, Laney WR, Harris D, Henry PJ, Krogh PH, Jr., Polizzi G, et al. Osseointegrated implants for single tooth replacement: a 1-year report from a multicenter prospective study. The International journal of oral \& maxillofacial implants. 1991 Spring;6(1):29-36. 
Jemt T, Lekholm U. Implant treatment in edentulous maxillae: a 5-year follow-up report on patients with different degrees of jaw resorption. The International journal of oral \& maxillofacial implants. 1995 May-Jun;10(3):303-11.

Jemt T. Failures and complications in 391 consecutively inserted fixed prostheses supported by Branemark implants in edentulous jaws: a study of treatment from the time of prosthesis placement to the first annual checkup. The International journal of oral \& maxillofacial implants. 1991 Fall;6(3):270-6.

Joly JC, Lima, A.F.M. . Comparação entre sistemas de implantes de um e dois estágios. Rev Bras Implant. 2001:8-11.

Kan JY, Rungcharassaeng K, Bohsali K, Goodacre CJ, Lang BR. Clinical methods for evaluating implant framework fit. The Journal of prosthetic dentistry. 1999 Jan;81(1):7-13.

Kapos T, Ashy LM, Gallucci GO, Weber HP, Wismeijer D. Computer-aided design and computer-assisted manufacturing in prosthetic implant dentistry. The International journal of oral \& maxillofacial implants. 2009;24 Suppl:110-7.

Kirsch A. The two-phase implantation method using IMZ intramobile cylinder implants. The Journal of oral implantology. 1983;11(2):197-210.

Krekmanov L, Kahn M, Rangert B, Lindstrom H. Tilting of posterior mandibular and maxillary implants for improved prosthesis support. The International journal of oral \& maxillofacial implants. 2000 May-Jun;15(3):405-14.

Lang NP, Wilson TG, Corbet EF. Biological complications with dental implants: their prevention, diagnosis and treatment. Clinical oral implants research. 2000;11 Suppl 1:146-55.

Li J, Fok AS, Satterthwaite J, Watts DC. Measurement of the full-field polymerization shrinkage and depth of cure of dental composites using digital image correlation. Dental materials : official publication of the Academy of Dental Materials. 2009 May;25(5):582-8. 
Li T, Kong L, Wang Y, Hu K, Song L, Liu B, et al. Selection of optimal dental implant diameter and length in type IV bone: a three-dimensional finite element analysis. International journal of oral and maxillofacial surgery. 2009 Oct;38(10):1077-83.

Lin CL, Wang JC, Ramp LC, Liu PR. Biomechanical response of implant systems placed in the maxillary posterior region under various conditions of angulation, bone density, and loading. The International journal of oral \& maxillofacial implants. 2008 Jan-Feb;23(1):57-64.

Maeda Y, Satoh T, Sogo M. In vitro differences of stress concentrations for internal and external hex implant-abutment connections: a short communication. Journal of oral rehabilitation. 2006 Jan;33(1):75-8.

Malhotra AO, Padmanabhan TV, Mohamed K, Natarajan S, Elavia U. Load transfer in tilted implants with varying cantilever lengths in an all-on-four situation. Australian dental journal. 2012 Dec;57(4):440-5.

Malo P, Rangert B, Nobre M. "All-on-Four" immediate-function concept with Branemark System implants for completely edentulous mandibles: a retrospective clinical study. Clinical implant dentistry and related research. 2003;5 Suppl 1:2-9.

Malo P, Rangert B, Nobre M. All-on-4 immediate-function concept with Branemark System implants for completely edentulous maxillae: a 1-year retrospective clinical study. Clinical implant dentistry and related research. 2005;7 Suppl 1:S88-94.

Melsen B, Lang NP. Biological reactions of alveolar bone to orthodontic loading of oral implants. Clinical oral implants research. 2001 Apr;12(2):144-52.

Mericske-Stern RD, Taylor TD, Belser U. Management of the edentulous patient. Clinical oral implants research. 2000;11 Suppl 1:108-25.

Merz BR, Hunenbart S, Belser UC. Mechanics of the implant-abutment connection: an 8-degree taper compared to a butt joint connection. The International journal of oral \& maxillofacial implants. 2000 Jul-Aug;15(4):519-26.

Moon IS, Berglundh T, Abrahamsson I, Linder E, Lindhe J. The barrier between the keratinized mucosa and the dental implant. An experimental study in the dog. Journal Clinical Periodontology. 1999 Oct; 26 (10): 658-63. 
Naconecy MM. Força e momento fletor em pilares de prótese tipo protocolo Branemark em função da inclinação dos implantes distais e do número de pilares (tese), Porto Alegre: Faculdade de Odontologia da Universidade Católica do Rio Grande do Sul ,2006.

Naert I, Quirynen M, van Steenberghe D, Darius P. A study of 589 consecutive implants supporting complete fixed prostheses. Part II: Prosthetic aspects. The Journal of prosthetic dentistry. 1992 Dec;68(6):949-56.

Naini RB, Nokar S, Borghei H, Alikhasi M. Tilted or parallel implant placement in the completely edentulous mandible? A three-dimensional finite element analysis. The International journal of oral \& maxillofacial implants. $2011 \mathrm{Jul}-\mathrm{Aug} ; 26(4)$ :776-81.

Norton MR. An in vitro evaluation of the strength of an internal conical interface compared to a butt joint interface in implant design. Clinical oral implants research. 1997 Aug;8(4):290-8.

Ogawa T, Dhaliwal S, Naert I, Mine A, Kronstrom M, Sasaki K, et al. Impact of implant number, distribution and prosthesis material on loading on implants supporting fixed prostheses. Journal of oral rehabilitation. 2010 Jul;37(7):525-31.

Paniz G, Stellini E, Meneghello R, Cerardi A, Gobbato EA, Bressan E. The precision of fit of cast and milled full-arch implant-supported restorations. The International journal of oral \& maxillofacial implants. 2013 May-Jun;28(3):687-93.

Papavasiliou G, Kamposiora P, Bayne SC, Felton DA. Three-dimensional finite element analysis of stress-distribution around single tooth implants as a function of bony support, prosthesis type, and loading during function. The Journal of prosthetic dentistry. 1996 Dec;76(6):633-40.

Patzelt SB, Bahat O, Reynolds MA, Strub JR. The all-on-four treatment concept: a systematic review. Clinical implant dentistry and related research. 2014 Dec;16(6):836-55.

Pierrisnard L, Hure G, Barquins M, Chappard D. Two dental implants designed for immediate loading: a finite element analysis. The International journal of oral \& maxillofacial implants. 2002 May-Jun;17(3):353-62. 
Rangert B, Jemt T, Jorneus L. Forces and moments on Branemark implants. The International journal of oral \& maxillofacial implants. 1989 Fall;4(3):241-7.

Riedy SJ, Lang BR, Lang BE. Fit of implant frameworks fabricated by different techniques. The Journal of prosthetic dentistry. 1997 Dec;78(6):596-604.

Rubo JH , Souza EA. Finite element analysis of stress in bone adjacent to dental implants. Journal Oral Implantology 2008;34(5):248-55

Salvi GE, Lang NP. Changing paradigms in implant dentistry. Critical reviews in oral biology and medicine : an official publication of the American Association of Oral Biologists. 2001;12(3):262-72.

Sanz M, Alandez J, Lazaro P, Calvo JL, Quirynen M, van Steenberghe D. Histo-pathologic characteristics of peri-implant soft tissues in Branemark implants with 2 distinct clinical and radiological patterns. Clinical oral implants research. 1991 Jul-Sep;2(3):128-34.

Schwarz MS. Mechanical complications of dental implants. Clinical oral implants research. 2000;11 Suppl 1:156-8.

Sertgoz A, Guvener S. Finite element analysis of the effect of cantilever and implant length on stress distribution in an implant-supported fixed prosthesis. The Journal of prosthetic dentistry. 1996 Aug;76(2):165-9.

Skalak R. Biomechanical considerations in osseointegrated prostheses. The Journal of prosthetic dentistry. 1983 Jun;49(6):843-8.

Sones AD. Complications with osseointegrated implants. The Journal of prosthetic dentistry. 1989 Nov;62(5):581-5.

Stegaroiu R, Sato T, Kusakari H, Miyakawa O. Influence of restoration type on stress distribution in bone around implants: a three-dimensional finite element analysis. The International journal of oral \& maxillofacial implants. 1998 Jan-Feb;13(1):82-90. 
Strub JR, Rekow ED, Witkowski S. Computer-aided design and fabrication of dental restorations: current systems and future possibilities. Journal of the American Dental Association (1939). 2006 Sep;137(9):1289-96.

Suedam V, Souza EA, Moura MS, Jacques LB, Rubo JH. Effect of abutment's height and framework alloy on the load distribution of mandibular cantilevered implant-supported prosthesis. Clinical Oral Implants Research. 2009 Feb;20(2):196-200.

Taylor TD. Fixed implant rehabilitation for the edentulous maxilla. The International journal of oral \& maxillofacial implants. 1991 Fall;6(3):329-37.

Tiossi R. Efeitos do uso de próteses múltiplas implantossuportadas, unidas e isoladas, nas tensões geradas em áreas posteriores da mandíbula. Ribeirão Preto: Faculdade de odontologia de Ribeirão Preto, Universidade de São Paulo, 2010.

Turcio KH, Goiato MC, Gennari Filho H, dos Santos DM. Photoelastic analysis of stress distribution in oral rehabilitation. The Journal of craniofacial surgery. 2009 Mar;20(2):471-4.

Ueda C, Markarian RA, Sendyk CL, Lagana DC. Photoelastic analysis of stress distribution on parallel and angled implants after installation of fixed prostheses. Brazilian oral research. 2004 Jan-Mar;18(1):45-52.

Van Zyl PP, Grundling NL, Jooste CH, Terblanche E. Three-dimensional finite element model of a human mandible incorporating six osseointegrated implants for stress analysis of mandibular cantilever prostheses. The International journal of oral \& maxillofacial implants. 1995 Jan-Feb;10(1):51-7.

Waskewicz GA, Ostrowski JS, Parks VJ. Photoelastic Analysis of Stress Distribution Transmitted From a Fixed Prosthesis Attached to Osseointegrated Implants. International Journal of Oral \& Maxillofacial Implants. 1994 07/Jul/Aug1994;9(4):405-11.

Watanabe F, Uno I, Hata Y, Neuendorff G, Kirsch A. Analysis of stress distribution in a screwretained implant prosthesis. The International journal of oral \& maxillofacial implants. 2000 Mar-Apr;15(2):209-18.

Wee AG, Aquilino SA, Schneider RL. Strategies to achieve fit in implant prosthodontics: a review of the literature. The International journal of prosthodontics. 1999 Mar-Apr;12(2):16778.

Weinberg LA. The biomechanics of force distribution in implant-supported prostheses. The International journal of oral \& maxillofacial implants. 1993;8(1):19-31. 
White SN, Caputo AA, Anderkvist T. Effect of cantilever length on stress transfer by implantsupported prostheses. The Journal of prosthetic dentistry. 1994 May;71(5):493-9.

Worthington P, Bolender CL, Taylor TD. The Swedish system of osseointegrated implants: problems and complications encountered during a 4-year trial period. The International journal of oral \& maxillofacial implants. 1987 Spring;2(2):77-84.

Zarb GA, Schmitt A. The longitudinal clinical effectiveness of osseointegrated dental implants: the Toronto study. Part III: Problems and complications encountered. The Journal of prosthetic dentistry. 1990 Aug;64(2):185-94.

Zarb GA, Albrektsson T. Osseointegration: A requiem for periodontal ligament? International Journal Periodontics Restorative Dentistry. 1991;11:88-91. 